\title{
Avaliações econômicas de programas de vacinação: as estimativas de custos em intervenções preventivas
}

Tese apresentada à Faculdade de Medicina da Universidade de São Paulo para a obtenção do título de Doutor em Ciências

Área de concentração: Medicina Preventiva Orientadora: Profa. Dra. Hillegonda Maria Dutilh Novaes

São Paulo 
Dados Internacionais de Catalogação na Publicação (CIP)

Preparada pela Biblioteca da

Faculdade de Medicina da Universidade de São Paulo

Creprodução autorizada pelo autor

\section{Valentim, Joice}

Avaliações econômicas de programas de vacinação : as estimativas de custos em intervenções preventivas / Joice Valentim. -- São Paulo, 2009.

Tese(doutorado)--Faculdade de Medicina da Universidade de São Paulo. Departamento de Medicina Preventiva.

Área de concentração: Medicina Preventiva.

Orientadora: Hillegonda Maria Dutilh Novaes.

Descritores: 1.Análise custo-benefício 2.Custos 3.Vacinas 4.Vacinas contra rotavírus 5.Vacina contra varicela

USP/FM/SBD-276/09 


\section{AGRADECIMENTOS}

Agradeço a minha orientadora, Maria Novaes, coordenadora do projeto de pesquisa para o Ministério da Saúde, que me proporcionou importante interação dentro e fora da Faculdade de Medicina/FMUSP. Agradeço também a Ana Marli Sartori, da Clínica de Moléstias Infecciosas e Parasitárias do HC/FMUSP, que me “contagiou" com seu interesse pelo mundo das vacinas.

Agradeço ao financiamento do Ministério da Saúde/MS e Conselho Nacional de Desenvolvimento Científico e Tecnológico/CNPq durante o projeto, através do qual foi possível a participação em congressos e reuniões. Foi uma grande experiência ter contato com especialistas de diferentes instituições e áreas, entre as quais o Comitê Técnico Assessor de Imunizações/CTAI/MS e Secretarias de Saúde de todos os estados, e presenciar ação bem sucedida como a vacinação em um país tão grande e heterogêneo.

Agradeço aos que colaboraram para a coleta de dados e elaboração desta tese: aos membros da banca de qualificação, professores Antonio Carlos Coelho Campino da FEA/USP, Ana Maria Malik da FGV e FMUSP e Marcos Bosi Ferraz da

UNIFESP; a Marizélia Leão Moreira da Agência Nacional de Saúde

Suplementar/ANS e Jacson Venâncio de Barros da Fundação Faculdade de Medicina/FFM; a Denise Schout do Núcleo de Informações em Saúde do HC/FMUSP; a Cristiana Toscano da OPAS/OMS; a Gabrielle de Freitas, do Instituto Butantan, e a José Maurício Prado, futuro professor na Universidade de Cambridge, que, mesmo tão longe, aceitou o meu convite e desafio para trabalharmos juntos.

Toda obra tem sua história, e esta remonta àqueles que desde a graduação têm me guiado pela economia da saúde. Meus agradecimentos a Basília Aguirre e ao 
Campino da FEA/USP; ao Geraldo Giovanni e Gabriel Ferrato dos Santos, da UNICAMP, através da qual tive a oportunidade de estudar na Universidade de York, formação fundamental para mim, e na FGV. Também da UNICAMP ficam as saudades do Norberto Dachs.

Deixo também meus agradecimentos a todos os demais que contribuíram e que não foram citados, contudo lembrados.

Assim como produto de uma história, toda obra, apesar de específica a uma área, é produto de diversas dimensões da vida de quem a gerou. Agradeço em especial a Ana Paula Magosso Cavaggioni, que tanto me ajudou para a conclusão desta tese, assim como a percebê-la e entendê-la como um processo interno e específico a mim mesma.

Agradeço, por fim, ao apoio, paciência, estímulo e suporte que toda minha família e meus amigos me deram, que foram fundamentais para eu poder continuar. Aos meus irmãos e a meu pai, por estarem ao meu lado. E a minha mãe, por todo seu amor, dedicação, força e fé, desde sempre. 


\section{SUMÁRIO}

Lista de figuras e quadros

Lista de tabelas

Resumo

Abstract

Apresentação

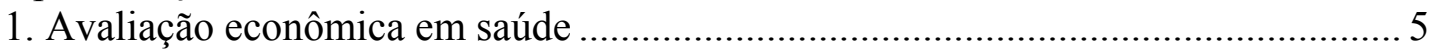

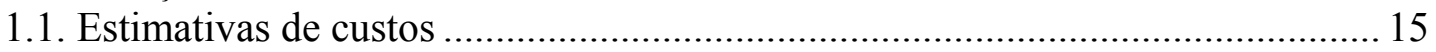

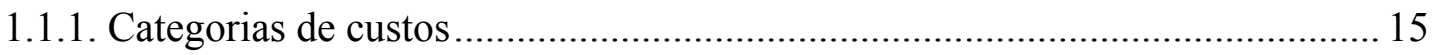

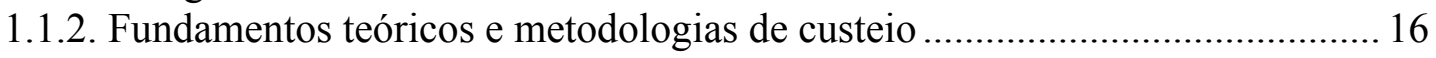

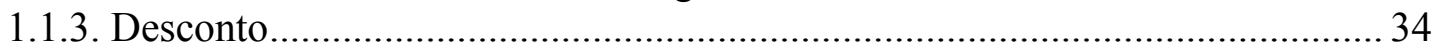

1.1.4. Diretrizes de avaliação econômica: estimativas de custos e desconto .............. 38

1.2. Avaliação econômica de vacinas ................................................................... 40

1.2.1. Diretriz para padronização de avaliações econômicas de programas de

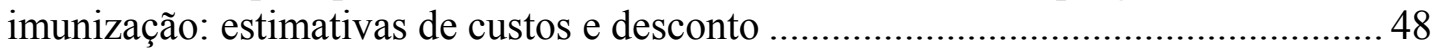

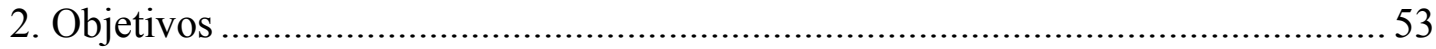

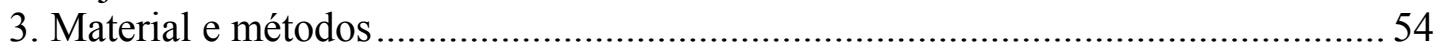

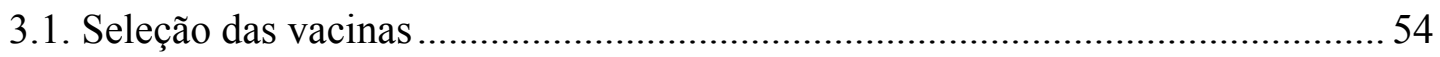

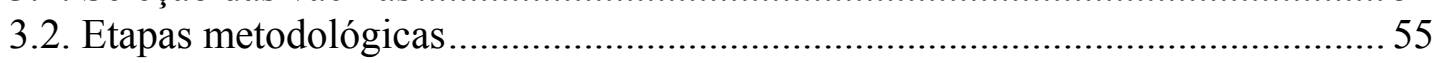

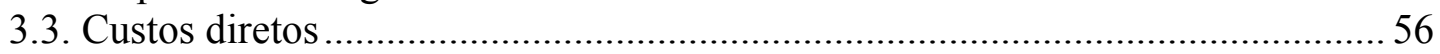

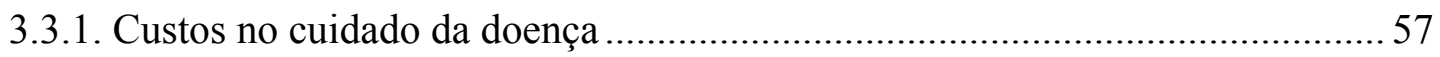

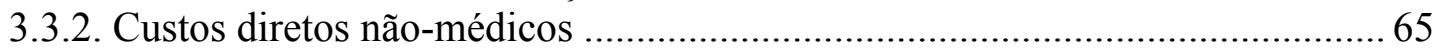

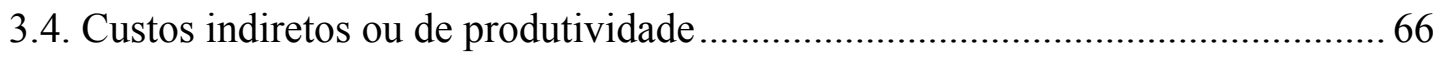

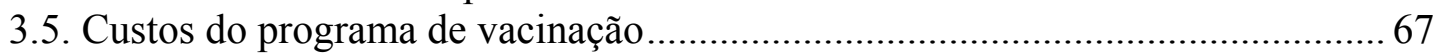



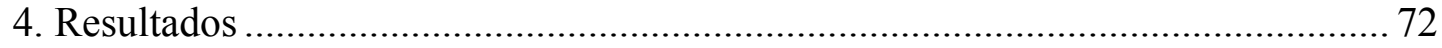

4.1.Análise de custo-efetividade do programa de vacinação universal de crianças

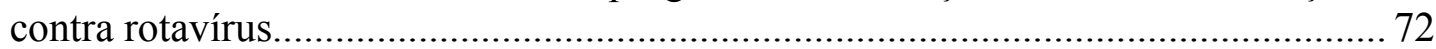

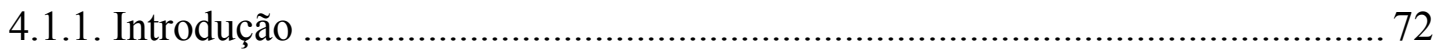

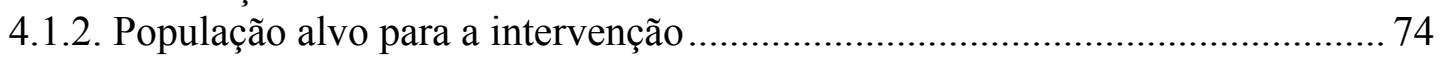

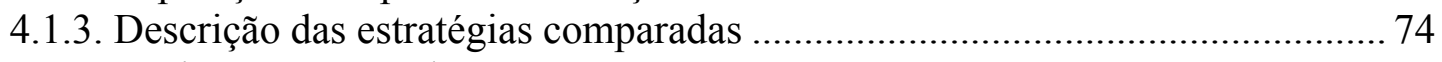

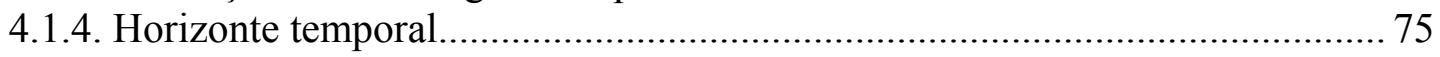

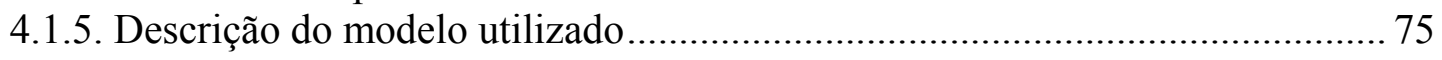

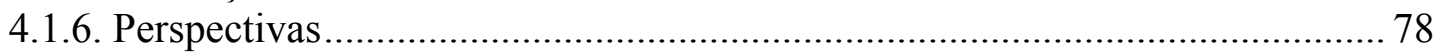

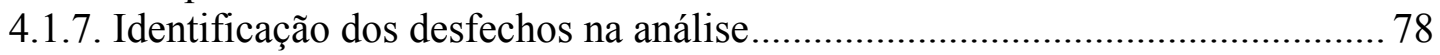

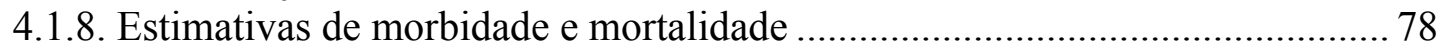



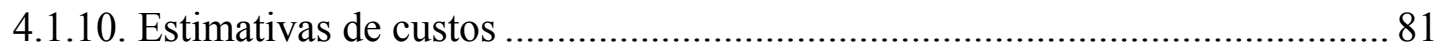

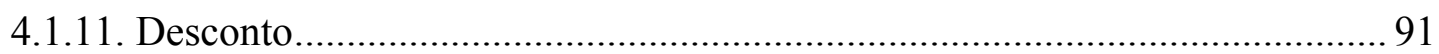

4.1.12. Custo-efetividade da vacinação contra rotavírus ........................................ 91

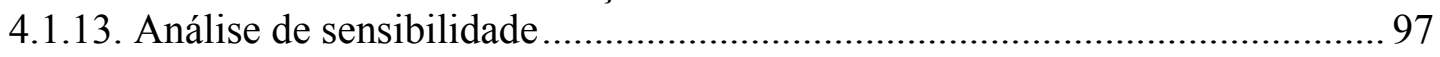

4.1.13.1. Análise de sensibilidade para estimativas de custos e desconto ................. 97

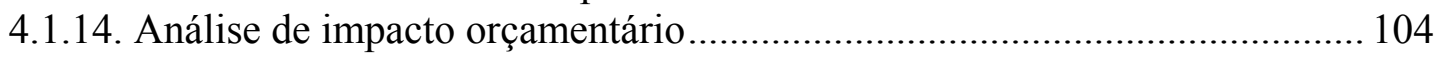

4.2. Análise de custo-efetividade do programa de vacinação universal de crianças contra varicela 
4.2.1. Introdução

4.2.2. População alvo para intervenção.............................................................. 110

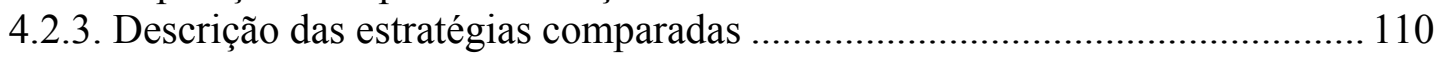

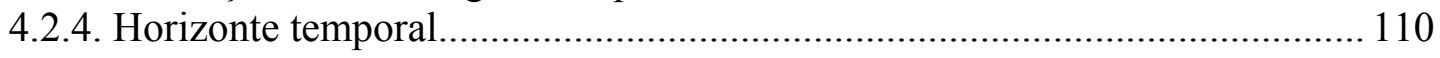

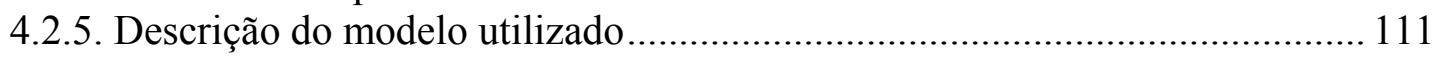

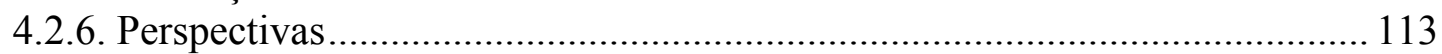

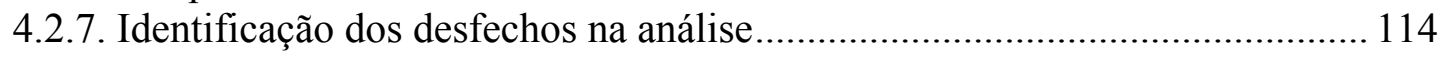

4.2.8. Estimativas de morbidade e mortalidade ................................................... 114

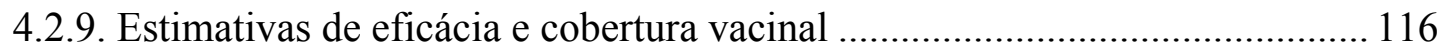

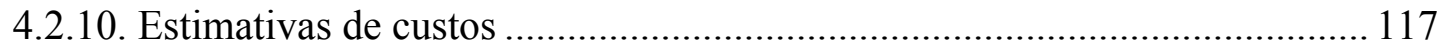

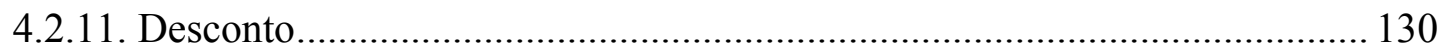

4.2.12. Custo-efetividade da vacinação contra varicela ....................................... 131

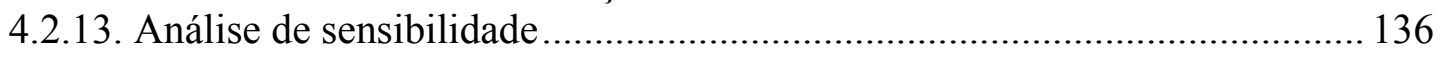

4.2.13.1. Análise de sensibilidade para estimativas de custos e desconto ............... 137

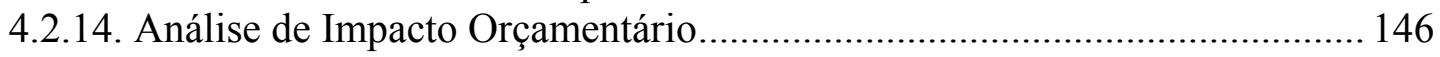

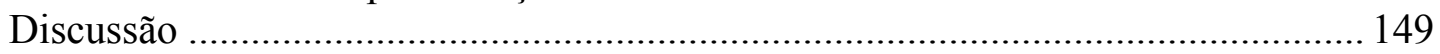

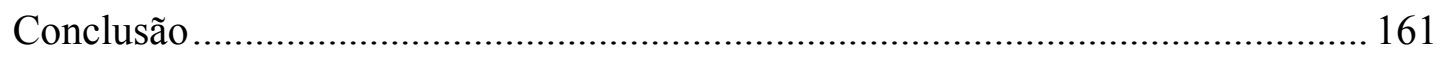

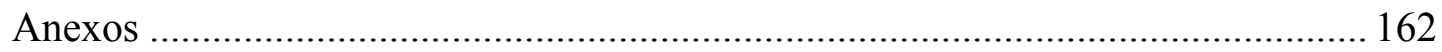

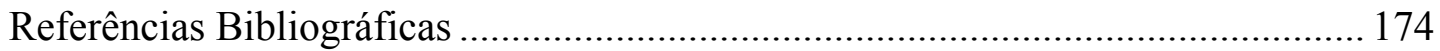




\section{LISTA DE FIGURAS E QUADROS}

Quadro 1. Componentes de avaliações econômicas em saúde ..................................... 12

Figura 1. Diagrama de decisão para inclusão de nova vacina...................................... 42

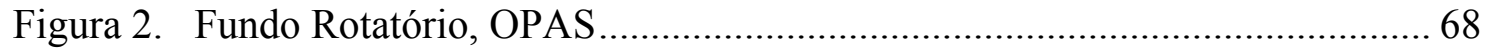

Figura 3. Esquema de distribuição nacional de vacinas, Brasil .................................. 70

Figura 4. Árvore de decisão - Diagrama do fluxo dos eventos no modelo (vacinação

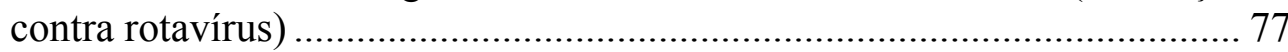

Figura 5. Número total de infectados nas duas estratégias analisadas, varicela,

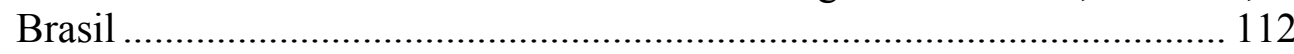




\section{LISTA DE TABELAS}

Tabela 1. Custos por caso de diarréia por rotavírus segundo tipo de tratamento, perspectiva e metodologia de estimativas de custos, Brasil, reais de 2004 ... 89

Tabela 2. Estimativas de custos e impacto da doença associada com a diarréia por rotavírus, segundo perspectiva da análise e status de vacinação.

Tabela 3. Custo-efetividade da vacinação contra rotavírus por perspectiva e metodologia de estimativas de custos, Brasil.

Tabela 4. Análise de sensibilidade univariada, estimativas de custos e desconto, rotavírus

Tabela 5. Análise de impacto no orçamento, vacinação universal contra rotavírus, perspectiva do PNI, 2004

Tabela 6. Análise de impacto no orçamento, vacinação universal contra rotavírus, perspectiva do Ministério da Saúde, 2004

Tabela 7. Número de casos de varicela estimado pelo modelo dinâmico em 30 anos por cenário, Brasil

Tabela 8. Custos de medicamentos por caso de varicela em tratamento ambulatorial, de acordo com o pagador e cenário de estimativa de custo, reais de 2004 ... 121

Tabela 9. Custos por caso de varicela, de acordo com faixa etária, tipo de tratamento, perspectiva e metodologia de estimativas de custos, Brasil, reais de 2004 .. 129

Tabela 10. Estimativas de custos e impacto da doença associados à varicela, segundo perspectiva da análise e estratégia de vacinação, assumindo eficácia da vacina de $85 \%$ e cobertura vacinal de $80 \%$ (cenário-base), acumulados para horizonte temporal de 30 anos.

Tabela 11. Custo-efetividade da vacinação contra varicela por perspectiva e metodologia de estimativas de custos, Brasil....

Tabela 12. Análise de sensibilidade univariada, estimativas de custos e desconto, varicela

Tabela 13. Análise de impacto no orçamento, vacinação universal contra varicela, perspectiva do PNI, 2004.

Tabela 14. Análise de impacto no orçamento, vacinação universal contra varicela, perspectiva do Ministério da Saúde, 2004

Tabela 15. Alterações das estimativas de custos para a tese, por doença

Tabela 16. Variações de custos, economia e razão de custo-efetividade incremental para a tese em comparação com estudos originais, perspectiva da sociedade, por doença 


\section{RESUMO}

VALENTIM, J. Avaliações econômicas de programas de vacinação: as estimativas de custos em intervenções preventivas [tese]. São Paulo: Faculdade de Medicina da Universidade de São Paulo; 2009. 186p.

Esta tese representa o aprofundamento do estudo das estimativas de custos, componente integrante e determinante das avaliações econômicas, enquanto parte do projeto de pesquisa "Estudos de custo-efetividade da incorporação de novas vacinas à rotina do Programa Nacional de Imunizações: Rotavírus, Varicela, Pneumocócica conjugada, Meningocócica C conjugada e Hepatite A" desenvolvido por solicitação do Programa Nacional de Imunização/PNI da Secretaria de Vigilância em Saúde/SVS do Ministério da Saúde, a partir de 2005. A tese teve como objetivo analisar as condições de uso, dificuldades e repercussões de diferentes métodos de estimativas de custos em estudos de custo-efetividade de vacinas de duas tecnologias específicas, vacinas contra rotavírus e varicela, assim como a relação entre as estimativas de custos e os resultados. As estimativas de custos estão condicionadas pelas características gerais da doença sob análise (aguda no caso de rotavírus e com seqüela no caso de varicela), assim como por questões metodológicas gerais (escolha teórico-conceitual, métodos e fontes de dados) e especificidades do caso brasileiro. Para esta tese, houve maior detalhamento das estimativas de custos diretos no cuidado da doença, com a inclusão de custos específicos do sistema de saúde suplementar para as duas doenças, inclusão de participação pública na dispensação de medicamentos no caso de rotavírus e inclusão de custos de medicamentos do sistema público de saúde no caso de varicela. Como resultado, houve aumento do custo total da doença estimado de $16 \%$ para rotavírus e $11 \%$ para varicela, assim como aumento de economia (custo total da doença evitado) de 18\% e 16\%, respectivamente, com a introdução de cada vacina. Apesar do maior detalhamento das estimativas de custos ter reduzido a razão de custo-efetividade incremental em $20 \%$ para rotavírus e $4 \%$ para varicela, o nível de custo-efetividade dos dois programas de vacinação não foi alterado. Os resultados das avaliações econômicas de vacinação contra rotavírus e varicela mostraram-se mais sensíveis às estimativas de custos do programa de vacinação, em especial o preço da vacina, apontando a relevância do custo da tecnologia sob análise para incorporação em comparação aos demais custos.

Descritores: análise de custo-benefício; custos; vacinas; vacinas contra rotavírus; vacina contra varicela 


\begin{abstract}
VALENTIM, J. Economic evaluations of vaccination programmes: cost estimates of preventive interventions [thesis]. São Paulo: Faculdade de Medicina da Universidade de São Paulo; 2009. 186p.

This thesis represents a deeper study of the cost estimates, an integrant and determinative component of economic evaluations, as part of the project "Costeffectiveness studies of the incorporation of new vaccines into the routine of the National Immunisation Program: Rotavirus, Varicella, Pneumococcal conjugate, Meningococcal C conjugate and Hepatitis A". The project has been developed on the request of the National Immunisation Program/PNI of the Secretary of Sanitary Surveillance/SVS of the Ministry of Health since 2005. The objective of the thesis was to analyse the conditions of use, difficulties and repercussions of different cost estimates methods in the cost-effectiveness studies of two specific technologies, vaccines against rotavirus and varicella, as well as the relationship between the cost estimates and the results. The cost estimates are conditioned by general characteristics of the disease under analysis (acute in the case of rotavirus and with long-term disability in the case of varicella), general methodological issues (theoretical choice, methods and sources of data) and specificities to the Brazilian case. This thesis brings a more detailed estimation of direct medical costs, with the inclusion of specific costs of the private health care system for the two diseases, inclusion of public participation for dispensing drugs in the case of rotavirus and inclusion of drugs costs in the public health care system in the case of varicella. As a result, there was an estimated disease total cost increase of $16 \%$ for rotavirus and $11 \%$ for varicella, as well as increase of savings (disease total cost avoided) of $18 \%$ and $16 \%$, respectively, with the introduction of each vaccine. Although the more detailed cost estimates have reduced the incremental cost-effectiveness ratio by $20 \%$ for rotavirus and $4 \%$ for varicella, the cost-effectiveness level of the two vaccination programs was not altered. The results of the economic evaluations of vaccination against rotavirus and varicella were more sensitive to the vaccination program cost estimates, especially the vaccine price, pointing out the relevance of the cost of the technology under analysis for incorporation comparatively to the other costs.
\end{abstract}

Descriptors: cost-benefit analysis; costs; vaccines; vaccines against rotavirus; vaccine against varicella 


\section{APRESENTAÇÃO}

Avaliação econômica em saúde, área de expressão da economia da saúde, é uma análise comparativa de alternativas, também denominadas intervenções ou estratégias, em termos de seus custos e conseqüências. As avaliações econômicas em saúde podem ter como objetos de análise tecnologias, serviços e programas, de caráter preventivo, diagnóstico ou terapêutico.

A avaliação econômica em saúde específica para tecnologias se insere no âmbito da Avaliação de Tecnologias em Saúde (ATS) introduzindo a dimensão econômica. Dada a escassez de recursos frente às demandas ${ }^{1}$ por cuidados de saúde, a avaliação econômica buscaria promover a racionalização e otimização do uso de recursos (públicos, privados, setoriais ou da sociedade) contribuindo para a eficiência alocativa (Drummond et al, 1997). A escassez de recursos implica que as decisões referentes à adoção de tecnologias (produto ou processo) contemplem também o componente custo e não apenas os componentes de eficácia, efetividade ou acurácia da tecnologia.

Ainda que não sendo o único fator, a incorporação e utilização contínua e intensa de novas tecnologias, muitas vezes dispendiosas, é tida como principal contribuinte para a elevação dos custos com saúde (Newhouse, 1992). Além disto, a utilização de tecnologias em saúde apresenta uma especificidade: tendem a ser cumulativa ao invés de substituta (Brasil, 2007). A escassez de recursos para a área

\footnotetext{
${ }^{1}$ A relação entre oferta e demanda em saúde apresenta uma particularidade que é a indução de demanda pelo provedor (Labelle et al, 2004). A demanda por cuidados de saúde é indireta, uma vez que há assimetria de informação e é o médico que determina a demanda do paciente/consumidor. A indução de demanda em saúde implica que esta pode exceder as necessidades por cuidados de saúde, havendo, portanto, distinção entre necessidades e demandas, sendo que para ambas os recursos são escassos.
} 
da saúde é acentuada pelo desenvolvimento e incorporação de novas tecnologias, mais sofisticadas e mais caras.

Dentre as tecnologias de caráter preventivo, as vacinas têm uma tradição mais longa de avaliações econômicas, quando comparadas com medicamentos, tecnologias de caráter terapêutico (Szucs, 2005). As avaliações econômicas de vacinas apresentam especificidades referentes à modelagem da doença, valoração dos desfechos em saúde e desconto de custos e desfechos (Beutels et al, 2003; Drummond et al, 2007). A primeira especificidade se refere à existência ou não de proteção de rebanho ${ }^{2}$, que se caracteriza como uma externalidade positiva, enquanto as duas últimas se referem à separação temporal entre a ocorrência da intervenção preventiva e o momento de aparecimento (ou prevenção quando da intervenção) da doença em questão. Como programas de vacinação significam investimentos presentes para retornos futuros, os custos da intervenção apresentam um peso importante, considerando ainda seu caráter universal freqüente e a tendência de aumento dos preços das vacinas.

O Brasil tem forte tradição em imunizações, com destaque para o Programa Nacional de Imunização (PNI). Inclusões de novas vacinas ao PNI têm se proposto a considerar avaliações econômicas, através de estudos nacionais destinados à Secretaria de Vigilância em Saúde do Ministério da Saúde. Esta tese é parte de projeto de pesquisa mais amplo, denominado "Estudos de custo-efetividade da incorporação de novas vacinas à rotina do Programa Nacional de Imunizações: Rotavírus, Varicela, Pneumocócica conjugada, Meningocócica C conjugada e Hepatite A", cujo objetivo é desenvolver estudos de custo-efetividade para as vacinas

\footnotetext{
${ }^{2}$ Efeitos indiretos potenciais do programa de imunização para crianças não vacinadas.
} 
mencionadas de forma a orientar o PNI no processo de decisão de inclusão de novas vacinas.

O objetivo da tese foi estudar o componente custo dentro das avaliações econômicas de programas de vacinação de duas tecnologias específicas, vacinas contra rotavírus e varicela, e a relação entre as estimativas de custos e os resultados, relação esta que influencia a recomendação para a inclusão de novas tecnologias.

Os perfis das doenças, aguda para rotavírus e com seqüelas para varicela, condicionaram as respectivas estimativas de custos, e possibilitaram a comparação entre intervenções de caráter semelhante (preventivo).

Esta tese aprofunda as estimativas de custos de estudos de custo-efetividade concluídos (Soárez et al, 2008; Valentim et al, 2008a) ao incluir: custos específicos do sistema de saúde suplementar para os custos diretos no cuidado da doença; participação pública na dispensação de medicamentos no caso de rotavírus; e custos de medicamentos do sistema público de saúde no caso de varicela. A partir da comparação dos resultados dos estudos de custo-efetividade com maior e menor detalhamento das estimativas de custos, torna-se possível mensurar o impacto do componente custo nos resultados de custo-efetividade e consequentemente analisar as recomendações para inclusão de tecnologias, para os perfis de doenças estudadas. Outros desafios das estimativas de custos resultaram de questões metodológicas gerais e especificidades do caso brasileiro, com articulações complexas do Sistema Único de Saúde/SUS e Sistema de Saúde Suplementar, e seus respectivos sistemas de informações.

São mais escassos trabalhos sobre avaliação econômica que estudam métodos. Esta tese buscou contribuir para diminuir esta lacuna, ao discutir as opções 
metodológicas das estimativas de custos e sua relação com resultados. Partindo-se do pressuposto de que as opções teóricas e metodológicas influenciam os resultados, assumindo-se a não neutralidade das avaliações econômicas, o estudo das estimativas de custos para as análises de custo-efetividade de vacinação contra rotavírus e varicela também contribuem ao serem exemplos da relação entre escolhas e resultados.

Usuários de avaliações econômicas, como gestores, pagadores etc, poderão melhor compreender as avaliações econômicas ao ler a tese, ao ser considerada a importância de clareza do conceito de custo, métodos e fontes de dados adotados e sua relação com os resultados das avaliações econômicas.

A tese está dividida em quatro capítulos, aos quais se seguem discussão e conclusão. O primeiro capítulo apresenta os aspectos teóricos, metodológicos e históricos do desenvolvimento da avaliação econômica em saúde, bem como das estimativas de custos e avaliação econômica específica de vacinas. O segundo capítulo detalha os objetivos da tese. O terceiro capítulo constitui o de material e métodos, com justificativa de seleção das vacinas e definição das etapas metodológicas. Os resultados, as análises de custo-efetividade dos programas de vacinação contra rotavírus e varicela, são apresentados no capítulo 4.

Conclui-se que o maior detalhamento das estimativas de custos não alterou o nível de custo-efetividade dos programas de vacinação contra rotavírus e varicela. Os resultados de ambas as avaliações econômicas mostraram-se mais sensíveis às estimativas de custos do programa de vacinação, em especial o preço da vacina, apontando a relevância do custo da tecnologia sob análise para incorporação em comparação aos demais custos. 


\section{AVALIAÇÃO ECONÔMICA EM SAÚDE}

A economia da saúde surge como área específica de conhecimento em $1963^{3}$ com o artigo de Kenneth Arrow sobre as especificidades do mercado de cuidado médico ${ }^{4}$, tendo por base teórica a economia do bem-estar ${ }^{5}$. A subdivisão de avaliação econômica dentro da economia da saúde é conseqüência do próprio desenvolvimento da análise de custo-benefício, também da década de 1960 (Spackman, 2004), sendo a construção da análise de custo-efetividade e custoutilidade uma especificidade da área da saúde, dada a resistência de se valorar saúde em termos monetários. Na literatura em economia da saúde, é possível observar a aplicação da avaliação econômica em saúde, sistematizada em 1977 (Weinstein, 1977), paralelamente à discussão de seus fundamentos teóricos (Sugden et al, 1978; Culyer, 1991; Williams, 1993; Brouwer et al, 2000 e 2008).

\footnotetext{
${ }^{3}$ Em 1958, Mushkin publica o artigo "Toward a Definition of Health Economics" definindo economia da saúde como uma disciplina específica. No entanto, o reconhecimendo oficial da disciplina somente ocorre com o artigo de Arrow de 1963, "Uncertainty and the Welfare Economics of Medical Care".

${ }^{4} \mathrm{O}$ autor (Arrow, 1963) utiliza o termo indústria, enfatizando o medical-care industry como seu objeto de análise.

${ }^{5}$ A economia do bem-estar é o ramo da análise econômica que se preocupa com a descoberta de princípios para maximizar o bem-estar social. Não constitui um sistema distinto e unificado de idéias. Concentra-se na definição de otimização do bem-estar e análise de como alcançar o bem-estar máximo e na identificação de fatores que impeçam a realização do máximo bem-estar e sugestões de como remover tais obstáculos. No grupo de pensamento da economia do bem-estar destacam-se os seguintes teóricos: Pareto, Pigou, Von Mises, Lange, Arrow e Buchanan. Alguns destes teóricos apoiaram a escola neoclássica enquanto outros foram contra ela. Os economistas do bem-estar trataram de tópicos heterogêneos como regras para se obter bem-estar máximo, problemas dos custos e benefícios, diferenças de renda, possibilidade de se alcançar o bem-estar máximo no socialismo, dificuldades associadas ao voto majoritário e processo de tomada de decisão no setor público (Brue, 2005).
} 
Têm sido identificadas na literatura (Brouwer et al, 2000 e 2008) duas vertentes teórico-metodológicas de avaliação econômica em saúde: avaliação econômica fundamentada na economia do bem-estar (welfarism ${ }^{6}$ ) e avaliação econômica baseada numa visão pragmática de sua aplicação, enquanto instrumento de ajuda no processo de tomada de decisão (decision maker's approach - DMA ou extra-welfarism).

O trabalho de Sugden e William de 1978 (apud Hauck et al, 2004) introduz a análise de tomada de decisão como fundamento normativo da análise de custobenefício em saúde.

A distinção reconhecida entre as duas escolas (welfarism e extra-welfarism) refere-se ao julgamento de estados limitado à utilidade individual, o que implica diferenças de desfechos considerados relevantes nas avaliações; fontes de valoração dos desfechos; base de ponderação dos desfechos e comparação interpessoal (Brouwer et al, 2008).

As diferenças conceituais e metodológicas das duas vertentes conduzem a diferentes conclusões, de modo que a opção teórico-conceitual inicial tem implicações não só no desenvolvimento metodológico das avaliações econômicas, ainda em construção, como também nos seus resultados empíricos, afetando as decisões tomadas ou a serem tomadas (assumindo a influência deste instrumento no processo de tomada de decisão).

\footnotetext{
${ }^{6} \mathrm{O}$ arcabouço teórico dominante da economia de bem-estar (welfare economics) baseia-se nos seguintes pressupostos da escola neoclássica: princípio de utilidade (indíviduos racionais maximizam seu bem-estar ordenando e escolhendo a opção preferida); soberania individual (somente os próprios indivíduos são capazes de julgar suas utilidades); consequencialismo (utilidade é somente derivada dos resultados do comportamento ao invés dos processos ou intenções que levam a tais resultados) e welfarism (informação de utilidades como única base para julgamento de estados (bons). Rigor conceitual estabelece que welfarism é apenas um dos componentes da economia do bem-estar (welfare economics).
} 
Seguindo o welfarism, avaliação econômica em saúde é consistente com os fundamentos teóricos da economia do bem-estar ${ }^{7}$, como, por exemplo, a análise de custo-benefício, enquanto para o DMA ela pode ser considerada uma ferramenta de ajuda para se tomar decisão, ferramenta esta imperfeita (Brouwer et al, 2000).

Na economia do bem-estar, o bem-estar social é uma função de bem-estar individual, descrito pelas utilidades dos agentes econômicos, que por sua vez são funções de bens e serviços consumidos. A questão da agregação das utilidades individuais para se chegar ao bem-estar social ainda não é um ponto definido dentro da teoria econômica (Buchanan, 1989 apud Brue, 2005).

O extra-welfarism ou DMA se baseia nas características não relacionadas apenas a bens dos indivíduos, mas incluem outras dimensões, como seu estado emocional, habilidade física, relação entre indivíduos, grupos e classes sociais (Culyer, 1991 e Williams, 1993 apud Brouwer et al, 2000). O extra-welfarism rejeita os fundamentos conceituais da teoria neoclássica, particularmente o foco exclusivo na noção de bem-estar baseada em utilidades (Hurley, 1998 apud Brouwer et al, 2000). Para esta vertente, a utilidade é substituída por saúde, como resultado primário de interesse na avaliação (Culyer, 1991 apud Brouwer et al, 2000). A visão extra-welfarist é freqüentemente interpretada como objetivando meramente a maximização de saúde a partir de uma restrição orçamentária. No entanto,

\footnotetext{
${ }^{7}$ Modelização da incorporação da análise de custo-efetividade na teoria de economia de bem-estar (Garber et al, 1997) demonstrou uma distância entre os modelos e a valoração de seus efeitos na vida real em relação ao processo de tomada de decisão em sociedade. A otimização individual se mantém quando na margem o salário se iguala à disposição a pagar (willingness to pay - WTP) de uma unidade de tempo. A relação entre produtividade (salário) e aquisição de anos de vida do modelo tem implicações éticas fortes: a WTP dos menos produtivos é menor, como no caso de pessoas com deficiência física, que teriam então menor potencial relativo de aquisição de anos de vida. Considerações de eficiência, éticas e de equidade não são necessariamente conciliadas nos modelos derivados da teoria da economia de bem-estar. A utilização de funções de bem-estar social ao invés de modelos individualistas, com a incorporação de distribuições de riqueza, saúde, ou mesmo utilidade, poderiam se aproximar mais da realidade.
} 
implicações não derivadas ou relacionadas à saúde podem ser incorporadas, como questões éticas referentes a grupos de idade, grupos sociais etc.

No DMA a avaliação econômica objetiva informar o tomador de decisão ao invés de prescrever qual decisão deve ser tomada. O tomador de decisão deve utilizála conjuntamente com informações que vão além da saúde em si, considerando todos os diferentes aspectos pertinentes à questão a ser analisada. A avaliação econômica aumentaria a transparência do processo de tomada de decisão, auxiliando o processo, sem ser a resposta final.

Em ambas as vertentes teóricas, a avaliação econômica em saúde estruturase a partir da comparação entre propostas alternativas de diferentes intervenções, utilizando técnicas de análise de custos e conseqüências da adoção de tecnologias em saúde (Gold et al, 1996). A análise desenvolvida permite a comparação de diferentes opções de prevenção, diagnóstico ou tratamento para uma mesma doença, buscando também permitir o estabelecimento de prioridades em saúde com a comparação entre diferentes doenças.

A avaliação econômica em saúde subdivide-se em quatro modalidades: custo-minimização, custo-efetividade, custo-utilidade e custo-benefício (Drummond et al, 1997). Nas análises de custo-minimização as conseqüências das intervenções são as mesmas, havendo somente diferenças nos custos. Nas demais análises, tanto as conseqüências quanto os custos se diferenciam. O que distingue as outras três modalidades são as unidades utilizadas para expressar as conseqüências. Em custoefetividade, utilizam-se unidades naturais de desfechos de saúde (casos evitados, anos de vida ganhos etc). Em custo-utilidade, as conseqüências são expressas por 
índices compostos de saúde (Quality Adjusted Life Years/QALYs; Disability Adjusted Life Years/DALYs). As análises de custo-benefício têm sido as menos utilizadas por expressar os benefícios em saúde em termos monetários, levantando questões éticas de mensuração monetária do valor de uma vida. Alguns autores (Gold et al, 1996) tratam as avaliações econômicas em geral como de custo-efetividade, sendo os demais tipos específicos desta.

Os componentes de uma avaliação econômica (Quadro 1) são dados por sua estrutura (caracterização do problema, definição de população alvo e tipo de análise, desenho do estudo, descrição das intervenções a serem comparadas, perspectiva do estudo e horizonte temporal); dados e métodos (identificação de medidas de desfecho, quantificação e custeio de recursos, modelagem e definição de taxa de desconto); seus resultados (caracterização e mensuração dos resultados, apresentação de razão de custo-efetividade incremental e análise de sensibilidade); e a discussão quanto às limitações do estudo, impacto orçamentário, implicações distributivas da intervenção e generalização dos resultados, sendo estas três últimas menos freqüentes.

A mensuração dos custos, ou custeio, é uma etapa que apresenta desafios ${ }^{8}$. Os custos refletem o funcionamento da economia na qual se insere a tecnologia, assim como expressam a estrutura organizacional de um determinado sistema de saúde, suas respectivas práticas/condutas locais, remunerações etc. A mensuração de custos referentes ao tempo do paciente e/ou cuidador, que constituem custos sociais,

\footnotetext{
${ }^{8}$ As especificidades e relações entre mercados de uma economia exigem que o pesquisador pondere o que é teoricamente correto e tecnicamente possível, mantendo a credibilidade do estudo. Uma avaliação econômica é sempre uma análise parcial, baseada num equilíbrio parcial, ou seja, assumemse variações no mercado em análise e que os demais permanecem constantes, ao contrário de uma análise de equilíbrio geral (análise do comportamento da oferta e demanda e dos preços de equilíbrio em todos os mercados de uma economia, simultaneamente) (Beutels et al, 2003).
} 
apresenta, por sua vez, peculiaridades relacionados ao mercado de trabalho em análise.

As estimativas de custos devem ser apresentadas para um determinado período, sendo necessário o desconto caso os custos estejam em moeda de diferentes anos. Como os estudos de avaliação econômica em saúde foram propostos em países desenvolvidos, as taxas de desconto apresentadas na literatura refletem realidades específicas. A preocupação com as análises de custo-efetividade feitas para o Brasil deve ser a de adequar os estudos à realidade brasileira, de modo a não simplesmente importar dados que não sejam consistentes.

O resultado do estudo de custo-efetividade é a razão de custo-efetividade incremental ${ }^{9}$. A razão de custo-efetividade incremental é definida como a razão entre o custo incremental e a efetividade incremental decorrentes da comparação entre as estratégias, como definido a seguir.

$\underset{\text { Razão de Custo-Efetividade }}{\text { Incremental }}=\frac{\text { Custo } \quad(\text { Estratégia } 1)-\text { Custo } \quad(\text { Estratégia } 2)}{\text { Desfecho }(\text { Estratégia } 1)-\text { Desfecho }(\text { Estratégia } 2)}$

As avaliações econômicas servirão de instrumento de apoio à tomada de decisão no caso de comparação de uma intervenção mais efetiva e de maior custo. Outra forma de definir a razão de custo-efetividade incremental é através da inclinação da reta $\mathrm{AO}$ do gráfico a seguir.

\footnotetext{
${ }^{9}$ ICER na literatura de língua inglesa (Incremental Cost-Effectiveness Ratio)
} 
Diferença de custo

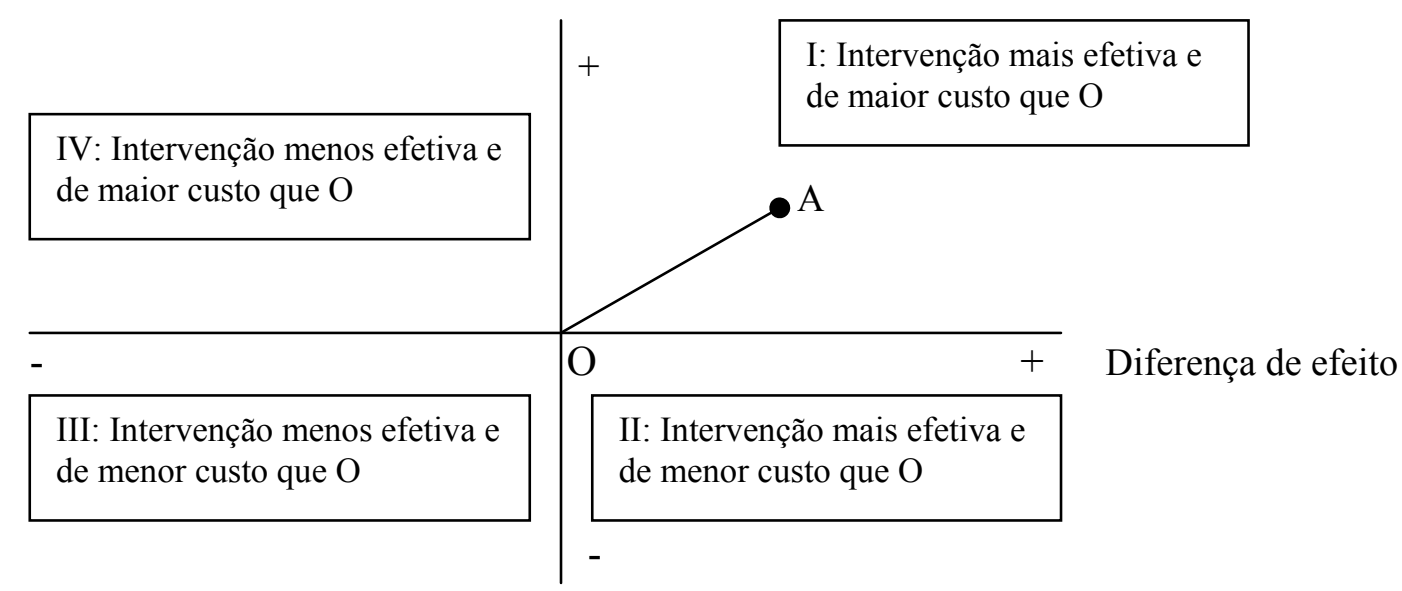

Resultados no quadrante IV referem-se a estratégias dominadas, sem respaldo para adoção, ao passo que resultados no quadrante II referem-se a estratégias dominantes, cuja recomendação de adoção dispensam avaliações econômicas.

Um passo seguinte ao cálculo da razão de custo-efetividade incremental é a definição se determinada estratégia, ou intervenção, é custo-efetiva ou não. Para tal, a razão deve ser comparada ao limiar de custo-efetividade. O Brasil ainda não tem um limiar próprio, sendo uma alternativa a adoção de limiar proposta pela OMS (2007) de três vezes o PIB $^{10}$ per capita.

Dada a incerteza referente às estimativas de dados para as avaliações econômicas em saúde (epidemiológicos, de eficácia, de custos etc), a análise de sensibilidade é etapa integrante da avaliação. Através da análise de sensibilidade é possível avaliar o impacto dos parâmetros nos resultados, identificando desta forma os parâmetros que mais influenciam as razões de custo-efetividade incrementais. A variação dos parâmetros pode ser analisada individualmente, através da análise 
univariada, ou conjuntamente, através da análise multivariada, quando mais de um parâmetro é variado ao mesmo tempo. Outra forma de análise de sensibilidade é a probabilística, que utiliza métodos estatísticos e atribuí funções de distribuição aos parâmetros. A análise de sensibilidade testa a robustez da avaliação econômica e seus parâmetros.

\section{Quadro 1. Componentes de avaliações econômicas em saúde}

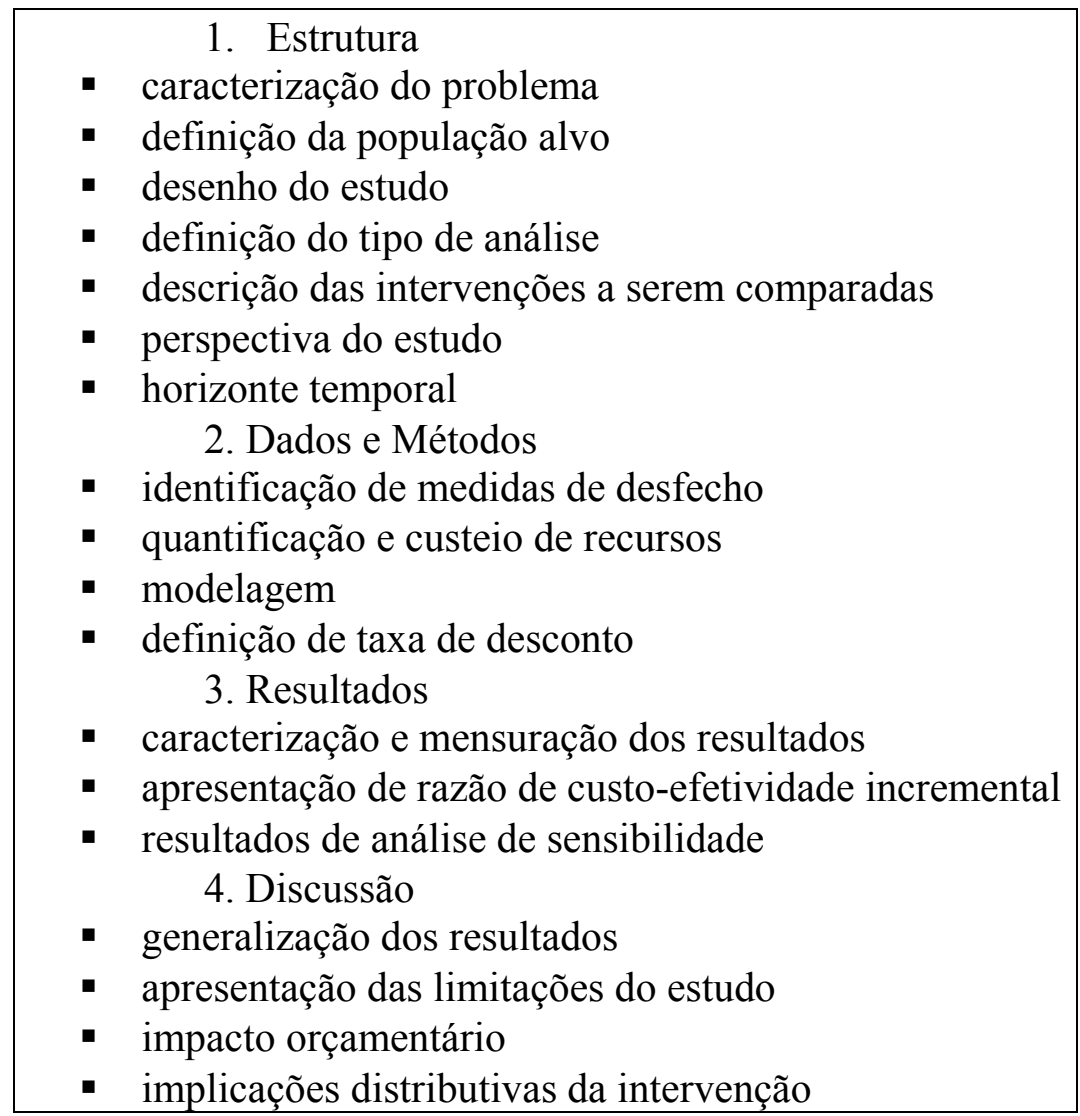

Fonte: Adaptado de Brasil (2007) e Gold et al (1996).

${ }^{10}$ Produto Interno Bruto 
O número de estudos de avaliação econômica cresceu significativamente nos últimos 20 anos nos países desenvolvidos (Beutels et al, 2003). O interesse nestes estudos reflete as preocupações com a elevação dos gastos em saúde, as pressões sobre os gestores nas decisões sobre a alocação de recursos e a necessidade dos produtores de demonstrar os benefícios de suas tecnologias. $\mathrm{O}$ refinamento metodológico tem acompanhado este crescimento de avaliações na literatura, com discussões a respeito de sua padronização (Gold et al, 1996; OMS, 2003, 2007).

A tendência de maior utilização de estudos de avaliação econômica em saúde para tomada de decisão também se faz presente no Brasil (Novaes, 2000), onde estes estudos começam a ser um dos elementos a serem considerados no processo de incorporação de novas tecnologias no país (Brasil, 2007). De forma geral, a elaboração e uso de avaliações econômicas ainda é incipiente dentro dos sistemas de saúde na América Latina (Iglesias et al, 2005).

Nos países de renda alta, com maiores recursos para inclusão de novas tecnologias, a avaliação econômica em saúde tem tido uma participação crescente, apesar de ainda limitada. É reconhecido o impacto limitado das avaliações econômicas na alocação de recursos em saúde (Williams et al, 2007). As decisões prioritárias não são necessariamente determinadas pelas avaliações econômicas. $\mathrm{Na}$ verdade, muitas vezes a elaboração dessas avaliações tem maior utilização, pelos decisores, de seus dados desagregados do que de suas medidas sínteses (razões de custo-efetividade incrementais). A própria metodologia das avaliações econômicas tem que ser compreendidas por gestores/decisores, de modo que seus resultados sejam aceitos e usados como instrumentos de tomada de decisão. No entanto, mesmo esta compreensão difundida, como em países de maior tradição na elaboração e 
incorporação de avaliações econômicas de programas de saúde, não garante que os resultados delas sejam a palavra final. As decisões são baseadas em negociações e no equilíbrio de interesses concorrentes entre si. As evidências de pesquisa, nas quais se incluem as avaliações econômicas, diluem-se entre as demais variáveis de influência, como as questões políticas, de julgamento, experiência e pressão social.

Assim como o trade-off inerente a qualquer processo de escolha, a opção metodológica para as estimativas de custos para avaliações econômicas depara-se entre o maior detalhamento e coerência metodológica e a viabilidade de dados e tempo para essas estimativas. Em locais onde a avaliação econômica é mais recente para auxiliar gestores no processo de inclusão de tecnologias, a elaboração dessas avaliações tem que lidar com pontos ainda não resolvidos. É o caso da padronização do uso de sistemas oficiais de dados e revisão destes sistemas, incluindo custos. Além disto, estudos de custos no Brasil são ainda incipientes, havendo o reconhecimento da necessidade de maior esforço para seu aprimoramento, também enquanto etapa indispensável das avaliações econômicas em saúde (ISPOR, 2008). 


\subsection{Estimativas de custos}

\subsubsection{Categorias de custos}

Toda avaliação econômica de tecnologias em saúde deve analisar os custos (Oostenbrink et al, 2002) e benefícios da tecnologia, a partir de categorias básicas que apresentam suas particularidades dependendo da tecnologia considerada.

Na literatura, os custos têm sido tradicionalmente divididos entre diretos e indiretos. Os custos diretos se referem aos custos que estão diretamente relacionados ao tratamento da doença sob análise. O termo indireto é usado em economia para se referir aos ganhos ou perdas de produtividade relacionada às doenças ou morte e são também chamados de custos de produtividade, associados à morbidade e à mortalidade (Gold et al, 1996). Por produtividade entende-se o produto do trabalho do indivíduo ponderado pelo tempo, expresso através de seu valor de mercado (salário).

Uma outra categoria de custos que não os diretos e indiretos são os denominados intangíveis, como por exemplo, o nível de dor e sofrimento do paciente. Apesar de terem sua inclusão recomendada (Beutels et al, 2003), praticamente não o são pela dificuldade de sua mensuração.

Os custos diretos incluem os valores dos bens e serviços utilizados na realização da intervenção, incluindo os cuidados gerados por eventuais efeitos adversos. A duração de consumo do recurso, ou seja, o período de ocorrência dos custos diretos dependerá da característica da intervenção em questão, podendo ser pontual no tempo ou para o resto da vida do indivíduo (Gold et al, 1996).

Os custos diretos se subdividem em custos no cuidado da doença e custos de transporte. Os primeiros são também chamados na literatura de custos médicos 
diretos. Os custos no cuidado da doença englobam atividades dos profissionais de saúde, o uso das instalações físicas, medicamentos, exames etc ${ }^{11}$. Os custos diretos não compreendem apenas os recursos referentes a sua utilização nos ambulatórios, hospitais ou unidades prestadoras de serviços de saúde. Há um custo de deslocamento até estes locais, que são os custos de transporte. Desta forma, quando se fala de custo domiciliar, somente são contabilizados para este os custos do cuidado da doença (medicamentos, materiais etc no domicílio), ao contrário dos custos ambulatoriais ou hospitalares, que também agregam os de transporte.

Os custos indiretos se referem à utilização do tempo pelo paciente ou cuidador, cuja parcela dedicada ao trabalho e lazer se reduz em um estado de doença (Tranmer et al, 2005). A perda de produtividade de trabalho na literatura tem buscado incorporar não somente a ausência do trabalho como também a redução de rendimento no mesmo sem ausência (Brouwer et al, 2002). A inclusão de custos indiretos amplia a perspectiva de análise da avaliação econômica, que passa a refletir a perspectiva da sociedade, permitindo a avaliação dos impactos sociais da introdução da tecnologia.

\subsubsection{Fundamentos teóricos e metodologias de custeio}

\section{Fundamentos teóricos}

As estimativas para os itens componentes das categorias de custos apresentam grande variabilidade no que se refere ao conceito de custo adotado e a metodologia aplicada. Não há consenso na literatura para a melhor prática de

\footnotetext{
${ }^{11}$ Outros elementos de custos são custos de aluguéis, material de escritório, segurança, pessoal etc, que são classificados por alguns autores como custos indiretos (Cyrillo et al, 1998). Na literatura de avaliação econômica de tecnologia em saúde o termo custo indireto é utilizado de outra forma, referente aos custos de perda de produtividade.
} 
estimativas de custos, seja em relação a princípios ou aplicação, com grande variação dos métodos de custeio usados nos estudos publicados (Mogyorosy et al, 2005).

Conceitualmente, custo pode ser definido como custo contábil e custo econômico. O custo contábil tem por objetivo a mensuração de custos para planejamento financeiro e relatórios contábeis e financeiros de organizações, tendo, portanto, uma perspectiva mais restrita. $\mathrm{O}$ custo contábil atende às necessidades de gestão de determinada organização, refletindo uma estrutura e funcionamento próprios que podem dificultar generalizações.

O custo econômico baseia-se no custo de oportunidade, que é o custo incorrido de uma escolha em função dos benefícios sacrificados de escolhas alternativas, ou seja, o custo de oportunidade é dado pela melhor alternativa de uso de recurso.

O conceito de custo de oportunidade surge na economia com a segunda geração de economistas da escola austríaca, sendo Friedrich Von Wieser (18511926) reconhecido como seu criador. O princípio dos custos de oportunidade ou conceito dos custos alternativos transformou o custo de produção em um custo psicológico subjetivo. A determinação de custo deslocou-se da produção para a utilidade, introduzindo parâmetros subjetivos e não apenas técnicos. Pelo custo de oportunidade, o valor de uma mercadoria é o valor das mercadorias que foram deixadas de lado. No entanto, esse conceito não define o que determina o valor dos bens alternativos, não sendo claro se explica qualquer fundamento sobre o valor de troca (Brue, 2005). 
O custo de oportunidade remete a uma idéia de sacrifício porque parte da premissa de eventos mutuamente exclusivos: a decisão por um uso de recurso implica rejeição de usos alternativos, dada a necessidade de escolha em um ambiente de escassez de recursos. O processo de escolha do agente considera as alternativas de escolha na economia como um todo, de modo que a perspectiva para o custo econômico é da sociedade, o que o torna o mais recomendado para estimativas de custos.

Além da diferença de representação de perspectivas, os custos econômico e contábil podem apresentar diferenças na inclusão de custos explícitos e implícitos. Os custos explícitos correspondem às quantias desembolsadas dentro do período em análise. Os custos implícitos correspondem ao consumo de recursos que excedem o período em análise e incluem custos não-monetários. Os custos contábeis, ao se basearem em custos históricos, de aquisição ${ }^{12}$, desconsideram o custo implícito existente depois da vida contábil de prédio e equipamentos, por exemplo. O custo econômico, ao contrário, ao considerar o valor corrente de mercado incluí os custos implícitos, assim como para itens não transacionados no mercado, portanto sem valor determinado neste, como é o caso do cuidado informal. Neste caso, é possível calcular o custo implícito aplicando um preço sombra, ou seja, caso o cuidador informal estivesse inserido no mercado de trabalho, quanto seria sua renda. O custo econômico é o único possível quando não há custos contábeis para itens de custos. A utilização do conceito de custo econômico, ao incluir custos explícitos e implícitos, torna as estimativas de custos maiores do que caso fosse aplicado o conceito de custo contábil (Cyrillo et al, 1996; Mogyorosy et al, 2005).

\footnotetext{
${ }^{12}$ Custo de financiamento menos depreciação.
} 
O custo econômico pode ser estimado a partir do preço de mercado, no caso de mercados perfeitos (concorrência perfeita). O mercado de saúde, no entanto, apresenta falhas, com segmentos oligopolizados, como é o caso da indústria farmacêutica no nível de classes terapêuticas (Fiuza et al, 2001) e produção de vacinas (Buss et al, 2005), e informação imperfeita. Além destas circunstâncias, o custo de oportunidade pode diferir do preço de mercado na existência de externalidades e/ou bens públicos; distorções por intervenções governamentais (impostos, regulação); imprevisibilidade do preço de mercado, assim como seu equilíbrio ainda em definição, caracterizado pela fase de aprendizado no ciclo de vida do produto (Dranove, 1996 apud Mogyorosy et al, 2005).

A rigor, dado que o custo de oportunidade reflete o(s) valor(es) do(s) uso(s) alternativo(s) de recursos, o cálculo destes valores exige conhecimento da utilidade agregada de todos os indivíduos na sociedade para cada alternativa possível, variando de contexto para contexto. O cálculo do custo de oportunidade, desta forma, se mostra muito custoso, demorado, e mesmo quase impossível de ser determinado (Buchanan, 1989 apud Brue, 2005; Byford, 2003; Mogyorosy et al, 2005).

As estimativas de custos na área da saúde ficam condicionadas, portanto, pelas particularidades dos diferentes componentes do mercado, que quando apresentam falhas de mercado comprometem o uso de preço de mercado como equivalente do custo de oportunidade. O pesquisador deve analisar cada item de custo, ponderando a validade da utilização de preços de mercado e, alternativamente, custos contábeis como proxies para os custos de oportunidade. A utilização de proxies deve respeitar (Mogyorosy et al, 2005):

- o propósito do custeio (problema de decisão); 
- a perspectiva do estudo;

- o tipo e complexidade do serviço de saúde ou tecnologia sob análise;

- a precisão requerida;

- a capacidade de generalização e representatividade;

- a consideração do método de custo contábil usado pela instituição, quando existente;

- a disponibilidade de dados válidos e confiáveis;

- a viabilidade de mensuração dos custos (informação existente);

- o tipo de usuários dos serviços/tecnologia;

- o número e variações das diferentes atividades do serviço/tecnologia.

O propósito do custeio influencia a seleção das técnicas de custeio. As técnicas de custeio são as de absorção e marginal. No custeio por absorção todos os custos, fixos e variáveis, são incluídos ao passo que na análise marginal há apenas inclusão dos custos variáveis, restringindo-se ao curto-prazo (não alteração de custos fixos). Para o longo prazo, custos médios podem ser usados como proxy para custos marginais de longo prazo, dada a incerteza quanto ao futuro (Mogyorosy et al, 2005).

As características do serviço ou tecnologia de saúde no que se refere a sua produção afetam custos e devem ser consideradas para suas estimativas, dada a possibilidade de economias de escala e escopo. A existência de economias de escala e/ou escopo pode afetar substancialmente os custos unitários. As fontes de economias de escala são economias específicas de produto (aprendizado), economias específicas de planta e economias específicas de operação. As economias específicas de produto ocorrem por especialização de fatores de produção (capital, trabalho) e 
por efeito da curva de aprendizado, que implica que a longo prazo os custos médios são declinantes devido ao aumento de eficiência técnica. As economias de escala específicas de planta referem-se à capacidade de um hospital em relação a custos fixos: quanto maior a ocupação do hospital, mais diluídos os custos fixos e menores os custos unitários. As economias de escala específicas de firma resultam de economias de marketing, venda, ou capacidade de capitalização ou distribuição de serviços entre diferentes plantas, como é o caso de diálise. As economias de escopo resultam de economias de produção conjunta de produtos ou serviços. Hospitais e ambulatórios são organizações multiproduto onde podem ser encontradas economias de escopo (Mogyorosy et al, 2005).

\section{Metodologias de custeio}

Nas estimativas de custos, são três os principais elementos para o custeio (Drummond et al, 1997; Mogyorosy et al, 2005):

i. identificação e classificação dos itens de recursos;

ii. mensuração das quantidades de uso de recursos (via ensaios clínicos; prontuários; sistemas de dados etc);

iii. aplicação de custos unitários aos respectivos recursos consumidos.

As três etapas apresentadas para as estimativas de custo estão condicionadas pelo problema de decisão, objetivos do custeio e definição dos serviços de saúde. $\mathrm{O}$ propósito do custeio influenciará a escolha metodológica, assim como a definição conceitual de custo define a forma de mensuração dos custos. Os objetivos do custeio são variados, como no estabelecimento de preços para novos serviços e tecnologias; 
comparação de custos entre diferentes provedores, regiões, países, serviços e tecnologias; identificação de áreas de redução de custos, avaliação de eficiência de serviço; decisões de reembolso; alteração de incentivos para pagamento etc (Mogyorosy et al, 2005). No caso de estudos de custo-efetividade, as estimativas de custos objetivam a comparação de custos, conjuntamente com desfechos, entre diferentes tecnologias/serviços, que podem servir para decisões de reembolso e inclusão da tecnologia ou serviço em questão.

$\mathrm{Na}$ literatura, há recomendação para que a descrição dos objetivos dos estudos seja específica, mensurável, alcançável, relevante e demarcada temporalmente (SMART pelas iniciais em inglês) (Hammod, 1999 apud Mogyorosy et al, 2005). Específica implica que os objetos de custo sejam claros, que as unidades de serviço sejam bem definidas (grupo de população, patologia existente, resultado esperado, tecnologia em questão). Mensurável refere-se à existência de dados de boa qualidade ou coleta de dados viável e não-custosa. Alcançável considerando-se que para a metodologia de custeio sempre há o trade-off entre acurácia, confiabilidade e conveniência. Relevância relaciona-se à importância do que se está medindo para a perspectiva do estudo. A demarcação temporal refere-se ao prazo do estudo e ano de mensuração dos custos.

Em relação ao horizonte temporal, os estudos de avaliação econômica estão condicionados pela história natural da doença e mudanças epidemiológicas resultantes da intervenção, de forma que após a definição do horizonte temporal pela parte clínica, devem ser observados os custos e eventuais mudanças destes no período fixado para análise. Para períodos muito longos, pode haver variação da prática clínica e mudanças tecnológicas afetando os custos unitários, assim como 
mudanças no mercado de trabalho afetando salários. A relação entre o horizonte temporal e a tecnologia sob análise deve considerar o ciclo de vida do produto e o efeito da curva de aprendizagem (Dranove, 1996 apud Mogyorosy et al, 2005), dado que tecnologias mais novas terão seu preço reduzido ao longo do tempo. A análise do mercado para a tecnologia deve considerar a interação e entrada de produtores, sendo a competição e determinantes técnicos de produção básicos para a determinação de preço da tecnologia. A inclusão de mudanças de práticas clínicas e tecnológicas, apesar de mais rigorosa, não é feitas em função de sua dificuldade.

i. Identificação e classificação dos itens de recursos

A etapa de identificação dos itens de recursos, após definição dos objetivos de custeio e dos serviços de saúde, pode basear-se no desenvolvimento de descrição detalhada do manejo clínico, como as existentes em diretrizes clínicas ou então a partir de revisão de literatura, grupo focal, entrevistas e consultas com especialistas. É importante garantir que os recursos identificados sejam classificados, de forma a refletir o sistema de custeio adotado. Uma forma de classificação, por exemplo, é separar os custos em fixos, variáveis etc. A definição da unidade apropriada de recursos também é fundamental para que os itens de custos possam ser agregados e comparados corretamente (Mogyorosy et al, 2005).

A identificação é a etapa da caracterização do problema de saúde em estudo e das tecnologias de processo e produto utilizadas na sua abordagem quando se inicia a avaliação, uma vez que é a doença em si, os procedimentos diagnósticos e terapêuticos disponíveis e aceitos pela comunidade médica, e demais profissionais de saúde, que determinarão a composição dos custos, principalmente os custos 
diretos. Fatores sócio-econômicos influenciam se a demanda para os itens identificados se efetivará, mas estes condicionantes só atuam após a identificação. A incidência da doença analisada determina a população atingida, a partir da qual são analisados demanda e oferta pelo tratamento, acesso etc.

ii. Mensuração das quantidades de uso de recursos

A mensuração das quantidades de uso de recursos pode ser feita utilizandose três técnicas: micro-costing ou bottom-up, gross-costing ou top-down e mista. Cada uma das técnicas apresenta vantagens e desvantagens. Micro-costing permite um alto grau de detalhamento, o que não pode ser obtido com gross-costing, uma vez que os custos correspondem a componentes agregados. Gross-costing pode ser simples e transparente, abrangendo variabilidade regional e institucional (validade externa), ao passo que micro-costing reflete as características da amostra (pacientes, instituições) cujo grau de generalização é menor. A escolha pela técnica dependerá do detalhamento e confiabilidade requeridas pelo estudo, assim como pela viabilidade da obtenção dos dados. A técnica mista combina micro-costing e grosscosting, usando este último na inexistência do primeiro, sendo que esta técnica apresenta as vantagens e desvantagens de ambas as técnicas combinadas. A técnica mista é a adotada pelo Manual de Custeio do National Health Service/NHS do Reino Unido (Curtis et al, 2006), bem como frequentemente pelos estudos de custos de doença, análise de custos e estudos de custo-efetividade (Mogyorosy et al, 2005).

O micro-costing pode se basear em métodos observacionais (questionários, entrevistas, classificação contábil etc) e métodos baseados em participantes (ensaios clínicos, questionários pelo correio etc), com coleta de dados primários. O gross- 
costing pode ser feito a partir de bancos de dados administrativos, sistemas de DRGs (Diagnosis-related Groups) etc, isto é, dados secundários, coletados para outros fins mas que podem ser utilizados em estudos.

A mensuração dos itens identificados pode ser feita retrospectiva ou prospectivamente, sendo que a técnica top-down só se aplica para estudos retrospectivos (dados secundários) (Gyldmark, 1995).

\section{iii. Aplicação de custos unitários aos respectivos recursos consumidos}

A etapa de aplicação de custos unitários às unidades de recursos é a que se insere na esfera econômica e é a partir dela que se faz necessária a determinação conceitual de qual custo será considerado para as estimativas. Apesar do custo de oportunidade ser o recomendado (Finkler, 1982; Drummond et al, 1997; Mogyorosy et al, 2005), na prática, os estudos de custos e avaliação econômica usam as seguintes formas de valoração de recursos (Mogyorosy et al, 2005):

- mensuração direta de custos;

- métodos contábeis de custos;

- custos unitários padrões (sistema de dados oficiais);

- pagamentos, remunerações ${ }^{13}$, tarifas, preços de mercado;

- estimativas, extrapolações.

\footnotetext{
${ }^{13}$ A revisão de sistemas de remuneração para refletir custos reais influencia todo o financiamento do sistema de saúde, enfrentando impasses sociais e econômicos. Se em casos de falhas de mercado, os preços de mercado são proxies distorcidas para o custo de oportunidade, remunerações podem refletir poder de barganha histórico, sendo o reflexo de diferentes sistemas de incentivos consolidados no sistema de pagamento, que podem ou não representar preços de equilíbrio de mercado.
} 
A utilização de outros custos que não o de oportunidade podem ser utilizados, dependendo da perspectiva adotada e do impacto dos custos nos resultados. A utilização de custos unitários de bancos de dados administrativos, oficiais, por exemplo, podem ser úteis para comparações entre resultados de avaliações econômicas, por serem dados existentes e acessíveis. Na existência de estudos de custos específicos bem elaborados metodologicamente, sua utilização é recomendada, assim como comparação com outras fontes de dados de custos, de modo a indicar a variabilidade nos resultados. Porém, estudos isolados no que se refere a fontes de custos podem seguir rigor metodológico, mas não serem comparáveis com outros.

Das formas de avaliação alternativas para valoração de custos, a mensuração direta de custos pode ser feitas pelas técnicas de bottom-up, top-down e mista, também utilizadas para a mensuração de usos de recursos, como já descritas. Microcosting é melhor opção de valoração para serviços mais complexos e quando recursos humanos têm peso maior. Quando tecnologias (medicamentos, equipamentos etc) são maioria do uso de recursos, gross-costing é uma boa aproximação (Mogyorosy et al, 2005).

Métodos contábeis de custos podem variar de instituição para instituição, entre países etc. São variadas as formas de custeio e quanto mais precisas mais dispendiosas, como é o caso do Método ABC (Activity-Based Costing), que é um método que atribuí custo de acordo com a atividade, que além de método contábil é também uma técnica de mensuração direta de micro-costing. O custeio por centro de custo é mais simples e comum no Brasil na rotina da gestão dos serviços do que o activity-based costing (Okazaki, 2006). 
Custos unitários padrões podem vir de sistema oficiais de dados ou listas publicadas, como é o caso dos "Custos Unitários de Saúde e Cuidado Social” do NHS (Curtis, 2006). No Brasil, são de livre acesso via internet os Sistema de Informações Ambulatoriais (SIA) e Sistema de Informações Hospitalares (SIH) do DATASUS, que disponibilizam valores praticados no sistema publico de saúde, que no caso são remunerações.

É comum o uso de cobranças ou remunerações ao invés do custo propriamente, pela dificuldade de alocação dos custos, sendo muitas atividades de um hospital, por exemplo, dividida entre diferentes especialidades, departamentos etc. Tal alocação, na verdade, teria como resultado o custo contábil, que pode ou não refletir o custo econômico (Mogyorosy et al, 2005). Caso um hospital comprasse suprimentos a preços mais altos que o de mercado, o custo contábil seria maior que o econômico. As cobranças ou remunerações, usadas muitas vezes na literatura como proxies para custos, são estabelecidas posteriormente aos custos contábeis, e podem ser maiores ou menores que aqueles. As cobranças ou remunerações, quando mais altas, podem cobrir custos com equipamentos, novas tecnologias etc ou compensar perdas em outras unidades menos eficientes. Algumas atividades menos eficientes em certos hospitais continuam a existir porque estes hospitais são mais eficientes em outras atividades, e desta forma conseguem persistir no mercado compensando perdas em determinadas atividades pela eficiência das demais. A lógica de estabelecimento de cobranças também segue a de comparação via mercado e nivelamento delas pela média vigente. Muitos hospitais nos EUA, por exemplo, vêem quanto seus concorrentes estão cobrando e então colocam seus próprios valores, sem nenhuma relação direta com seus custos. Não há correlação entre 
cobranças e custos econômicos e não é possível analisar economias/deseconomias de escala por cobranças (Finkler, 1982). Determinadas especificidades podem permitir que outros custos além do de oportunidade sejam usados sem muito viés (Drummond et al, 1997; Mogyorosy et al, 2005), como é o caso da perspectiva da análise. Quando se consideram os pagadores, custos para eles são na verdade as cobranças que sofrem por determinado serviço/instituição.

A perspectiva da análise é de grande importância para a inclusão dos custos numa avaliação econômica e conseqüentemente os resultados desta. A defesa do uso da perspectiva da sociedade não ocorre apenas por ser esta a mais ampla possível, mas muitas vezes em função das características de um sistema de saúde e seu financiamento. Em sistemas majoritariamente públicos de saúde, financiados por impostos que recaem na sociedade como um todo, como, por exemplo, o NHS no Reino Unido, argumenta-se a adoção da perspectiva da sociedade também porque todos os membros desta financiam diretamente a inclusão de novas tecnologias (Raftery, 2000).

São muitas as dimensões a serem consideradas para as estimativas de custos: a definição do custo em questão (contábil, econômico); a perspectiva, que influenciará não só os itens de custos (diretos, indiretos e suas subdivisões), mas sua própria definição, sendo para a sociedade o custo econômico o mais preciso; e os métodos tanto para os custos diretos quanto indiretos. Para a perspectiva do sistema de saúde é interessante ressaltar que para os resultados de um estudo de custoefetividade (razão de custo-efetividade incremental), vieses causados pela utilização de remuneração ao invés de custos podem não alterar o status de custo-efetiva de uma determinada estratégia se o modelo é pouco sensível a variações de custos e/ou 
se a razão de custo-efetividade incremental está tão distante do limiar que variações dela não alteram seu status.

A transparência e coerência das estimativas de custos na definição conceitual de custo, na perspectiva adotada, método aplicado e fontes de dados possibilitam evitar os problemas mais correntes nas estimativas de custos publicadas. Entre os principais problemas, destacam-se os referentes à alocação de recursos humanos, à inclusão de custos de capital e investimento (depreciação), benefícios, pagamentos informais e impostos e à apresentação de resultados em um mesmo ano e moeda (Mogyorosy, 2005). As dificuldades para a comparação de custos e uniformização metodológica são (Mogyorosy, 2005):

- falta de clareza dos conceitos de custos e termos técnicos usados nos estudos publicados, detalhes insuficientes de metodologia utilizada;

- discrepância entre interpretação e uso de termos técnicos e princípios metodológicos;

- diferenças de classificação de diferentes itens de custos;

- variação da inclusão e exclusão de itens de custos;

- variação do tratamento de alocação de custos conjuntos de recursos humanos.

\section{Variabilidade metodológica em estimativas de custos}

Os tipos de publicação sobre custos em saúde variam de estudos de custos de doença, estudos de análise de custo, avaliação econômica ou tecnológica a estudos comparativos, dependendo da definição dos serviços/tecnologias de saúde. O foco do estudo determina se os custos serão os de serviços/procedimentos, de tratamento de episódios ou custo de doença (Mogyorosy et al, 2005). Para todos os tipos de 
publicação mencionados constata-se variabilidade metodológica nas estimativas de custos.

A preocupação com a validade das estimativas de custos e métodos aplicados se reflete na literatura com a expansão dos estudos de custo e de avaliação econômica em saúde publicados, cujas estimativas de custos apresentam variabilidade. Os métodos são apontados como fator nuclear da variabilidade nos estudos de custo-efetividade e das variações das estimativas de custos propriamente (Adam et al, 2003; Akobundu et al, 2006), como ocorre com os custos diretos, indiretos e tratamento de custos futuros. A análise de sensibilidade é etapa complementar e fundamental às estimativas de custos, a fim de avaliar o impacto nos resultados decorrente de diferentes premissas e metodologias. A seguir são apresentadas as variabilidades específicas a custos diretos, indiretos e custos futuros e qualidade da tecnologia.

- Custos diretos

Para custos diretos, não há uma sistematização de metodologias. As escolhas de métodos são basicamente o gross-costing e micro-costing.

A partir de revisão da literatura ${ }^{14}$ foi verificado o aumento do número de estudos de custo de doença (três vezes maior em 1980 do que em 1960), estudos estes que puderam ser agregados de forma a seguir uma categorização de métodos, categorias estas ainda não estabelecidas como dominantes na literatura, mas que ajudam a sistematizar as estimativas de custos de doença (Akobundu et al, 2006). Quatro grandes categorias de métodos de estudos de custo de doença foram

\footnotetext{
${ }^{14} 365$ artigos completos entre 1996-2005 foram identificados.
} 
definidas: método de soma de todos os diagnósticos, método de soma de diagnóstico específico, método de controle comparável e método estatístico (regressão). O método de soma de todos os diagnósticos $(17 \%$ dos artigos publicados) é indicado para doenças sem comorbidade. O mais utilizado é de soma de diagnóstico específico (57\% dos artigos publicados), que identifica todos os pacientes com um diagnóstico primário e soma todos os custos para tratamento daquele. Este método pode subestimar custos de comorbidade dependendo de como estas são atribuídas às causas básicas (diagnósticos primários). O método de controle comparável (18\% dos artigos publicados) se baseia em algoritmos para parear pacientes e então estimar custos. Sua desvantagem é a superestimação de custos incrementais mesmo após controle de comorbidade, porque as condições médicas de comorbidade não são os únicos fatores de confusão, como, por exemplo, fatores demográficos. As regressões (8\% dos artigos publicados), que podem ou não incluir controles comparáveis, podem restringir fatores de confusão, mas também não estão isentas de viés. Especificações incorretas de modelo e distribuições podem comprometer as estimativas de custos. Além disto, apresentam melhores resultados para doenças infecciosas que crônicas, por serem estas multicausais e relacionadas a estilos de vida. Cada método apresenta sua especificade, vantagem e desvantagem. No entanto, o método de soma de diagnóstico específico se mostra como o de maior disseminação, como ressaltado pela proporção de estudos publicados.

- Custos indiretos

Assim como para custos diretos, não há uma uniformidade da metodologia de cálculo de custos indiretos, metodologia esta que se divide em Método de Capital 
Humano, Método de Fricção e Método do Painel de Washington (Koopmanschap et al, 1995; Liljas, 1998; Brouwer et al, 2002; Tranmer et al, 2005).

O Método de Capital Humano tem sido o mais freqüentemente usado quando há o cálculo de custos de produtividade. Ele pressupõe pleno emprego na economia e que qualquer absenteísmo é compensando no curto prazo pelo aumento de produtividade de demais trabalhadores sem alterações de custos para empregadores e para a sociedade. O cálculo é feito pela multiplicação do período de ausência pelo salário proporcional ao período. A teoria neoclássica, base teórica para o Método de Capital Humano, demonstra que na margem a produtividade iguala o salário real, daí este ser usado para expressar a perda de produtividade. Mesmo em ausências longas, o método não assume reposição de trabalhadores, no sentido de reduzir custos de produtividade. Conseqüentemente, as estimativas por este método seriam potenciais e não reais, sendo o máximo de custos de produtividade ocorrentes para a sociedade (Brouwer et al, 2002). Economias com níveis salariais diferentes ou doenças que afetam grupos sócio-econômicos específicos exigem um cuidado quando da comparação dos custos de produtividade.

O Método de Fricção (Koopmanschap et al, 1995) assume a existência de custos de fricção, que são custos de transação associados com a reposição de um trabalhador. Como não existe pleno emprego, existem outros trabalhadores dispostos a repor aquele que se ausentou. Perdas de produtividade seriam evitadas com a reposição, sendo os custos mais próximos dos reais. O período de fricção iguala um período médio de férias, necessário para se repor o trabalhador. O valor da perda de produtividade não é estimado pelos salários, mas pelo valor adicional de um 
trabalhador. Depois do período de fricção, não há mais custos de produtividade adicionais, exceto para custos macroeconômicos mais longos (Brouwer et al, 2002).

O Método de Fricção reconhece circunstâncias locais, como taxa de desemprego, e especificidades da ocupação e firmas sob análise (Tranmer et al, 2005). Apesar deste método propor uma mensuração mais real dos custos de produtividade, recebe críticas por não ter um referencial teórico tão consolidado como o Neoclássico, além de em casos de convalescença curta não necessariamente haver reposição do trabalhador.

No Método do Painel de Washington, os custos de produtividade não necessariamente precisam ser expressos monetariamente, podendo-o ser em termos de qualidade de vida, entrando desta forma no denominador da razão de custoefetividade incremental Os métodos de mensuração de qualidade de vida captariam variações de renda decorrentes de redução de produtividade (Gold et al, 1996).

Apesar da sensibilidade já mencionada de tais tipos de custos, por refletirem parâmetros particulares de cada sociedade, sejam estes sócio-econômicos, institucionais, culturais, ou ainda pela diversidade de métodos, sua inclusão é relevante, uma vez que uma determinada intervenção ou tecnologia de saúde pode ser afetada e afetar tal contexto. A mensuração dos custos indiretos também toca em questões éticas, uma vez que os indivíduos, sendo representados por seu valor no mercado de trabalho e pela economia na qual estão inseridos, refletem falhas ou iniqüidades existentes nos mesmos. 
- Custos futuros e qualidade da tecnologia

Não há consenso na literatura sobre a inclusão de custos de cuidados à saúde que são induzidos pelo fato da vida de um paciente tratado ter tido sua expectativa de vida aumentada por determinada intervenção (Weinstein et al, 1997). Garber et al (1997) e Meltzer (1997) partem da economia do bem-estar para derivar dois modelos, distintos. Garber et al (1997) concluem que a inclusão ou exclusão de custos futuros se traduzem apenas em razões de custo-efetividade multiplicadas por uma constante sem alteração da hierarquia dos programas de saúde para as razões de custo-efetividade. Meltzer (1997) chega a conclusões opostas: a inclusão de custos futuros de cuidados à doença importa, assim como os custos futuros líquidos não relacionados à saúde (ganhos líquidos de produção), para se maximizar o bem-estar.

A relação temporal e as estimativas de custos também estão relacionadas com a qualidade da tecnologia, que se subdivide em curativa e preventiva, sendo que para cada uma destas modalidades os custos se diferenciarão. As tecnologias curativas lidam com doenças já ocorrentes enquanto as tecnologias preventivas são intervenções que se propõem a atuar sobre enfermidades que podem ou não se realizar no futuro, além de não estarem limitadas ao nível do indivíduo ${ }^{15}$, apresentando desta forma especificidades (Kane et al, 2004).

\subsubsection{Desconto}

Os custos e desfechos relacionados a uma doença e ao uso de uma determinada tecnologia podem ocorrer em diferentes períodos do tempo. A utilização

\footnotetext{
${ }^{15}$ No caso de vacinas, por exemplo, indivíduos que não tomaram a vacina podem se beneficiar da redução do risco de contração da doença por efeito de proteção de rebanho, ou seja, a menor circulação de um vírus contribui para sua menor disseminação, de forma que a ação individual tem um resultado social proporcional maior.
} 
de estimativas de desconto tem por objetivo possibilitar a comparação em um mesmo ponto do tempo, usualmente o momento presente. Como apresentado no Quadro 1, uma avaliação econômica completa assume uma preferência temporal, que é expressa pela taxa de desconto.

A taxa de desconto a ser adotada nas avaliações econômicas em saúde deve refletir uma taxa social de desconto ${ }^{16}$ e não taxas de juros de mercado (Sen 1967, 1982; Drèze, 1990; Caplin, 2004; Hepburn, 2006). As taxas de desconto social estão intrinsecamente relacionadas à tomada de decisão pelo setor público. A racionalidade para projetos sociais, geradores de externalidades positivas, exige estabilidade e incentivo para investimentos sociais de resultados de longo prazo, racionalidade esta que difere da regente de mercados financeiros.

As recomendações da OMS (2003) são de usar taxa de desconto de 3\% e para análise de sensibilidade $0 \%$ para desfechos de saúde e $6 \%$ para custos, sendo 6\% a taxa máxima para custos. As recomendações são gerais, não diferenciando as taxas entre países, objetivando comparabilidade entre estudos, desconsiderando, entretanto, especifidades das economias dos países sob análise. As diretrizes da OMS também não diferenciam as taxas por tipo de tecnologia (preventiva ou curativa).

Um estudo (Valentim et al, 2008) estimou a taxa de desconto social para 167 países para o ano de 2006 e para o Brasil entre 2005 e 2050. A taxa de desconto

\footnotetext{
${ }^{16}$ Desconto social se refere ao processo de ponderar custos e benefícios de investimentos sociais no tempo. Imperfeições de mercado podem causar dificuldades para derivar a taxa de desconto apropriada. Além disto, agregação individual de taxas de desconto não é recomendada, mesmo quando decisões sociais ao invés de privadas são consideradas, a fim de se incluir os interesses de gerações futuras (Spackman, 2004).
} 
social foi calculada com base na derivação de Feldstein (1965) de metodologia de preferência temporal social ${ }^{17}$. A taxa de desconto social, $d^{18}$, é definida como:

$$
d_{t}=\left(1+\pi_{t}\right)^{1-\alpha}\left(1+\gamma_{t}\right)^{\sigma}(1+r)-1
$$

onde:

$\alpha$ é o peso da população

$\pi$ é o crescimento populacional

$\sigma$ é o coeficiente de aversão ao risco

$\gamma$ é o crescimento de renda per capita

$r$ é a taxa de preferência temporal pura

As taxas de desconto social variaram entre os países e no tempo para o Brasil. A média da taxa de desconto social para os 167 países incluídos foi de $6,8 \%$, próximo ao valor máximo estipulado pela OMS (2003). No entanto, houve grandes variações da taxa de país para país ${ }^{19}$, o que mostra que a aplicação de uma média geral está muito distante de taxas específicas dos países, o que pode trazer grandes distorções aos resultados. Novamente, as recomendações da OMS objetivam antes uma comparação, sem pretensão de ser uma previsão. A taxa média para o Brasil entre 2005 e 2050 foi de 4,7\%, com valor mínimo de 3,6\% e máximo de 5,5\% (Anexo, Tabela i). A variação temporal da taxa para o Brasil, por sua vez, está de acordo com um dos desafios metodológicos apontados pela OMS (2003).

\footnotetext{
${ }^{17}$ A metodologia de preferência temporal social é a mais recomendada. Uma outra metodologia é a de custo de oportunidade social (Spackman, 2004).

${ }^{18}$ A taxa de desconto social cresce conforme há aumento populacional e de renda, assim como para taxas de preferência temporal pura e coeficientes de aversão ao risco maiores (preferência pelo presente).

${ }^{19}$ A taxa de desconto social various entre $-6.8 \%$ para a Guinea Equatorial e $18.6 \%$ para Armênia, países com menor e maior crescimentos de renda per capita na amostra de países selecionados no estudo.
} 
A questão do desconto ainda não atingiu um estágio definitivo na economia da saúde. Um dos pontos que mostra as possibilidades de avanço é a variabilidade da taxa ao longo do período considerado, principalmente quando este é muito longo, numa tendência de declínio, decorrente da redução da preferência temporal pura para horizontes muito distantes no futuro (OMS, 2003). Este tipo de cálculo ainda não foi incorporado nas avaliações econômicas correntes. Outro ponto ainda não estabelecido na literatura é a taxa de desconto a ser aplicada aos desfechos (nas análises de custo-efetividade e custo-utilidade), que são itens não monetários (OMS, 2003; Bos et al, 2005).

O Ministério da Saúde em sua diretriz para avaliação econômica em saúde (Brasil, 2007), versão ainda preliminar e não publicada oficialmente, sugere a taxa de desconto de 5\% para o Brasil, baseada em diretrizes internacionais de outros países. 


\subsubsection{Diretrizes de avaliação econômica: estimativas de custos e desconto}

Com o objetivo de padronizar a elaboração das avaliações econômicas em saúde, muitos países desenvolveram diretrizes próprias. As diretrizes de avaliação econômica pretendem servir de guia para elaboração de estudos que podem ser submetidos para pedidos de reembolso nos países.

A fim de comparar as recomendações para estimativas de custos e taxa de desconto e analisar possíveis variabilidades entre os países, foi realizado um levantamento das diretrizes nacionais reunidas e disponibilizas pela ISPOR (International Society For Pharmacoeconomics and Outcomes Research), conjuntamente com revisão da literatura sobre elas (Schulenburg et al, 2000). As "Diretrizes Metodológicas para Elaboração de Estudos de Avaliação Econômica para o Ministério da Saúde” (Brasil, 2007) do Brasil não constam da relação de diretrizes da ISPOR, e foram incluídas à parte.

As diretrizes de avaliação econômica (Anexo, Quadro i) apresentam variabilidade no que se refere à perspectiva recomendada, custos a serem incluídos, fontes a serem consultadas para estes e metodologias para suas estimativas, assim como as taxas de desconto a serem aplicadas. A variabilidade das estimativas de custos identificada na literatura repete-se nas diretrizes existentes em mais de 25 países, incluindo o Brasil.

Análise sistemática para identificar as fontes principais de variação de métodos de custeio usados em avaliações econômicas mostrou que as diretrizes não concordam em suas recomendações, o que resulta em estudos que usam diferentes métodos. Exemplos de não concordância são a abordagem de perda de produtividade, de cuidado informal e de custos futuros. Mesmo quando concordam em princípio, 
fornecem poucos detalhes de como seguir recomendações, como é o caso de alocação de custos compartilhados, utilização de capacidade e preços sombra. A recomendação do uso de custos de oportunidade é mais discutida quando aplicado ao mercado de trabalho, sendo que poucos detalhes são fornecidos para o uso de preço sombra de outros insumos. De forma geral, não há discussão se preços de mercado são reflexo realístico dos custos de oportunidade. Para outras questões, como a perspectiva de analise, custos a serem incluídos e a apresentação separada de quantidades e custos unitários (ingredients approach), as diretrizes podem concordar, mas os estudos não seguem as recomendações (Adam et al, 2003). A falta de harmonização de diretrizes de avaliação econômica em saúde, verificada também anteriormente (Hjelmgren et al, 2001), refere-se especificamente a custos, sendo que os demais itens apresentam pouca variabilidade. 


\subsection{Avaliação econômica de vacinas}

Apesar do mercado mundial de vacinas ainda ter a maior participação de vacinas pediátricas, o mercado de vacinas para adultos tem crescido consideravelmente (LeadDiscovery, 2004). Além disto, o avanço biotecnológico permite o desenvolvimento de outras vacinas, terapêuticas. A utilização de vacinas tem, desta forma, grande potencial de crescimento. O mercado mundial de vacinas passou de US\$ 6 bilhões em 2006 para US\$ 10 bilhões em 2008, com estimativa de chegar a US\$ 12 bilhões em 2012 (Homma, 2008). Atualmente, a Europa lidera a inovação e produção de vacinas (Galambos, 2008).

Do ponto de vista econômico, a imunização é tida como importante instrumento para melhorar a sobrevivência e desta forma fortalecer a economia. É um investimento de retorno alto, comparável à educação. A vacinação se correlaciona com o rendimento escolar futuro, a produtividade, a expectativa de vida, poupança e investimento. Isto é um reflexo de evidências da importância da saúde como um fator de desenvolvimento econômico e redução de pobreza, ou seja, saúde gerando riqueza além do próprio bem-estar (Bloom et al, 2005). Dentre as intervenções públicas de saúde, as imunizações são uma das mais bem sucedidas, globalmente (OMS, 2005).

Economicamente, as vacinas ainda apresentam particularidades no que se refere a sua produção e transferência tecnológica. Mesmo com a existência de patentes, tem sido possível a transferência tecnológica acordada entre laboratórios multinacionais e nacionais, como ocorre com o Instituto Butantan e Biomanguinhos. A decisão de incorporação de uma nova vacina afeta, da perspectiva econômica, não somente custos incorridos e evitados e seu conseqüente impacto orçamentário, bem 
como uma capacitação nacional de produção, apropriação e controle de novas tecnologias, gerando externalidades positivas.

Cada vacina tem suas próprias questões específicas (OMS, 2005). A decisão de introdução de uma vacina dependerá de questões de políticas de saúde, de questões programáticas, culminando finalmente no processo de tomada de decisão. As questões de políticas de saúde se referem à aceitação de uma particular vacina a partir da perspectiva da política de imunização. As questões programáticas apresentam a viabilidade ou não da introdução de uma vacina de uma perspectiva técnica. O processo de tomada de decisão, produto de avaliações, resultará em duas possibilidades: introdução ou espera até novo cenário favorável. Este pode englobar obtenção de mais evidências relacionadas à carga de doença ou novos estudos de custo-efetividade ou mudança de condições, como preços, recursos financeiros, oferta, solidez do programa etc, ou ainda a perspectiva de lançamento de outra vacina para a doença em análise (OMS, 2005). O fluxo a seguir apresenta o processo descrito. 


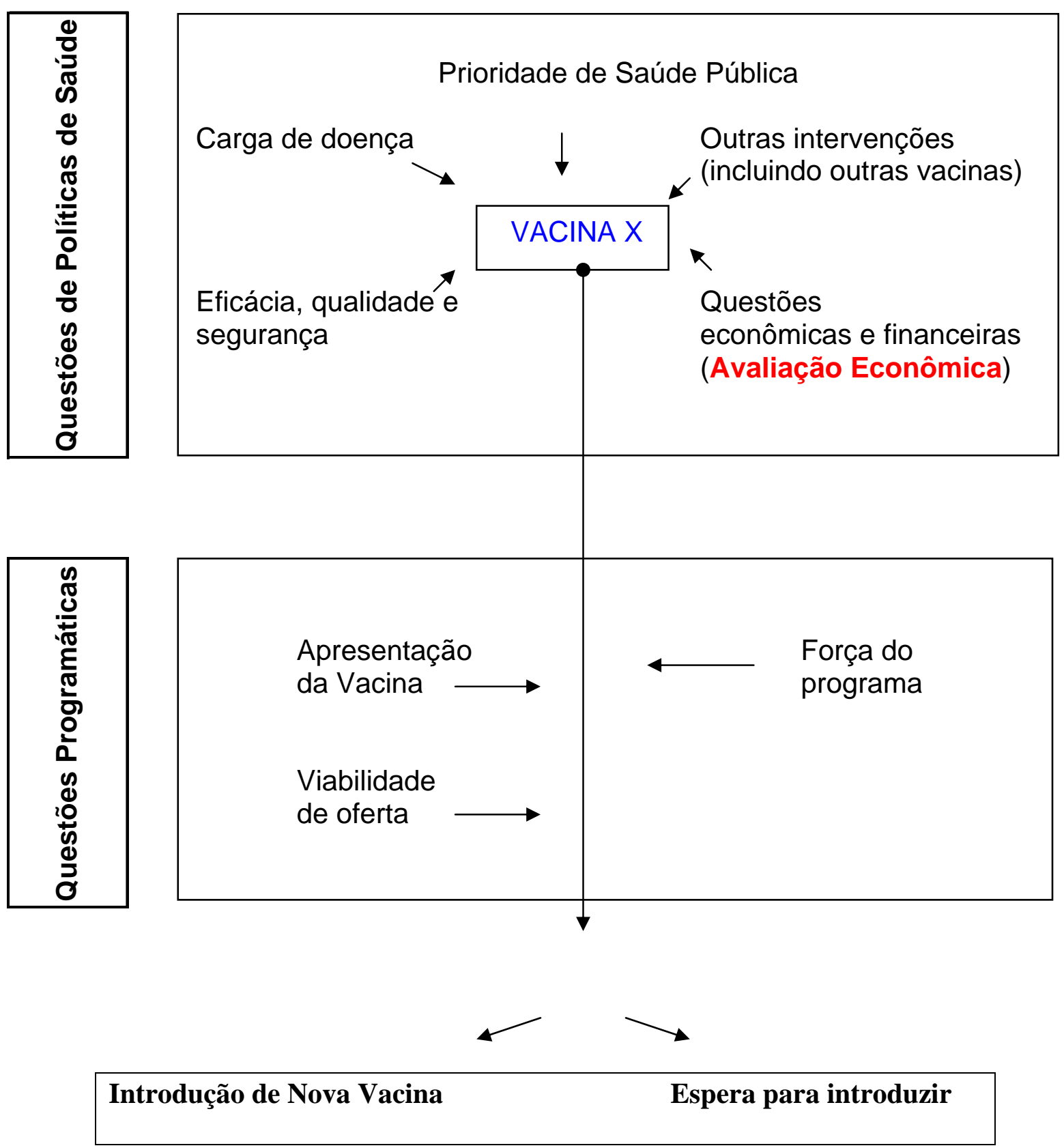

Figura 1. Diagrama de Decisão para Inclusão de Nova Vacina Fonte: OMS (2005) 
Dentro da prioridade de saúde pública, é importante salientar a percepção da comunidade médica e da sociedade sobre a vacina e a doença, de modo a tê-las como prioridade ou não. Investigações qualitativas entre decisores-chave, comunidade médica, parceiros de imunização e sociedade são úteis para se avaliar os prováveis impactos de uma nova vacina (OMS, 2005).

As forças que dirigem o processo de tomada de decisão de inclusão não se restringem ao âmbito nacional. Além dos decisores nacionais, do Programa Nacional de Imunização, organizações internacionais são atuantes, sendo que a comunidade científica e o setor privado têm sua interface local como também internacional (OMS, 2005).

As questões econômicas e financeiras decorrem do encarecimento das novas vacinas. A avaliação econômica de programas de vacinação se apresenta relevante pela disponibilidade de novas vacinas para a prevenção de doenças infecciosas cujos altos custos têm dificultado sua introdução na rotina de imunização, principalmente em países de renda mais baixa. O custo para se vacinar uma criança, a preços da UNICEF de 2005 excluindo transporte, seguro e desperdício, com o EPI (Expanded Programme on Immunization), que incluí DTP, Sabin, BCG e sarampo era de USD 0,8. Adicionando hepatite B, o custo subia para USD 1,6 e com a Hib para USD 10 (OMS, 2005). A dose da vacina de rotavírus negociada pelo Ministério da Saúde para a vacinação que se iniciou em 2006 chegou ao valor de USD 7 a dose, sendo necessárias 2 doses, chegando-se a um valor de USD 14 para uma única vacina (PNI).

O aumento dos preços das vacinas, que em 20 anos (1980 a 2000) ultrapassa crescimento de $950 \%$, coincide com uma expansão do suporte de pesquisa e 
desenvolvimento e uma especialização do ramo de vacinas dentro da indústria farmacêutica, seja como parte de grandes multinacionais ou empresas menores de biotecnologia, que acabam então sendo incorporadas àquelas posteriormente. Apesar da projeção de crescimento do setor de vacinas ser alta (12\% aa) e consequentemente haver potencial de aumento de escala de produção, os preços de algumas vacinas tendem ainda a permanecer altos, pela justificativa tecnológica de maior complexidade, que muitas vezes não permite que a oferta atenda à demanda, como no caso da vacinas conjugadas (Milstien, sd). As cooperações de fundações privadas, públicas e organismos internacionais buscam aliviar estes gargalos, como é o caso da de vacina pneumocócica conjugada, para a qual um consórcio de 5 países com financiamento da Fundação Bill \&Melinda Gates espera fornecê-la a partir de 2010 para países pobres a preços muito mais baixos. Este programa conta com US\$ 1,5 bilhão para o desenvolvimento de vacinas para países pobres a partir de uma perspectiva pública, mas com financiamento via mecanismos de mercado (Fapesp, 2007).

As questões econômicas e financeiras de políticas de saúde de vacinação se intensificam com os preços mais altos das vacinas, que dificultam sua inclusão pelo forte impacto orçamentário ou mesmo por restrições orçamentárias que restringem novas inclusões, tendo que priorizar as mais importantes a partir agora de um contexto não apenas clínico-epidemiológico, mas também econômico.

A avaliação das implicações econômicas e financeiras de novas vacinas no programa de imunização pode fornecer informações valiosas para tomada de decisão tanto para governos e potenciais parceiros, no sentido de se saber (OMS, 2005): 
- se uma vacina em particular é custo-efetiva relativamente a outros usos dos recursos escassos;

- as exigências de recursos de longo-prazo para sua introdução e seu impacto nos orçamentos governamentais, de forma a se garantir sua sustentabilidade;

- a magnitude de gargalos de financiamento, havendo mobilização de financiamento adicional doméstico ou externo.

A aplicação de avaliações econômicas de vacinas, assim como as demais avaliações econômicas em saúde, tem crescido exponencialmente desde a década de 1980. A maioria das avaliações econômicas de programas de vacinação foi feita em países de renda alta. A alta freqüência de pesquisa em doenças preveníveis por vacinas deve-se ao seu uso populacional, de decisão centralizada, com respaldo social, assim como à existência de múltiplos grupos alvos e múltiplas vacinas, que demandam análises separadas em diferentes cenários. As avaliações econômicas de programas de vacinação têm em comum os preços mais altos das vacinas estudadas em comparação com outras de grande uso corrente (Beutels et al, 2003).

A avaliação econômica de vacinas apresenta algumas peculiaridades em relação às demais tecnologias na área da saúde, principalmente as terapêuticas, por se constituir em tecnologias que se propõem a interferir sobre a incidência de doenças infecciosas, muitas delas transmissíveis, e objetivando a sua eliminação em populações determinadas. A mensuração dos benefícios nos casos das vacinas exige uma modelização adequada para cada doença e vacina, dividindo-se os modelos epidemiológicos em estáticos e dinâmicos, sendo estes indicados quando da 
ocorrência de proteção de rebanho (Brisson et al, 2003; Thiry et al, 2003; Brisson et $a l, 2006)$.

No que se refere aos custos, os custos de intervenção têm um impacto muito grande no caso de vacinação, uma vez que ocorrem no presente para prevenirem doenças no futuro. Os custos da nova vacinação dependerão de como esta pode se adequar ao esquema já existente e aos grupos selecionados para recebê-la. Os custos mais fortemente afetados pela adição de uma nova vacina ao programa existente são os custos variáveis do programa (tempo gasto com o vacinado, número de vacinas compradas etc) ao passo que a influência dos custos fixos da intervenção (equipamentos, instalações físicas, campanhas etc) dependerão da utilização da capacidade existente. A estimação de custos marginais de intervenção apresenta dificuldades específicas, principalmente para vacinas multivalentes. Um julgamento subjetivo é necessário para decidir como os custos marginais da intervenção devem ser divididos entre os vários antígenos (Beutels et al, 2003).

Além do preço das vacinas e seu custo de administração, outros custos a serem incluídos são os decorrentes de eventuais desperdícios e de efeitos adversos, sendo que estes tornam a intervenção menos custo-efetiva.

Os custos indiretos nos estudos de custo-efetividade de vacinas apresentam as mesmas questões já apresentadas, como a sensibilidade e a não conformidade de métodos para sua mensuração. A estimação de custos indiretos pode ser muito influenciável para alguns programas de vacinação, como no caso de infecções raramente fatais que, no entanto, geram custos de tempo perdido, como no caso da varicela (Thiry et al, 2003). Doenças que gerem perda de produtividade futura, como 
na ocorrência de seqüelas, terão custos de produtividade maiores quando acometerem mais freqüentemente crianças.

Outro ponto não bem estabelecido ainda metodologicamente são os custos indiretos de outras doenças adquiridas ao longo da vida, custos denominados futuros ou não diretamente relacionados. Quando comparando cura com prevenção, a exclusão dos custos não diretamente relacionados tende a favorecer as intervenções de cura, que têm custos de cuidados à saúde imediatos mais altos. Desta forma, a inclusão destes custos futuros de comorbidade permitiriam a compreensão da real dimensão de uma intervenção de caráter preventivo (Beutels et al, 2003).

As particularidades das vacinas, que se expressam nas peculiaridades de suas avaliações econômicas, podem ser resumidas em três pontos, quando comparadas a medicamentos (Szucs, 2005):

- vacinas apresentam tradição mais longa de avaliações econômicas;

- menos decisores centrais precisam ser convencidos, uma vez que a decisão de vacinação é um processo mais centralizado de recomendação e política de saúde;

- externalidades são mais relevantes no campo das vacinas (ex. proteção e imunidade de rebanho).

Dada a importância das vacinas enquanto estratégias preventivas, o fato do Brasil ter um bom desempenho neste tipo de intervenção e a necessidade de avaliações econômicas para suas inclusões, frente às restrições orçamentárias, o estudo dos custos daquelas é de grande relevância, estando ainda em um estágio de definição de diretrizes a serem seguidas. 
O estudo dos custos em avaliações econômicas de vacinas para o Brasil apresenta uma contribuição metodológica enquanto discussão daqueles e uma contribuição aplicada, para o caso de um país com tradição neste tipo de intervenção. O Programa Nacional de Imunizações (PNI), criado em 1973, tem sido bem sucedido, com importante investimento na universalidade do atendimento, na descentralização das ações, na adequação se sua rede de frios e na vigilância de efeitos adversos pós-vacinação. As altas taxas de cobertura vacinal existentes no país são um fator a favor da inclusão de novas vacinas no calendário nacional, inclusões estas que tenderão a se basear em estudos de custo-efetividade, sendo os custos componente imprescindível para o processo de tomada de decisão.

\subsubsection{Diretriz para padronização de avaliações econômicas de programas de imunização: estimativas de custos e desconto}

Dada a necessidade de aumentar a transparência, complitude e comparatibilidade, melhorando a qualidade das avaliações econômicas de programas de vacinação, a OMS desenvolveu diretriz de avaliações econômicas específicas para vacinação, direcionada a economistas, pesquisadores de serviços de saúde nos setores público e privado, nos níveis local, nacional, regional e global (OMS, 2008).

Como os programas de vacinação apresentam características específicas, as diretrizes gerais não são suficientes para padronizar as avaliações daqueles. Por exemplo, há inconsistências nos métodos usados para estimar benefícios futuros dos programas de vacinação e a eficiência relativa desses programas pode ser sensível aos aspectos mais controversos das diretrizes gerais, como a inclusão de custos indiretos e desconto de custos e desfechos. Dado o caráter preventivo das vacinações, 
a questão temporal é muito importante para os custos (investimento hoje para retorno futuro).

Juntamente com a estrutura da análise, os efeitos do programa de vacinação e a modelagem, a avaliação dos custos do programa de vacinação e o desconto são itens estruturantes da diretriz.

$\mathrm{Na}$ avaliação dos custos do programa de vacinação, duas abordagens são identificadas: o custeio completo (full) e incremental. Ao contrário da abordagem completa, que incluí os custos de todos os recursos envolvidos, a incremental considera apenas a diferença entre os custos decorrentes da introdução da nova vacina versus os custos sem a vacina em questão, como calculado para análise de custo-efetividade. Independente da abordagem, recomenda-se a técnica de ingredientes ('ingredients' aprroach), que consiste na separação de preços e quantidades, sendo atribuídos custos unitários às quantidades consumidas.

Entre os custos identificados, encontram-se os custos do programa de vacinação, os custos de tratamento, custos para pacientes e famílias (transporte, produtividade) e custos futuros, reconhecidos como sem consenso na literatura e, portanto, não recomendados.

Os custos do programa de vacinação variam de acordo com a apresentação da vacina e limite da infra-estrutura existente. A inclusão de uma nova vacina em programas de vacinação deve considerar o estado anterior do sistema de distribuição (transporte e armazenamento de tempratura controlada). Quando o programa de vacinação opera no limite de sua infra-estrutura, novos investimentos são requeridos, como expansão da rede de frio, de modo que os custos adicionais da inclusão de uma 
nova vacina não são apenas referentes a esta, mas também ao aumento de capacidade para comportar seu armazenamento e distribuição.

Os custos do programa de vacinação, que ocorrem previamente ao evento da doença, dependem de dados econômicos, demográficos, epidemiológicos, tecnológicos e estruturais do programa de vacinação. O custo da tecnologia é dado por seu preço no mercado local. As características demográficas, epidemiológicas e de atuação da própria tecnologia determinam a população-alvo. A estrutura do programa de vacinação possibilita baixas ou altas taxas de cobertura vacinal.

As etapas de identificação, mensuração e valoração de recursos para o tratamento da doença analisada dependem de suas características. No caso de doenças infecciosas, os custos de tratamento são delimitados temporalmente, ao contrário das doenças crônicas.

A mensuração do uso de recursos pode ser feita ex ante ou ex post à introdução de nova vacina. Para os custos de tratamento, são identificadas as seguintes fontes de dados: ensaios clínicos randomizados controlados, revisão de amostra de prontuários, entrevistas com médicos e desenvolvimento de consensos, diretrizes existentes, literatura.

Para a valoração dos recursos é orientado o uso de listas nacionais de preços, preços de compra e de mercado, listas internacionais de preços padronizadas, estimativas do WHOCHOICE, dados de custo unitários e estudos de custeio completo se existentes.

Para estimativas de custos indiretos, são reconhecidos os dois métodos existentes, Capital Humano e Fricção, sendo recomendada a apresentação separada destes custos. 
A diretriz da OMS (2008) para avaliações econômicas no campo de doenças preveníveis por vacinas indicam que suas estimativas de custos enfrentam as mesmas dificuldades das estimativas de custos em geral na área da saúde. Há ausência de uniformindade metodológica, seja para custos diretos ou indiretos ou para as etapas de mensuração e valoração da estimação de custos. Nesta etapa, as recomendações são abrangentes, repetindo a variabilidade de conceitos de custos encontrada na literatura para as estimativas de custos em saúde (Mogyorosy et al, 2005).

Em relação ao desconto, a diretriz ressalta a alta sensibilidade dos programas de vacinação a ele, uma vez que ao contrário das terapias curativas, os benefícios não ocorrem imediatamente ou brevemente após a intervenção. Recomenda-se o uso de taxa constante de 3\% para custos e desfechos, e para análise de sensibilidade 0 e 5\%, e $10 \%$ para países em desenvolvimento. Apesar desta sugestão, baseada no pressuposto de custo do capital livre de risco ser maior em países em desenvolvimento, reconhece-se a falta de consenso quanto às taxas a serem aplicadas. Taxa de desconto declinante é aceita para os casos nos quais os efeitos começam somente bem depois da intervenção ou duram por um período excepcionalmente grande (erradicação).

Alguns trabalhos mostram que a avaliação econômica tradicional em saúde pode não refletir adequadamente a relevância das vacinas (Bos et al, 2004; Drummond et al, 2007). Uma das explicações seria que o desconto correto difere nas intervenções preventivas. O principal efeito de intervenções preventivas é a redução de risco de contrair uma certa doença durante um período de exposição. A redução de risco, como no caso de vacinação, nem sempre coincide com o momento no qual o impacto nos anos de vida ganhos ocorre. Os efeitos tradicionais de saúde (anos de 
vida ganhos, QALYs ou vida salvas) são medidas indiretas e parciais dos efeitos de intervenções preventivas. Os benefícios da vacinação deveriam ser incluídos já no momento em que a redução de risco ocorre e não mais tardiamente no período de exposição ao risco. Outra característica das vacinações que justificaria o desconto baseado em redução de risco e não apenas em efeitos tradicionais de saúde é a redução de transmissão de agente causador em subgrupos da população não vacinadas (imunidade ou proteção de rebanho) para doenças infecciosas. 


\section{OBJETIVOS}

\section{Objetivo geral}

Analisar as condições de uso, dificuldades e repercussões de diferentes métodos de estimativas de custos para avaliação econômica em saúde em estudos de custo-efetividade de vacinas.

\section{Objetivos específicos}

1) Apresentar e analisar estimativas de custos e suas repercussões sobre os resultados em estudo de custo-efetividade de vacina contra rotavírus;

2) Apresentar e analisar estimativas de custos e suas repercussões sobre os resultados em estudo de custo-efetividade de vacina contra varicela. 


\section{MATERIAL E MÉTODOS}

Esta tese é um subprojeto de projeto de pesquisa mais amplo, denominado "Estudos de custo-efetividade da incorporação de novas vacinas à rotina do Programa Nacional de Imunizações: Rotavírus, Varicela, Pneumocócica conjugada, Meningocócica C conjugada e Hepatite A", cujo objetivo é desenvolver estudos de custo-efetividade para as vacinas mencionadas de forma a orientar o PNI no processo de decisão de inclusão de novas vacinas. Este projeto vem sendo realizado desde 2005 no Departamento de Medicina Preventiva da FMUSP. Os estudos de vacina contra rotavírus e varicela já foram concluídos (Soárez et al, 2008; Valentim et al, 2008a) e o de vacina pneumocócica conjugada heptavalente sendo finalizado.

\subsection{Seleção das vacinas}

A seleção de doenças para a tese restringiu-se a rotavírus e varicela. A comparação entre as duas doenças justifica-se pelas diferenças entre as próprias doenças, afetando a inclusão de itens de custos, e as fontes dos dados de custos, que remetem às questões metodológicas de suas estimativas.

A primeira doença, rotavírus, exemplifica uma doença aguda, sem seqüela, e a segunda, varicela, doença com seqüela, o que implica inclusão de custos diretos de tratamento ao longo da vida do paciente e maior peso dos custos indiretos, decorrentes de seqüela. Em relação às fontes de dados de custos, para rotavírus havia estudo específico de custo para o Brasil, como etapa anterior à realização do estudo de custo-efetividade. Já para varicela, as estimativas de custos foram conduzidas paralelamente ao estudo de custo-efetividade. A análise dos dois casos permite 
avaliar a viabilidade de utilização de estimativas já prontas, assim como modificações dos dados em caso de necessidade de correções, e suas limitações, e as etapas metodológicas e fontes de dados para estimativas de custos em caso de inexistência de estudos de custo de doença no Brasil, o que é mais freqüente.

\subsection{Etapas metodológicas}

As estimativas de custos nesta tese estão condicionadas pelo contexto da avaliação econômica em saúde, e do ponto de vista metodológico devem obedecer as seguintes etapas (Thiry et al, 2003; Beutels et al, 2003 e 2006; Graeve, 2004; Brisson et al, 2006):

- definição da estratégia de vacinação e população alvo;

- estimação epidemiológica;

- escolha de modelo epidemiológico, em função do efeito da proteção de rebanho;

- definição de horizonte temporal;

- estimação dos custos da intervenção e de tratamento;

- estimação de custos indiretos, que englobam a perda de trabalho por adoecimento e/ou perda de produtividade decorrente de seqüela;

- aplicação das estimativas de custos ao modelo epidemiológico.

Especificamente em relação aos custos, as seguintes etapas metodológicas foram seguidas:

i. estimação de custos, com definição de técnicas e fontes de dados;

ii. discussão das limitações de estimativas de itens de custo;

iii. aplicação das estimativas de custos aos estudos de custo-efetividade;

iv. análise de sensibilidade para custos;

v. comparação da sensibilidade dos custos entre os estudos de custoefetividade de vacina contra rotavírus e varicela; 
vi. comparação do impacto econômico, através de análise de impacto orçamentário, dos dois programas de vacinação no orçamento do PNI.

As etapas i e ii são apresentadas neste item de "Material e Métodos", uma vez que estão relacionadas a estimação de custos de forma geral, independente da doença, e retomadas com as estimativas de custos para cada doença para as análises de custo-efetividade. As etapas iii e iv são abordadas nas seções de resultados específicas a cada doença, problematizando-se a estimação de custos para os estudos de cada uma das vacinas. A partir da análise de sensibilidade e da identificação dos itens de custo de maior impacto, são discutidas as incertezas na estimação de custos, ponderando-se o quanto estas incertezas podem contaminar ou não a tomada de decisão. As etapas v e vi são tratadas na seção de discussão dos resultados.

\subsection{Custos diretos}

A estimação de custos diretos seguiu técnica mista para a mensuração de quantidades dos itens de custos identificados, assim como para a valoração dos itens consumidos, usando micro-costing, quando possível, e gross-costing. Para a valoração dos custos unitários, preços de mercados foram usados como proxies de custos de oportunidade, sendo discutidas suas limitações e implicações no caso de falhas de mercado. $\mathrm{Na}$ inexistência de custos de oportunidade, custos contábeis e remunerações foram utilizadas como proxies, sendo também suas limitações e implicações discutidas e analisadas a partir de análise de sensibilidade.

Foram buscadas estimativas para o sistema de saúde suplementar a fim de se discutir as dificuldades de estimativas de custos em sistemas de saúde público e privado, com articulações complexas como as do Brasil. 


\subsubsection{Custos no cuidado da doença}

- Consultas

As consultas médicas em especialidades básicas no Brasil são financiadas pelo Piso de Atenção Básica ${ }^{20}$ (PAB). O PAB foi criado na NOB 96 e entrou em vigor efetivamente apenas a partir de 1998, sendo o valor per capita entre R\$ 10 e $\mathrm{R} \$ 18$. Os critérios de repasses de recursos federais para a atenção básica pelo $P A B$ no seu componente fixo nos municípios obedecem critérios populacionais. Além do PAB fixo, há o PAB variável ${ }^{21}$ que estabelece repasses em função do número de equipes do Programa de Saúde da Família, saúde bucal e agentes comunitários de saúde em atividade nos municípios. O valor médio per capita da Atenção Básica atingiu o valor médio de $\mathrm{R} \$ 32,93$ em 2005. Entre os anos de 1998 e 2005 houve um aumento relativo da participação da atenção básica no financiamento da saúde comparativamente aos recursos destinados para a Média e Alta Complexidade (MAC) e os recursos do Fundo de Ações Estratégicas (FAEC) (Solla et al, 2007). O financiamento das consultas médicas em especialidades básicas no Brasil por critérios populacionais dificulta a obtenção de custos unitários por consulta, uma vez que os repasses financiam grupo variado de ações.

\footnotetext{
${ }^{20}$ Além das consultas médicas, os recursos do PAB financiam as seguintes ações: atendimento odontológico básico; atendimentos básicos por outros profissionais de nível superior e nível médio; visita e atendimento ambulatorial e domiciliar do Programa de Saúde da Família (PSF); vacinação; atividades educativas a grupos da comunidade; assistência pré-natal e ao parto domiciliar; atividades de planejamento familiar; pequenas cirurgias; atividades dos agentes comunitários de saúde; pronto atendimento em unidade básica de saúde.

${ }^{21}$ O PAB Variável responde pelos seguintes programas: Programa de Saúde da Família, Programa de Agentes Comunitários de Saúde, Programa de Combate às Carências Nutricionais, Ações Básicas à Saúde dos Povos Indígenas, Assistência Farmacêutica Básica, Ações Básicas de Vigilância Sanitária, Saúde Bucal, Ações Básicas de Média e Alta Complexidade em Vigilância Sanitária. Fonte: FNS, Disponível em: http://www.fns.saude.gov.br/. Acesso: 17 de abril de 2008.
} 
Com o aumento da demanda por informações para análises de custoefetividade tornou-se imprescindível a derivação de custos unitários de itens nucleares como consultas. Revisão da literatura (Graham et al, 1997) feita sobre estudos publicados referentes a custos unitários de consultas de GPs (General Practioners) no NHS do Reino Unido mostrou que há uma grande variação de metodologias aplicadas, não sendo, na maioria dos estudos, explicitadas, ou não sendo consideradas uma das três etapas (identificação, mensuração e valoração). As estimativas de custo de consulta de 10 minutos variaram entre $£ 3,04$ e $£ 11,22$, com média de $£ 6,9$, em 1995/96.

O exemplo do NHS é útil porque o sistema também tem ênfase na atenção básica e a forma de financiamento é semelhante (capitation). Uniformização de metodologia é necessária para evitar conclusões inapropriadas, uma vez que as avaliações econômicas são instrumento de suporte de tomada de decisão, garantindo consistência entre estudos comparados. Apesar da existência de estimativas nacionais de custos (Personal Social Services Research Unit) (£11,04 para consulta de 10 minutos em 1995/96; Graham et al, 1997), há recomendação para se estimar o custo local unitário. Metodologia proposta (Kernick et al, 2002) para a estimativa de custo de consulta considera a variação deste custo em função da perspectiva e do contexto (quantificação do custo de oportunidade) da avaliação, decisão por custos marginais ou médios, de acordo com horizonte temporal e provisão de novos serviços ou expansão de existentes e a análise de sensibilidade. Para o caso britânico, estimou-se o custo total com atividades de cuidados curativos, telefone, consulta, visitas domiciliares, tempo de viagem e ausência para estudo e o tempo gasto (total e por 
atividade). A partir de um exercício hipotético, foi estimado o minuto de consulta em $£ 0,92$.

Esta metodologia proposta tem por objetivo, como descrito, o cálculo de estimativas locais de custo de consulta, uma vez que está disponível uma estimativa nacional de valor da consulta no Reino Unido. No caso do Brasil, não há uma estimativa nacional ${ }^{22}$.

Para as estimativas de custo unitário de consulta para o Brasil no SUS foi usado o valor disponível no SIA (Sistema de Informações Ambulatorial)/DATASUS para consulta de especialista em atendimento não básico como proxy para as consultas financiadas pelo $\mathrm{PAB}$ para atendimento básico, partindo-se, portanto, de uma possível superestimação dos custos unitários de consulta.

Para o sistema de saúde suplementar, foi considerado valor médio de consulta fornecido pela ANS (Agência Nacional de Saúde Suplementar). O sistema de saúde suplementar é composto por distintas modalidades de operadoras (autogestão, cooperativa médica, filantropia, medicina de grupo e seguradora) cujo financiamento ocorre através das seguintes categorias de adesão a planos de saúde (Andrade et al, sd): adesão voluntária, no caso de adesão individual e gasto individual e/ou familiar, e adesão por intermédio de emprego, no setor públicou ou privado, havendo contrapartida do empregador. O valor de consulta disponibilizado pela ANS é uma média dos valores praticados por todas as modalidades de operadoras.

\footnotetext{
22 A transposição dessa metodologia para o caso brasileiro deveria rever o tempo aplicado em cada uma das atividades, assim como valores dos itens componentes de custos considerados (remuneração do médico, despesas, viagem, custos de capital e horas extras). A diferenças poderiam ser avaliadas entre regiões, unidades da federação, ou ainda dentro destas.
} 
Para a valoração de consultas, foram usados, portanto, sistemas de dados oficiais de valores a serem pagos aos prestadores de serviços como proxies para custos unitários.

- Medicamentos e exames complementares

Informações sobre o perfil de consumo nos atendimentos em serviços de saúde no nível ambulatorial, como a utilização de medicamentos e testes laboratoriais, não estão disponíveis em bases de dados oficiais para diagnósticos específicos de doença, como é o caso do Sistema de Informações Ambulatorial (SIA) do DATASUS. As estimativas de custos ambulatoriais de doença específica podem ser feitas a partir de recomendações de diretrizes clínicas ou coleta primária de dados.

Os dados referentes a padrão de tratamento ambulatorial e recursos consumidos foram obtidos, no caso de rotavírus, de estudo primário de custos realizado pelo Centro Paulista de Economia da Saúde/CPES/UNIFESP e Secretaria de Estado da Saúde de São Paulo (Soárez et al, 2005). Para varicela, metodologia de levantamento rápido de dados (rapid assessment) foi utilizada para coleta de dados nos prontuários de três serviços ambulatoriais de saúde de São Paulo: um serviço de atenção primária (Centro de Saúde Escola Prof. Samuel B. Pessoa, da Faculdade de Medicina da Universidade de São Paulo), um hospital secundário (Hospital Universitário da USP) e um hospital terciário (Instituto da Criança do Hospital das Clínicas da FMUSP). Esta metodologia pode fornecer aos profissionais de saúde e pesquisadores, em um período curto de tempo (seis a oito semanas), informações de determinada população sobre seu comportamento de busca por serviços de saúde e 
como as doenças são diagnosticadas e tratadas neste meio (Afonja, 1992). Foram coletados dados de consultas, medicamentos e exames complementares, realizados em um período determinado.

A técnica de micro-costing foi utilizadada nas estimativas de custos de medicamentos, produtos (no caso de rotavírus) e exames complementares. Para a valoração dos medicamentos consumidos, foram consultados preços na $\mathrm{ABCFarma} \mathrm{e}$ Banco de Preços em Saúde do Ministério da Saúde. Apesar das falhas de mercado existentes no mercado farmacêutico, os preços foram usados como proxies para as estimativas de custos de oportunidade. No caso de compras de medicamentos feitas pelo governo, considerou-se que o Banco de Preços em Saúde do Ministério da Saúde refletiria os preços praticados em negociações públicas, como licitações e pregões. Para as estimativas de custos de produtos foram usados preços de mercado. De forma análoga às estimativas de custo de consulta, para exames foi utilizado o Sistema de Informações Ambulatoriais (SIA) do DATASUS. Para o sistema de saúde suplementar, a tabela CBHPM (Classificação Brasileira Hierarquizada de Procedimentos Médicos) foi consultada.

\section{- Hospitalização}

Assim como os demais itens de custos, as hospitalizações refletem a divisão do sistema de saúde no Brasil entre as esferas pública ${ }^{23}$ e privada. De acordo com o Suplemento de Saúde do inquérito populacional PNAD (Pesquisa Nacional por

\footnotetext{
${ }^{23}$ A Tabela de Procedimentos utilizada como referência para a remuneração dos serviços hospitalares prestados ao SUS foi implantada na década de 80, como parte do SAMHPS (Sistema de Assistência Médico-Hospitalar da Previdência Social). O sistema adotou a remuneração fixa por procedimento diagnóstico com base em valores médios globais calculados a partir de procedimentos aceitos na remuneração por serviços da atenção prestada pela rede de assistência hospitalar. O SAMHPS foi renomeado SIH (Sistema de Informações Hospitalares) em 1991 e continua sendo a base para os
} 
Amostra de Domicílio, IBGE) de 2003, 67,6\% do total de internações foram financiadas pelo SUS, $24,3 \%$ tiveram participação integral ou parcial do plano de saúde no financiamento e apesar de não ter sido levantado o quantitativo de hospitalizações pagas diretamente (desembolso) é possível assumir que estejam contemplados nos $8,1 \%$ restantes (Carvalho, 2007).

Em relação ao SUS, não há uma caracterização clara e parametrização da atenção de média complexidade. Longos períodos de congelamento dos valores atribuídos a procedimentos de média e alta complexidade nas tabelas de referência nacional e reajustes insuficientes, quando existentes, têm levado a um subfinanciamento. Como resultante, há um estrangulamento de algumas ações com oferta comprometida em estados e municípios, obrigados a complementar os valores de remuneração a prestadores com recursos próprios (Carvalho, 2007).

Estudos (Planisa 2002 apud Carvalho, 2007; Bittencourt, 1999; Araújo et al, 2005) que se propuseram a comparar os custos dos procedimentos hospitalares e os respectivos valores de remuneração da tabela SIH (Sistema de Informações Hospitalares) do DATASUS constataram discrepâncias entre valores de remuneração e custos estimados ${ }^{24}$.

pagamentos de hospitais. No entanto, os valores constantes da tabela guardam pouca ou nenhuma relação com custos (Carvalho, 2007).

${ }^{24}$ Para procedimentos como transplante de fígado, transplante renal - receptor (doador vivo), transplante de coração e correção cirúrgica da cardiopatia congênita a remuneração da tabela SIH estava acima do custo estimado, chegando a ser mais de três vezes o custo estimado no caso de transplante de fígado. Já para os procedimentos de tratamento de AIDS, apendicectomia, colecistectomia e crise hipertensiva a remuneração do SUS era inferior ao custo estimado, representando somente $18,12 \%$ do custo no caso de crise hipertensiva. A metologia utilizada para a comparação entre custos e remunerações não é explicitada, assim como o conceito de custo adotado no estudo não é definido (Carvalho, 2007). Para pacientes com câncer de esôfago, mostrou-se que o procedimento faturado pelo SUS representava $35,8 \%$ do custo para gastrostomia e $65,9 \%$ para avaliação clínica de tumores malignos do esôfago, com custo estimado pelo método ABC. Houve variação do custo dependendo do método utilizado (método $\mathrm{ABC}$ e centro de custo), sendo os custos menores pelo método ABC (Bittencourt, 1999). Estudo de custo de insuficiência cardíaca apontou que a remuneração de AIH (Autorização de Internação Hospitalar) cobriria apenas 13\% do custo por paciente internado (Araújo et al, 2005). 
As diferenças nas metodologias dos estudos de estimativas de custos (Bittencourt, 1999; Planisa, 2002 apud Carvalho, 2007; Araújo et al, 2005) e o grande número de procedimentos da tabela SIH dificultam a generalização das suas conclusões para o SUS com um todo. Mesmo na existência de estudos de custos de hospitalização, como é o caso de câncer de esôfago (Bittencourt, 1999) e insuficiência cardíaca (Araújo et al, 2005), a generalização de resultados para o país como um todo é restrita, dado que refletem as características e condições das instituições nas quais os estudos foram realizados (Hospital de Clínicas de Porto Alegre (HCPA) e Hospital Universitário Antônio Pedro, Niterói, respectivamente).

Apesar das limitações na validade do uso dos valores de remuneração do SIH para estimativas de custos hospitalares, sua utilização possibilita a padronização de fonte de dados das estimativas e a comparabilidade entre estudos de avaliação econômica. Quando da perspectiva do SUS, o próprio Ministério da Saúde orienta a utilização de bases de dados oficiais para os estudos (Brasil, 2007), com a justificativa de que em sua perspectiva as remunerações, como hospitalizações, são custos. Esta posição restringe-se às avaliações econômicas em si, desconsiderando o cruzamento de financiamentos e capacidades locais de fornecimento de serviços de saúde, que levam a uma distribuição heterogênea daqueles pelo país. Por apresentar abrangência nacional, o SIH fornece custos do país como um todo, que são os que devem ser considerados nas avaliações econômicas de programas de vacinação universais. Desta forma, foi utilizada a base de dados de AIH (Autorização de Internação Hospitalar), com busca pela CID (Classificação Internacional de Doença), 
considerando-se a freqüência de internação, permanência média e valor médio de AIH.

O SIH vem sofrendo mudanças, que afetam também valores de remuneração. A partir de 2008 passou a vigorar a nova Tabela de Procedimentos, Medicamentos, Órteses, Próteses e Materiais Especiais do SUS ${ }^{25}$. O objetivo da nova tabela é o de transformar a tabela de procedimentos primordialmente em um instrumento de gestão para as ações de planejamento, programação, regulação, avaliação, controle e auditoria em saúde e integrar as bases de informações do SIA e SIH/SUS, tendo em vista a construção de um sistema unificado de atenção à aaúde. O valor da internação (AIH) passou a ter apenas 02 componentes: SH (serviço hospitalar) e SP (serviço profissional). O valor do SADT fica incorporado ao componente SH (Gomes, 2007).

Para os estudos de custo-efetividade de vacinação contra rotavírus e varicela foram usados dados de internação identificada por procedimentos e CID para o ano de 2004, portanto anterior às mudanças da atual tabela do SUS. Os valores médios de AIH de diarréia e varicela foram comparados entre a tabela de procedimentos antiga e a atual unificada através da tabela "De-Para" com códigos antigos e novos. Constatou-se que os valores não sofreram alteração, houve apenas redução do número de procedimentos. ${ }^{26}$

\footnotetext{
${ }^{25}$ Reajuste geral dos valores dos procedimentos foi desencadeado a partir de uma crise no sistema hospitalar do SUS, para buscar melhorar a situação financeira dos hospitais. Não se caracteriza, portanto, uma garantia de melhor atendimento de condição clínica, o que não altera a deficiência já apontada.

${ }^{26}$ No caso de diarréia por rotavírus, passou-se de três para um procedimento listado, e para varicela de 11 para 8 procedimentos, considerando a Compatibilidade Procedimento x CID da Secretaria de Atenção à Saúde/SAS/MS anterior à tabela unificada. Para varicela houve inclusão de um procedimento novo (Tratamento de infecções virais caracterizadas por lesões de pele e mucosas (B00 A B09)).
} 
Em relação aos custos de hospitalização no sistema de saúde suplementar, estes, podem, em média, representar mais de três vezes os valores no sistema público. Em 2004, o valor médio de internação no SUS era de R\$572,63 enquanto para os planos de saúde os valores médios de internação variavam entre $\mathrm{R} \$ 1.502,79$ para planos individual ou familiar, $\mathrm{R} \$ 1.761,83$ para planos coletivos com patrocinador e $\mathrm{R} \$ 1.468,16$ para planos coletivos sem patrocinado, de acordo com dados da ANS (Carvalho, 2007).

Para os custos de hospitalização no sistema de saúde suplementar, adotou-se a TUNEP (Tabela Única Nacional de Equivalência de Procedimentos), que é a tabela de ressarcimento ao SUS por planos privados. A TUNEP é considerada uma lista intermediária entre os valores do SUS e os valores da CBHPM, podendo ser usada como representativa de uma média para o Brasil (Comunicação pessoal Marizélia Moreira, ANS).

Dado que o DATASUS ainda não disponibiliza dados do sistema de saúde suplementar pelo sistema existente, CIH (Comunicação de Internação Hospitalar), com abertura para a CID, a TUNEP é uma tabela de procedimento realizado que possibilita o rastreamento da CID e, portanto, fornece valor médio de internação para diagnóstico específico, assim como feito para o sistema público.

\subsubsection{Custos diretos não-médicos}

Para custos de transporte, o estudo de custo de diarréia por rotavírus (CPES/UNIFESP; Secretaria de Estado da Saúde de São Paulo) considerou para a composição dos custos os seguintes meios de transporte: bicicleta, ônibus, carro, moto, táxi, ambulância e a pé, dados coletados a partir dos questionários aplicados. 
No caso de varicela, para uma estimativa nacional, os custos de transporte foram estimados com base no valor da tarifa média de transporte público para capitais brasileiras (Associação Nacional das Empresas de Transportes Urbanos NTU), multiplicado pelo número de viagens necessárias para cada tipo de tratamento, ambulatorial e hospitalar. Dados do número de viagens vêm de coleta primária e dados de internação (SIH).

\subsection{Custos indiretos ou de produtividade}

Para o cálculo dos custos indiretos foi adotado o Método de Capital Humano. O estudo de custo de doença para rotavírus (CPES/UNIFESP; Secretaria de Estado da Saúde de São Paulo) coletou os dados de absenteísmo e renda através dos questionários aplicados.

Para varicela, foi considerada para renda média a variável utilizada na PNAD 2003 "renda mensal de todos os trabalhos" (V4719) ponderada pela proporção de economicamente ativos (PEA) (V4713), ambas as variáveis abertas por gênero e idade (PNAD, 2003). A renda média da PEA foi convertida em renda diária. Os dias de ausência do trabalho foram estimados a partir dos dias de convalescença, característicos de cada doença, levantamento de bases de dados (SIH/DATASUS), coleta primária e comparação com a literatura internacional e nacional Os dias de absenteísmo foram também abertos por idade, considerando-se para crianças a ausência da mãe com sua respectiva renda mensal. Os custos indiretos foram calculados separadamente para cada tipo de tratamento. Deflacionamento da renda foi feito pelo INPC do IBGE. 


\subsection{Custos do programa de vacinação}

Os custos do programa de vacinação são compostos pelo custo das doses das vacinas, custo de administração das doses e taxa de desperdício.

- Preço da vacina

Os preços das vacinas a serem considerados nas análises de custoefetividade de programas de vacinação no Brasil são os preços praticados através do Fundo Rotatório de Imunizações da Organização Pan-Americana de Saúde/OPAS, mecanismo de compra e financiamento de vacinas para América Latina e Caribe.

O objetivo do Fundo Rotatório é garantir um planejamento nacional melhor e mais eficiente, evitando interrupções no fornecimento das vacinas ou dos recursos para sua aquisição. $\mathrm{O}$ fundo permite a compra em moeda local, impedindo atrasos e perdas cambiais; consolida os pedidos obtendo economias de escala e preços menores e ainda garante a qualidade das vacinas junto a fornecedores. A centralização dos planejamentos dos países e da posterior compra garante não apenas preços mais baixos, mas a própria efetivação da compra, uma vez que os fabricantes podem planejar sua produção com antecedência, administrando melhor seus estoques, acompanhando a demanda. Um dos critérios para a seleção do fornecedor, além do preço, histórico de qualidade, capacidade de entrega dentro do prazo, é se a compra estimulará competição, garantindo preços baixos futuramente. O fundo opera como um mecanismo de redução de preço, estabilidade deste e conseqüentemente sustentabilidade dos programas de vacinação nos países (Andrus et al, 2005).

Os estados membros da OPAS desenvolveram o Fundo Rotatório, inaugurado em 1979. Como descrito na Figura 2, a OPAS consolida as necessidades 
recebidas dos países e, por meio de uma licitação anual internacional, efetua as compras. Os países usam seus próprios recursos para reembolsar o fundo num prazo de 60 dias (Andrus et al, 2005).

A OPAS cobra 3\% sobre os custos dos países membros. Essa taxa de serviço permitiu que a capitalização do fundo passasse de um milhão de dólares em 1979 para 23 milhões em 2003. O número de países passou de 19 em 1977 para 35 em 2002, e os gastos cresceram para mais de 120 milhões de dólares em 2003 (Andrus et al, 2005).

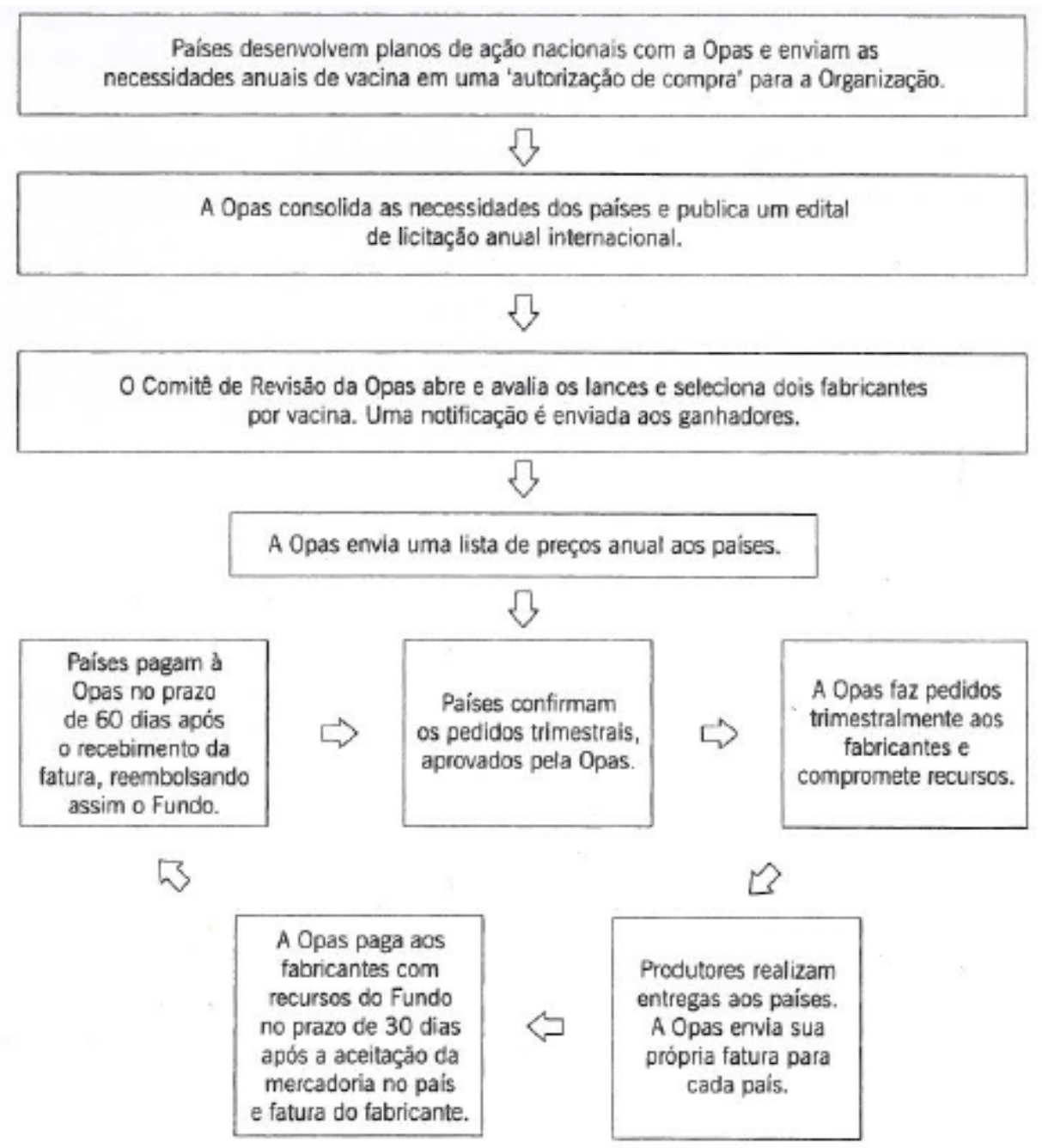

Figura 2. Fundo Rotatório, OPAS

Fonte: (Andrus et al, 2005) 
No caso das vacinas selecionadas, os preços a serem considerados no caso base serão o preço inicialmente acordado entre Ministério da Saúde e GlaxoSmithKline para rotavírus e o preço de compra de vacina para os grupos de risco atualmente imunizados para varicela, ambas as compras efetuadas através do Fundo Rotatório da OPAS.

- Custo de administração e taxa de desperdício

O custo de administração inclui custos referentes à rede de frio, pagamento de pessoal etc. Não existe dado nacional para este item de custo, sendo a distribuição nacional das vacinas extremamente complexa, dada o tamanho do território nacional e a necessidade de temperatura controlada do produto.

A distribuição nacional das vacinas demandadas pelo PNI inicia-se com a centralização das vacinas no CENADI (Central Nacional de Armazenamento e Distribuição de Imunobiológicos). Neste local permanecem em câmaras frias até a aprovação dos lotes de vacinas e diluentes pelo INCQS (Instituto Nacional de Controle de Qualidade em Saúde). Após liberação, a CENADI envia lotes em caixas térmicas para as Coordenações Estaduais, onde são conservados em câmaras frias. Desta mesma forma, é feito o transporte para as Centrais Regionais, onde as vacinas também ficam armazenadas. Nas centrais regionais, os representantes dos postos de vacinação retiram a quantidade de vacinas necessárias por um determinado período de tempo para a área onde atuam. A Figura 3 ilustra a distribuição nacional, a partir das vacinas produzidas em Biomanguinhos.

Considerando que os custos de administração e taxa de desperdício não estão disponíveis no Ministério da Saúde, foram utilizadas referências da literatura 
internacional (Podewils et al, 2005) ${ }^{27}$. O valor de $\mathrm{R} \$ 2,65$ para o custo de administração foi obtido pela conversão do valor assumido de US\$1,00 pelo câmbio oficial de 2004. Esta estimativa tem limitações, uma vez que variações cambiais mudarão a conversão do custo de administração para moeda local sem que isto reflita qualquer mudança do custo real de administração nacional, não conhecido. Dado que o custo de administração é composto por diversos itens (recursos humanos, rede de frio etc), a participação de itens que não são afetados pela taxa cambial e tem seus preços determinados internamente deve ser considerável e, portanto, a variação ano a ano decorrente de conversão cambial apresenta distorção.

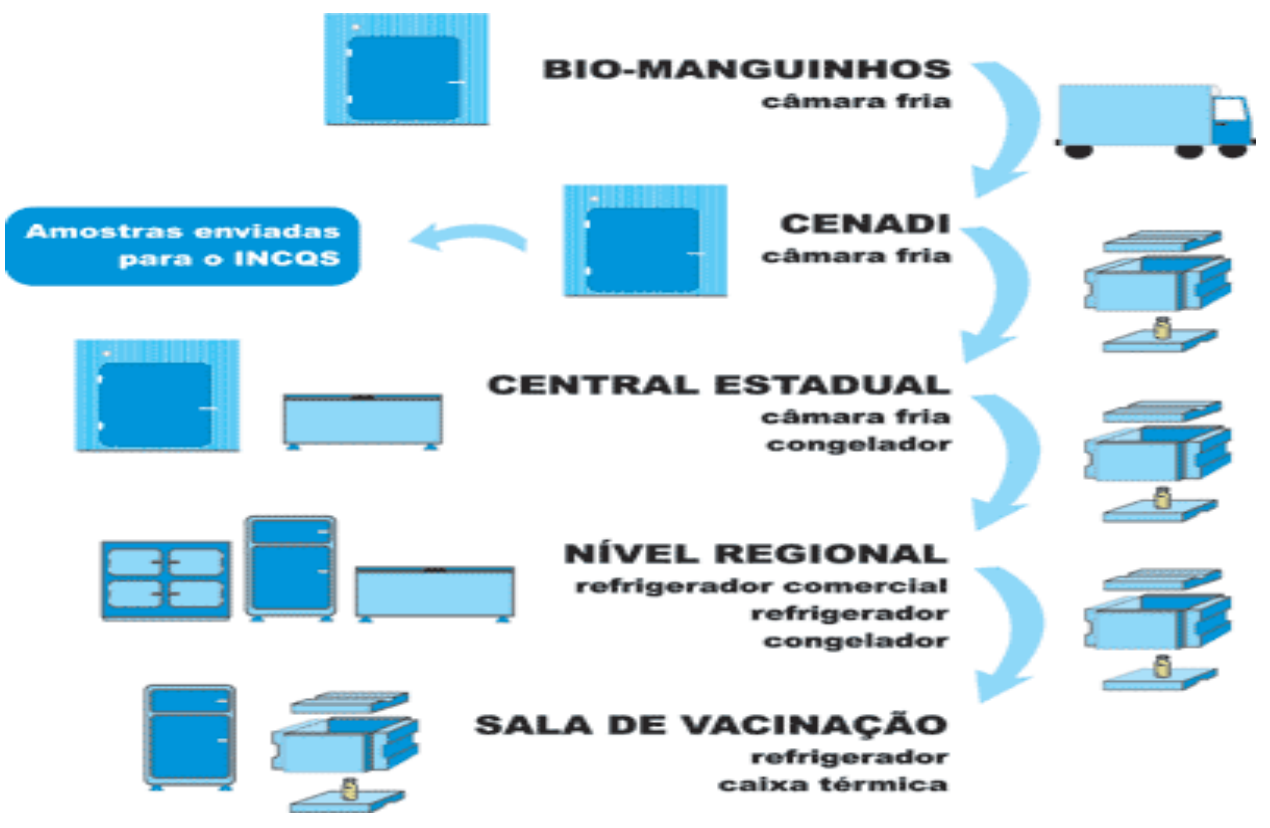

Figura 3. Esquema de distribuição nacional de vacinas, Brasil

Fonte: Biomanguinhos. Disponível em: http://www.bio.fiocruz.br/interna/vacinas_distribuicao.htm. Acesso: 17 de abril de 2008.

${ }^{27}$ Os dados aplicados ao Brasil referem-se aos dos países de renda média alta, conforme categorização do Banco Mundial. 


\subsection{Desconto}

De acordo com o que vem sendo feito na literatura, adotou-se uma taxa fixa para o cálculo do desconto. Definiu-se para o caso base cenário conservador com taxa de desconto de $6 \%$, por ser a maior taxa sugerida pela Organização Mundial da Saúde (OMS, 2003).

As taxas calculadas para o Brasil (Valentim et al, 2008), apresentadas no item 1.1.3 sobre desconto (Anexo, Tabela i), e a taxa sugerida pelo Ministério da Saúde de 5\% serão utilizadas na análise de sensibilidade, as primeiras por terem sido calculadas especificamente para o país e a segunda por ser uma recomendação do MS, ainda que não vigente. 


\section{RESULTADOS}

\subsection{Análise de custo-efetividade do programa de vacinação universal de crianças contra rotavírus}

\subsubsection{Introdução}

As doenças diarréicas continuam sendo importante causa de morbidade e mortalidade infantil nos países em desenvolvimento. No Brasil, a mortalidade e o número de hospitalizações por diarréia em crianças menores de 5 anos, e em particular no primeiro ano de vida, diminuíram significativamente desde os anos 1980, tanto pela diminuição da incidência quanto pela maior acessibilidade aos serviços de saúde e disseminação do uso da terapia de rehidratação oral pelas mães. Entretanto, persistem as diferenças regionais e sócio-econômicas na morbimortalidade associada às diarréias (Sastry et al, 2005).

Os rotavírus são causas comuns de diarréia grave na infância. Estima-se que ocorram a cada ano no mundo 111 milhões de episódios de diarréia, 25 milhões de consultas médicas, 2 milhões de hospitalizações e 440.000 mortes de crianças menores de cinco anos devido às rotaviroses (Parashar et al, 2003). Quase todas as crianças são infectadas até os cinco anos de idade. Não se observam diferenças significativas na incidência da infecção entre países em desenvolvimento e países desenvolvidos, entretanto a grande maioria das mortes ocorre nos primeiros. A diminuição da infecção por rotavírus não depende fundamentalmente da melhora do saneamento básico e a vacinação rotineira na infância tem sido recomendada para prevenir doença grave e morte. 
Nas duas últimas décadas ocorreram grandes investimentos no desenvolvimento de vacinas para infecção por rotavírus. Uma delas chegou a ser incorporada no programa de imunização infantil americano no final dos anos 1990, sendo retirada do mercado após 9 meses, por suspeita de estar associada a evento adverso grave, a intussuscepção intestinal em lactentes (Glass et al, 2005). Duas novas vacinas de rotavírus vivos para uso oral foram recentemente comercializadas uma vacina monovalente de rotavírus humano atenuado (G1P[8]) (Ruiz-Palacios, 2006) e uma vacina pentavalente combinada humana / bovina (G1, G2, G3, G4 e P[8]) (Vesikari et al, 2006). Ambos os produtos demonstraram eficácia contra doença grave e hospitalizações e bom perfil de segurança nos ensaios clínicos de fase 3. A vacina monovalente de rotavírus humano atenuado foi introduzida no Programa Nacional de Imunizações do Brasil em março de 2006, sendo recomendada para todas as crianças, respeitando-se as contra-indicações clínicas específicas, e administrada em duas doses, por via oral, aos dois e quatro meses de idade.

Foi realizada uma análise de custo-efetividade (ACE) da vacina contra rotavírus após a decisão de introdução da vacina no calendário do PNI (Soárez et al, 2008), a fim de se analisar a custo-efetividade da vacina no Brasil e estimar preços da vacina que atenderiam aos padrões internacionais de custo-efetividade.

A ACE a ser apresentada nesta tese utiliza o mesmo modelo e premissas do estudo publicado ${ }^{28}$ (Soárez et al, 2008) com outra metodologia para estimativas de custos. As estimativas próprias de custos do sistema de saúde suplementar foram incluídas, sendo que no trabalho anterior a participação privada nos serviços de saúde foi valorada com base nos custos praticados no sistema público, provavelmente

\footnotetext{
28 As probabilidades usadas na análise de custo-efetividade da vacinação contra rotavíus são apresentadas no anexo, Tabela ii.
} 
subestimados. Incluiu-se também a participação pública na dispensação de medicamentos.

A tese se diferencia por avaliar separadamente na análise de sensibilidade os itens de custos que apresentam os maiores desafios metodológicos para estimação. A análise de sensibilidade específica para as estimativas de custos aumenta o detalhamento do estudo e permite a identificação dos itens de custos com maior influência nos resultados. A seguir são apresentadas as etapas metodológicas da ACE e finalmente discutidas as estimativas de custos.

\subsubsection{População alvo para a intervenção}

Foi definida uma população alvo para a intervenção: crianças de uma coorte hipotética de nascidos vivos, a ser seguida durante cinco anos. Adotou-se a estimativa do Censo 2000 (IBGE) de 3.210.361.

Justifica-se a não inclusão de crianças maiores e adultos pelo fato das diarréias terem maior impacto na saúde de crianças menores.

\subsubsection{Descrição das estratégias comparadas}

Foram duas as estratégias comparadas:

\section{Estratégia 1: "Vacinar"}

Esta estratégia significa a implementação de programa nacional de imunização contra o rotavírus, com recomendação de vacinação para todas as crianças nascidas em 2004, sendo a primeira dose administrada entre 1,5 meses e 3 meses e 1 semana e a segunda dose entre 3 meses e 1 semana e 5,5 meses.

\section{Estratégia 2: "Não Vacinar"}


Nesta estratégia seria mantido o "status quo" vigente no qual as crianças não são vacinadas.

\subsubsection{Horizonte temporal}

Esta análise avaliou os custos e efeitos das duas estratégias anteriormente citadas por um período de cinco anos, começando em 2004.

\subsubsection{Descrição do modelo utilizado}

Este estudo é uma avaliação econômica do tipo análise de custo-efetividade (ACE), ainda a forma dominante para avaliações econômicas de vacinas contra o rotavírus na literatura internacional (Smith et al, 1995; Tucker et al, 1998; Carlin et al, 1999; Podewils et al, 2005; Fisher et al, 2005; Constenla et al, 2006; Rheingans et al, 2007).

A modelagem adotada é a de árvore de decisão, que se baseia na construção de árvores de probabilidades de eventos para uma determinada coorte populacional, em uma perspectiva temporal linear.

Foi utilizado na análise o software Excel (Microsoft) para construir a árvore de decisão (Figura 4) a partir de algumas premissas assumidas. Em virtude do programa de vacinação não ter sido implementado anteriormente, a árvore de decisão foi utilizada para modelar o que aconteceria com esta coorte hipotética de crianças nascidas em 2004 se as mesmas fossem acompanhadas por cinco anos. Foram estimadas a incidência cumulativa de casos, número de tratamentos domiciliares, ambulatoriais e hospitalares, e mortes ocorridas para os cinco anos de acompanhamento. Na seqüência, comparou-se o resultado da estratégia "Vacinar" 
com o "status quo" que seria a estratégia "Não Vacinar". As estratégias foram comparadas com relação as suas possibilidades de prevenir casos, evitar mortes e salvar anos de vida.

$\mathrm{Na}$ estratégia "Vacinar", com base nas estimativas de vacinação, a população é separada em um grupo de crianças que seria vacinado e um grupo de crianças que não seria vacinado. No grupo "Vacinados" alguns receberiam 2 doses da vacina e outros receberiam somente 1 dose da vacina. No grupo que recebeu 2 doses, as crianças teriam a chance de desenvolver diarréia leve, moderada, grave ou não adoecer. Para cada tipo de quadro clínico de diarréia a ser desenvolvida a vacina teria uma efetividade específica. O grupo no qual a vacina foi efetiva recebeu o nome de "Protegidos" e o outro é o grupo que desenvolveu a diarréia, os "Doentes". As crianças que adoecessem com diarréia leve receberiam tratamento domiciliar, as que adoecessem com diarréia moderada receberiam tratamento ambulatorial e as que adoecessem com diarréia grave receberiam tratamento hospitalar e eventualmente iriam a óbito. A mesma lógica se desenvolve no grupo que recebeu apenas 1 dose, sendo as probabilidades de adoecer iguais porém a efetividade da vacina adotada diferente.

No grupo "Não Vacinados", as crianças teriam a chance de desenvolver diarréia leve, moderada, grave ou não adoecer. E cada tipo de diarréia evoluiria para os seus tratamentos já descritos anteriormente.

Na estratégia "Não Vacinar", o fluxo de eventos que acontece no grupo "Não Vacinados" se repete. 


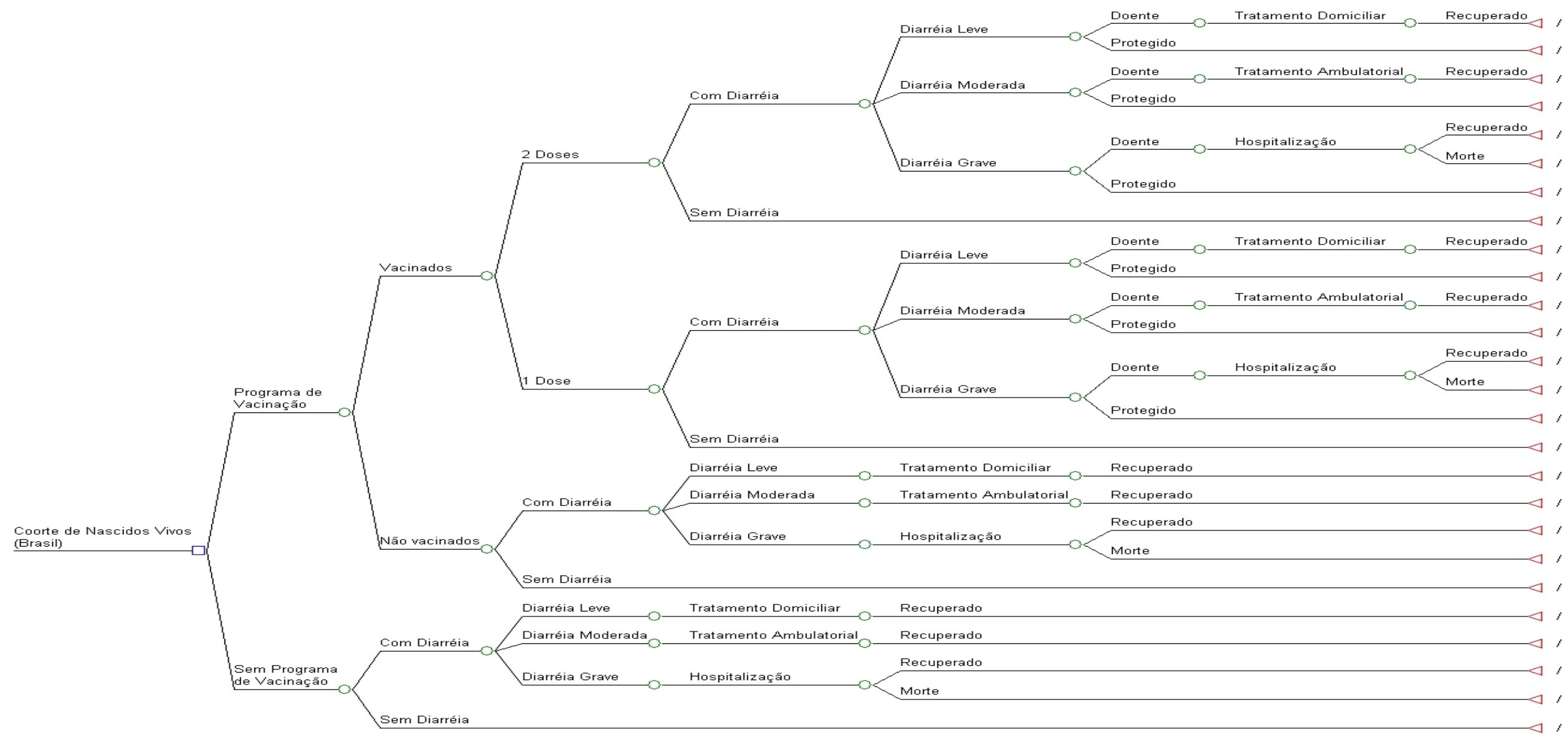

Figura 4. Árvore de Decisão - Diagrama do fluxo dos eventos no modelo (vacinação contra rotavírus) 


\subsubsection{Perspectivas}

1. Sociedade - na qual todos os custos diretos e indiretos foram valorados;

2. Sistema de Saúde - na qual somente os custos diretos médicos foram valorados, incluindo sistemas público e de saúde suplementar.

\subsubsection{Identificação dos desfechos na análise}

Usando este modelo, foram calculadas três medidas sínteses: (1) custo incremental por caso evitado, (2) custo incremental por morte evitada e (3) custo incremental por ano de vida salvo. O modelo estimou o número de casos domiciliares, ambulatoriais, hospitalares e mortes que ocorreriam nestes cinco anos em cada uma das estratégias. Essas medidas de desfecho intermediárias foram convertidas em três medidas de desfecho finais: casos evitados, mortes evitadas e anos de vida ganhos. Para este desfecho, assumiu-se de expectativa de vida de 69 anos (Censo 2000 IBGE).

\subsubsection{Estimativas de morbidade e mortalidade}

Estimativas de morbidade e mortalidade de rotavírus tiveram por base revisão da literatura, sistemas de informação em saúde do DATASUS (SIH e Sistema de Informações sobre Mortalidade/SIM) que resultaram em estudo específico de morbidade e mortalidade por rotavírus no Brasil (Sartori et al, 2008). Foi estimado que ocorreram 3.525.053 episódios de diarréia por rotavírus, 655.853 consultas, 92.453 hospitalizações e 850 mortes de crianças menores de 5 anos de idade ao ano no Brasil. A incidência estimada acumulada em 5 anos de diarréia por rotavírus foi de 1,2 casos por criança (Sartori et al, 2008). 
Modelos lineares de árvores de decisão não permitem estimativas de efeitos de episódios múltiplos de doença, portanto a incidência total por rotavírus não pode ser maior que uma infecção por criança. Apesar de imunidade ativa adquirida após infecção natural não proteger completamente após reinfecção, ela protege contra subsequentes diarréias severas (Velázquez et al, 1996). Portanto, diarréia severa é mais provável de ocorrer durante o primeiro episódio de infecção por rotavírus (Velázquez et al, 1996; Jiang et al, 2002). Baseado nesses parâmetros, o modelo foi usado para estimar a incidência de diarréia moderada e grave somente (com a incidência de diarréia leve calculada como valores complementares da incidência total de 1). Este método foi usado para garantir que somente diarréias leves seriam subestimadas. As estimativas finais de incidência acumulada em 5 anos de episódios de diarréia leve, moderada e grave por rotavírus são apresentadas no anexo (Tabela ii).

\subsubsection{Estimativas de eficácia e cobertura vacinal}

A vacina monovalente de rotavírus humano atenuado G1P[8] foi escolhida para a vacinação universal no Brasil. A dose recomendada é um esquema de 2 doses administradas de acordo com um esquema restrito, com a primeira dose sendo dada somente a crianças entre 6 e 14 semanas de vida e a segunda dose dada entre um e dois meses depois, para crianças entre 14 e 24 semanas de vida.

Em 1999, uma vacina tetravalente de origem símio-humana, RRV-TV (rhesus-human rotavirus reassortant tetravalent live vaccine - RotaShield ${ }^{\circledR}$ ) foi retirada do mercado em função de uma associação temporária com intussuscepção. Não se sabe se a síndrome pode ocorrer em outras vacinas vivas de rotavírus, já que 
o mecanismo biológico ainda não foi estabelecido. Como precaução, a administração experimental da primeira dose da nova geração de vacinas contra rotavírus foi restrita a crianças nos primeiros três meses de vida, uma vez que este grupo de idade é menos vulnerável a intussuscepção natural (Simonsen et al, 2005). Apesar da vacina monovalente de rotavírus humano atenuado ter tido um perfil de segurança garantido em estudo de fase 3 com 60.000 crianças (Ruiz-Palacios et al, 2006), ainda não tinha sido usada em programas de imunização em larga-escala até sua introdução no Brasil em 2006.

Como vacinação de crianças mais velhas suscetíveis (catch-up) contra rotavírus não é recomendada, não foi considerada no modelo.

Devido a possíveis restrições causadas pela administração restrita recomendada para a vacinação contra rotavírus, a cobertura estimada baseou-se na cobertura de hepatite B $(90,49 \%)$, a mais baixa entre as vacinas recomendadas para crianças abaixo de 1 ano de idade pelo PNI em 2004 (DATASUS). Dados de esquemas de vacinação incompletos de hepatite B e DTPw-Hib foram usados para estimar proporção de crianças que receberiam 1 versus 2 doses da vacina contra rotavírus.

A eficácia estimada da vacina baseou-se nos resultados obtidos nos ensaios clínicos. Em um estudo de fase 3, a eficácia da vacina monovalente de rotavírus humano atenuado G1P[8] contra doença grave foi de 84,7\% (com 2 doses) e $81,1 \%$ (com 1 dose) (Ruiz-Palacios et al, 2006). Em um estudo de fase 2 na América Latina, a eficácia de 2 doses da vacina contra diarréia grave variou de $66 \%$ a $86 \%$, com eficácia contra qualquer gastroenterite por rotavírus variando de $56 \%$ a $70 \%$, dependendo da dose da vacina (Salinas et al, 2005). A eficácia da vacina contra 
doença leve e moderada não foi reportada (Ruiz-Palacios et al, 2006; Salinas et al, 2005). Como muitas outras vacinas, a vacina contra rotavírus é considerada mais efetiva contra doença grave do que doença leve ou moderada. A eficácia da vacina contra diarréia leve foi estimada com base na eficácia máxima de $70 \%$ contra qualquer tipo de diarréia relacionada a rotavírus, assumindo que a eficácia da vacina contra qualquer tipo de diarréia cairia entre a eficácia contra diarréia severa e diarréia leve. Do mesmo modo, a eficácia de 1 dose da vacina foi assumida como inferior à eficácia de 2 doses.

Possíveis efeitos adversos após vacinação não foram considerados no modelo porque as taxas de efeitos adversos em crianças que receberam a vacina monovalente de rotavírus humano atenuado $\mathrm{G} 1 \mathrm{P}[8]$ nos ensaios clínicos foram similares aos controles de não vacinados (Ruiz-Palacios et al, 2006; Salinas et al, 2005).

Proteção de rebanho potencial (efeitos indiretos potenciais do programa de imunização para crianças não vacinadas) não foi considerada no modelo uma vez que não há dados existentes na literatura.

\subsubsection{Estimativas de custos}

Custos foram estimados para os anos de 2004 e se basearam em estudo primário de custos de diarréia por rotavírus da Secretaria de Estado da Saúde de São Paulo e CPES/UNIFESP (Soárez et al, 2005) e em estudo de custo-efetividade de vacinação contra rotavírus no Brasil (Soárez et al, 2008). Neste, a participação do sistema de saúde suplementar foi incluída, e os respectivos custos foram valorados com base no sistema público de saúde. Como descrito no item 4.1.1, para esta tese 
foram incluídas as estimativas de custos específicas do sistema de saúde suplementar e a participação pública na dispensação de medicamentos.

\section{a. Custos diretos}

a.1. Custos diretos no cuidado da doença

Para os itens de consultas médicas, internações e exames complementares os custos estimados do estudo de custos de rotavírus (CPES/UNIFESP; Secretaria de Estado da Saúde de São Paulo), que incluíam somente estimativas no SUS, foram ajustados de modo a incluir os custos específicos do sistema de saúde suplementar. Estes foram pesquisados na ANS, CBHPM e TUNEP e incorporados para esta tese.

O estudo de custos de rotavírus (CPES/UNIFESP; Secretaria de Estado da Saúde de São Paulo) foi realizado em dois municípios da cidade de São Paulo, Guarulhos e Rio Claro, e os dados extrapolados para o país. A valoração dos recursos consumidos foi feita a partir de bases de dados do SUS, com valores de listas de preços de medicamentos (ABCFarma, ICMS de 18\%), e produtos a preços de mercado. Assume-se que a padronização dos sistemas de dados e listas utilizados permita tal extrapolação. A posterior inclusão dos custos do sistema de saúde suplementar utilizou valores vigentes para o país como um todo (ANS, CBHPM e TUNEP). 


\section{a.1.1. Consultas médicas}

O estudo de custos de rotavírus (CPES/UNIFESP; Secretaria de Estado da Saúde de São Paulo) utilizou o valor da consulta em especialidade de R \$ 7,55 em 2004 (SIA/DATASUS) para custo da consulta médica no sistema público, único sistema considerado neste estudo de custos. Como apresentado no item de "Material e Métodos", o valor de uma consulta em especialidade está possivelmente superestimado, uma vez que o financiamento do PAB per capita (entre $\mathrm{R} \$ 10$ e $\mathrm{R} \$ 18$ ao ano) incluí diversas ações conjuntamente com as consultas médicas.

Para esta tese, foi incluído o custo unitário do sistema de saúde suplementar, tendo sido utilizado o valor de consulta geral de $\mathrm{R} \$ 26,14$ (Sistema de Informações de Produtos-SIP/ANS) de 2004. A participação do sistema de saúde suplementar baseou-se na PNAD 2003 (Anexo, Tabela iii), confome feito no estudo de custoefetividade de vacinação contra rotavírus publicado (Sóarez et al, 2008).

\section{a.1.2. Medicamentos e produtos}

No estudo de custos de rotavírus (CPES/UNIFESP; Secretaria de Estado da Saúde de São Paulo), calculou-se o custo de cada medicamento através de preços publicados na revista farmacêutica ABCFarma de junho de 2004. Foi considerado o valor do preço ao consumidor com alíquota de $18 \%$ para o estado de São Paulo do medicamento de marca. Foi utilizada a técnica do micro-costing, que impõem um detalhamento da mensuração e valoração separada de todos os itens envolvidos. De cada medicamento citado no questionário foi calculado o valor médio de acordo com a sua apresentação (por exemplo, valor médio do comprimido, da gota, do ml, do 
envelope etc). Em seguida se multiplicou este valor pelo número de vezes e de dias que a medicação foi tomada.

As estimativas de custos de medicamentos do estudo de custos de rotavírus (CPES/UNIFESP; Secretaria de Estado da Saúde de São Paulo) foram utilizadas com modificação para o estudo de custo-efetividade de rotavírus nesta tese, com a inclusão da participação pública na dispensação de medicamentos. Os dados do estudo primário de rotavírus apresentam o consumo agregado por classe terapêutica, mas não princípios ativos e respectivas dosagens. Desta forma, só foi possível reestimar os custos de medicamentos com a participação pública na dispensação, mas não incluir os custos dos mesmos no SUS.

No estudo de custos de rotavírus, os produtos comprados em virtude da diarréia foram classificados em: produtos de higiene pessoal, produtos de limpeza em geral, pomadas para assaduras, hortifrutigranjeiros, laticínios, cereais, bebidas e energéticos e alimentos industrializados. Os produtos de higiene pessoal englobam as fraldas e lenços umedecidos.

Foi usado como referência o valor pago pela família para cada produto. Novamente utilizou-se a técnica do micro-costing. De cada produto foi multiplicado o valor pago pelo número de unidades consumidas. Em alguns casos em que o valor do produto não foi informado, atribuiu-se um valor médio pago por esse produto na população.

\section{a.1.3. Exames complementares}

Os exames considerados pelo estudo de custos de rotavírus (CPES/UNIFESP; Secretaria de Estado da Saúde de São Paulo) foram os solicitados pelos médicos das 
unidades de atendimento. Os exames incluídos foram hemograma completo, potássio, sedimento corado, parasitológico, radiografias e tomografia de abdômen. Para determinação dos custos dos exames complementares foram utilizados os valores da tabela de procedimentos do SIA/ DATASUS de julho de 2004. Para o custo unitário do sistema de saúde suplementar para esta tese, a CBHPM foi consultada. $^{29}$

\section{a.1.4. Hospitalizações}

Foi usado como valor de referência no estudo original de custos o valor médio da AIH para internação por diarréia e gastroenterite de origem infecciosa do período de fevereiro de 2004 a fevereiro de 2005 nos respectivos municípios. (Guarulhos R\$323,09 e Rio Claro R\$ 306,70). Em seguida multiplicou-se o número de internações, dado fornecido pelo estudo, pelo valor médio da AIH para internação por diarréia do respectivo município.

Para a inclusão do custo do sistema de saúde suplementar para esta tese, a TUNEP foi escolhida como representativa por ser uma lista intermediária entre os valores do SUS e os valores da tabela CBHPM. Utilizou-se a "Compatibilidade Procedimento x CID 10" para se obter os valores de internação na TUNEP. Foram escolhidos os procedimentos 74300270 (entero infecções em pediatria), 74500252 (entero infecções em clínica médica) e 76400271 (entero infecções em lactente), nos valores de $\mathrm{R} \$ 610,30$ para os primeiros e $\mathrm{R} \$ 741,65$ para o último. Supondo-se que a distribuição de casos de diarréia por rotavírus seja a mesma para os casos atendidos pelos sistemas de saúde suplementar e público, calculou-se a média ponderada do

\footnotetext{
${ }^{29}$ Em média, os custos unitários dos exames complementares incluídos são três vezes maiores no sistema de saúde suplementar do que no SUS.
} 
valor da internação no sistema de saúde suplementar com a freqüência dos mesmos procedimentos $(35,6 \%, 37,7 \%$ e $26,7 \%$ respectivamente) pelas AIHs no sistema público (DATASUS), uma vez que a TUNEP fornece valor mas não freqüência de internações. O valor estimado da internação no sistema de saúde suplementar por diarréia por rotavírus foi de $\mathrm{R} \$ 645,35$, aproximadamente o dobro do valor no SUS.

\section{a.2. Custos diretos não-médicos}

As estimativas de custos diretos não-médicos baseiam-se também no estudo de custos de rotavírus (CPES/UNIFESP; Secretaria de Estado da Saúde de São Paulo), realizado nos municípios de Guarulhos e Rio Claro.

\section{a.2.1. Transporte}

Foi usado como referência o valor pago pela família para cada tipo de transporte. Novamente foi utilizada a técnica do micro-costing. Para cada tipo de transporte $^{30}$ multiplicou-se o valor pago pelo número de viagens percorridas.

\section{b. Custos indiretos ou de produtividade}

As estimativas de custos de produtividade referentes ao estudo de custos de rotavírus (CPES/UNIFESP; Secretaria de Estado da Saúde de São Paulo) basearamse no Método de Capital Humano. A renda média familiar mensal foi de aproximadamente $\mathrm{R} \$ 500$, próximo ao rendimento médio de $\mathrm{R} \$ 474,00$ para o Brasil para o mesmo ano (PNAD 2004).

\footnotetext{
${ }^{30}$ Em caso de transporte requerido, foram utilizados carro, moto, ônibus, táxi, ambulância e bicleta.
} 
Para valoração dos dias de trabalho perdido pelo cuidador, pelo Método de Capital Humano, considerou-se a produtividade total perdida do cuidador devido à doença da criança, calculada multiplicando-se o número de dias de trabalho perdido pelo salário médio deste respectivo período.

O salário médio do período foi calculado a partir do salário mensal do indivíduo. O valor de um dia de salário foi então multiplicado pelo número de dias de trabalho perdidos, chegando-se ao salário médio do respectivo período perdido. Foram considerados três dias como período de ausência do trabalho, a duração média dos episódios de diarréia

\section{c. Custos por tipo de tratamento e perspectiva}

\section{c.1. Tratamento domiciliar}

Foram considerados somente os itens de medicamentos e produtos para tratamento domiciliar. Como o estudo primário de custos de diarréia por rotavírus foi por busca ativa de pacientes, assumiu-se que houve indução de demanda. $\mathrm{O}$ custo médio em tratamento domiciliar foi reduzido pela metade ${ }^{31}$, de modo a representar as condições habituais de conduta das mães frente à diarréia, sem procura por serviços de saúde e prescrições. O custo por caso de diarréia em tratamento domiciliar $(\mathrm{R} \$ 11,78)$ consta somente da perspectiva da sociedade no estudo de custoefetividade do programa de vacinação contra rotavírus. Assume-se, para o cenário base, que o caso domiciliar não acarreta custo de produtividade.

\footnotetext{
${ }^{31}$ Pressuposto assumido.
} 


\section{c.2. Tratamento ambulatorial}

O estudo primário considerou haver tratamento domiciliar também nos casos de diarréia que receberam atendimento em serviços de saúde, de modo que para se estimar os custos em tratamento ambulatorial foram também considerados os itens incorridos em tratamento domiciliar.

Os custos de consultas e exames foram recalculados para incluir os custos unitários praticados no sistema de saúde suplementar ${ }^{32}$ e a participação pública no fornecimento de medicamentos. A partir da PNAD 2003, assumiu-se que 38\% dos medicamentos, para a coorte de crianças menores de 5 anos de idade (Anexo, Tabela iv), foram obtidos gratuitamente através dos programas públicos de distribuição de medicamentos. Na perspectiva do sistema de saúde, incluindo sistemas de saúde (SUS e Sistema de Saúde Suplementar), o custo por caso de diarréia em tratamento ambulatorial foi de $\mathrm{R} \$ 18,87$, e na perspectiva da sociedade $\mathrm{R} \$ 56,98$.

\section{c.3. Tratamento hospitalar}

Os custos em tratamento hospitalar foram compostos por internações, consultas, exames complementares, medicamentos, produtos, transporte e custos de produtividade, os últimos três quando da perspectiva da sociedade.

\footnotetext{
${ }^{32}$ Sabendo-se que houve 1,18 consultas no tratamento domiliciar definido pelo estudo primário e 1,21 consultas no tratamento ambulatorial e que $27 \%$ (anexo) das consultas no Brasil são feitas no sistema de saúde suplementar, recalculou-se o custo médio com consultas com os valores apresentados no item de consultas médicas ( $\mathrm{R} \$ 7,55$ para sistema público e $\mathrm{R} \$ 26,14$ para privado). Para o item de exames, considerou-se que 36\% (anexo) deles são realizados no sistema de saúde suplementar, a valor 2,7 maior, como descrito no item de exames complementares. Após a inclusão dos custos do sistema de saúde suplementar, o custo em tratamento ambulatorial para serviços de saúde (consultas e exames complementares) e medicamentos foi recalculado como a média dos custos em tratamento domiciliar e ambulatorial médios iniciais do estudo primário, de modo a representar todos os atendimentos feitos para os casos de diarréia. Para os demais itens de custos, considerou-se o custo médio em tratamento ambulatorial.
} 
Para as internações, considerou-se o valor de $\mathrm{R} \$ 645,35$ descrito no item de "Hospitalizações" e a participação de 23\% (Anexo, Tabela iii) do sistema de saúde suplementar. Para a perspectiva do sistema de saúde (SUS e Sistema de Saúde Suplementar), o custo por caso de diarréia em tratamento hospitalar foi de $\mathrm{R} \$ 438,92$ e para a perspectiva da sociedade $\mathrm{R} \$ 479$.

A Tabela 1 resume os custos por caso de diarréia por rotavírus de acordo com tratamento e perspectiva, comparando as estimativas de custos do estudo de custo-efetividade original (Soárez et al, 2008) e as estimativas de custos para esta tese, com a inclusão de custos específicos do sistema de saúde suplementar e da participação pública na dispensação de medicamentos. Considerando a perspectiva da sociedade, houve aumento das estimativas de custos de aproximadamente $26 \% \mathrm{em}$ tratamento ambulatorial e de aproximadamente $23 \%$ em tratamento hospitalar.

Tabela 1. Custos por caso de diarréia por rotavírus segundo tipo de tratamento, perspectiva e metodologia de estimativas de custos, Brasil, reais de $2004^{33}$

\begin{tabular}{lcccccc}
\hline & \multicolumn{5}{c}{ Perspectiva } \\
Tratamento & & Sociedade & \multicolumn{4}{c}{ Sistema de Saúde } \\
\hline & (a) & (b) & $(\Delta)$ & (a) & (b) & $(\Delta)$ \\
Domiciliar & 11,78 & $\mathbf{1 1 , 8 0}$ & $0 \%$ & 0 & $\mathbf{0}$ & - \\
Ambulatorial* & 45,10 & $\mathbf{5 6 , 9 8}$ & $26 \%$ & 19 & $\mathbf{1 8 , 8 7}$ & $-1 \%$ \\
Hospitalar & 388,36 & $\mathbf{4 7 9 , 0 0}$ & $23 \%$ & 348 & $\mathbf{4 3 8 , 9 2}$ & $26 \%$ \\
\hline
\end{tabular}

(a) Soárez et al (2008); (b) Estimativas de custos recalculadas para esta tese, com a inclusão de custos específicos do sistema de saúde suplementar e da participação pública na dispensação de medicamentos.

* No estudo original, os custos com medicamentos foram alocados para o sistema de saúde. Para esta tese, houve separação dos custos dos medicamentos para sistema de saúde e famílias.

${ }^{33}$ Custos unitários em anexo, Tabela v. 


\section{d. Custos do programa nacional de imunização contra rotavírus}

Os custos de vacinação incluem o preço de cada dose, o número de doses administradas (baseadas nas estimativas do esquema de 2 doses), os custos de administração, e as perdas esperadas de desperdício da vacina.

O preço de cada dose foi estimado em US\$7 $(\mathrm{R} \$ 18,6)^{34}$ baseado no valor estabelecido em negociação entre o Ministério da Saúde e o produtor da vacina (GlaxoSmithKline) (Coordenação Geral/PNI, comunicação pessoal). Custos de administração incrementais foram assumidos como baixos, uma vez que a vacina contra rotavírus pode ser administrada conjuntamente às vacinas recomendadas DTPw-Hib tetravalente e poliomielite oral, não implicando novos materiais e treinamentos específicos. Custos de administração (US\$1) e desperdício (10\% das doses da vacina) vieram da literatura (Podewils et al, 2005), uma vez que não há dados locais disponíveis ${ }^{35}$.O valor total unitário por dose de vacina foi de $\mathrm{R} \$ 23,1$.

Os custos de vacinação foram calculados somente para o sistema público de saúde. Dados do programa de imunização de São Paulo, estado com maior participação do setor privado, indicam baixa participação deste na imunização de crianças em 2004, cobrindo cerca de 1,3\% da população (Comunicação pessoal, Sato, HK, Janeiro de 2006).

\footnotetext{
${ }^{34}$ Taxa de câmbio oficial: R $\$ 2,65$ = US\$1 (BCB, 2004).

${ }^{35}$ Quando do início da vacinação contra rotavírus houve problemas de armazenamento. O PNI operava em seu limite. É possível que a inclusão da nova vacina tenha requerido expansão da rede de frio, com aumento do custo de administração.
} 


\subsubsection{Desconto}

Os custos decorrentes da doença, com exceção dos custos do programa de vacinação, e os valores dos desfechos foram trazidos a valor presente a uma taxa de desconto anual de 6\% (OMS, 2003). Os custos de vacinação não foram descontados porque, no modelo adotado, todas as crianças são vacinadas no primeiro ano ${ }^{36}$.

Para análise de sensibilidade, taxa de desconto de 5\% sugerida pelo MS (Brasil, 2007) e média da taxa de desconto social calculada para Brasil para 5 anos (horizonte temporal do modelo de rotavírus) de 4,76\% foram consideradas (Valentim et al, 2008), assim como taxas de desconto menores para desfechos (0 e 3\%).

\subsubsection{Custo-efetividade da vacinação contra rotavírus}

A Tabela 2 apresenta os resultados de desfechos e de custos do programa de vacinação universal contra rotavírus na perspectiva do sistema de saúde e sociedade nos 5 anos do programa. A partir das premissas do caso base, o programa de vacinação universal contra rotavírus preveniria 1.735 .351 casos e 703 mortes por rotavírus.

O programa de vacinação resultaria em custos adicionais aos serviços de saúde. Apesar das economias de custo total (direto e indireto) de R\$ 84.953.329 (R\$ 16.990.666 ao ano) na perspectiva da sociedade e de $\mathrm{R} \$ 46.276 .463$ ( $\mathrm{R} \$ 9.255 .293$ aa) na perspectiva do sistema de saúde, os custos de vacinação adicionais seriam de $\mathrm{R} \$ 121.673 .966$.

A inclusão de custos específicos do sistema de saúde suplementar e participação pública na dispensação de medicamentos aumentou o custo total da

\footnotetext{
${ }^{36}$ Custos são analisados no final e não começo do primeiro ano do modelo, de modo que os custos de imunização não são descontados.
} 
doença em $16 \%$ na perspectiva da sociedade e $13 \%$ na perspectiva do sistema de saúde, assim como produziu maiores economias (acréscimo de $18 \%$ na perspectiva da sociedade e de $20 \%$ na perspectiva do sistema de saúde) com a introdução da vacinação universal contra rotavírus (Tabela 2). 
Tabela 2. Estimativas de custos e impacto da doença associada com a diarréia por rotavírus, segundo perspectiva da análise e status de vacinação

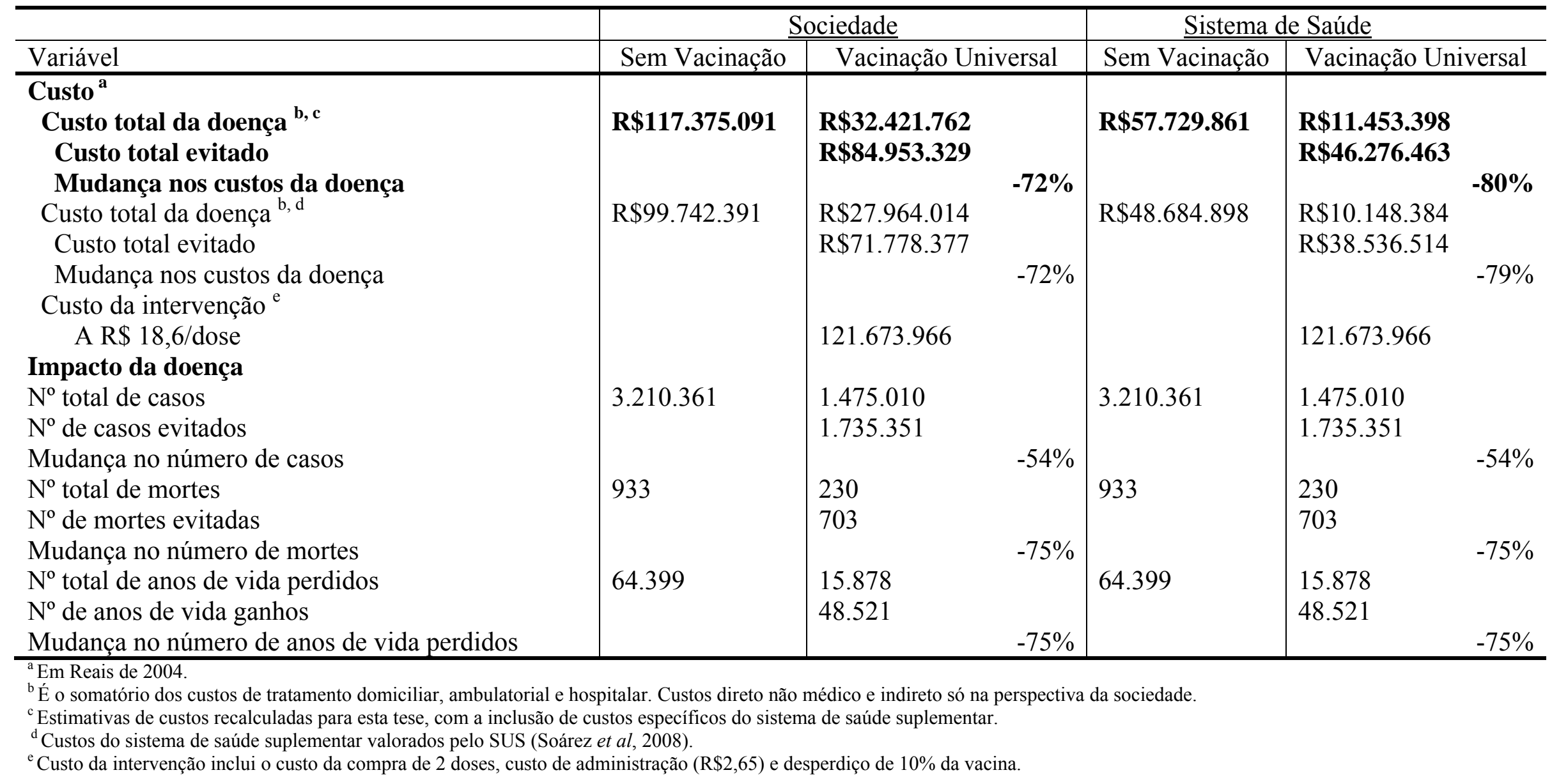


Para calcular a razão de custo-efetividade incremental, definida pela divisão do custo pela efetividade incremental, foi utilizada a fórmula:

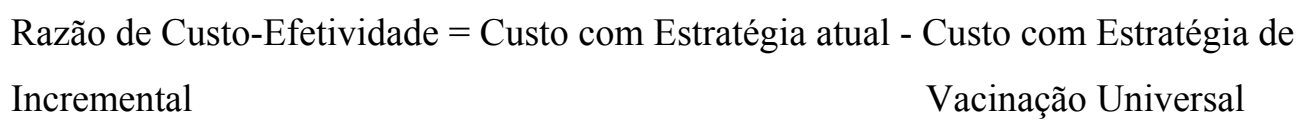
Desfecho da Estratégia atual - Desfecho da Estratégia de Vacinação Universal

As razões de custo-efetividade incremental são apresentadas na Tabela 3. Não existe limiar nacional de custo-efetividade. A OMS sugere limiar baseado no PIB (WHOCHOICE). Caso uma intervenção tenha razão de custo-efetividade incremental menor que 1 x PIB per capita é considerada muito custo-efetiva. No intervalo entre 1 x PIB per capita e 3 x PIB per capita é custo-efetiva e acima de $3 \times$ PIB per capita não mais custo-efetiva. A OMS usa DALYs como desfecho da razão incremental neste critério de limiar de custo-efetividade.

Rotavírus é uma doença aguda, evoluindo para total recuperação ou morte, portanto, pode-se assumir que um DALY seja equivalente a um ano de vida salvo, desfecho calculado para o estudo de custo-efetividade de vacinação contra rotavírus para o Brasil.

Considerando o PIB per capita do Brasil de R\$ 10.692 (IBGE) em 2004, o programa de vacinação universal contra rotavírus é muito custo-efetivo em ambas as perspectivas (sociedade e do sistema de saúde).

A inclusão das estimativas de custos do sistema de saúde suplementar e participação pública na dispensação de medicamentos (Tabela 3) reduziu o custo incremental por ano de vida salvo em $26 \%$ e $20 \%$ na perspectiva da sociedade (sem e com desconto, respectivamente) e em $9 \%$ na perspectiva do sistema de saúde (sem e 
com desconto, respectivamente), em comparação ao estudo com estimativas de custos unitários baseados apenas no SUS (Soárez et al, 2008).

A decisão de introdução de inclusão da vacina contra rotavírus no calendário do PNI baseou-se em considerações de saúde pública, decisão esta prévia à realização do estudo de avaliação econômica. Os resultados do estudo de avaliação econômica confirmaram a justificativa de introdução da vacina, por critérios técnicos de custo-efetividade. 
Tabela 3. Custo-efetividade da vacinação contra rotavírus por perspectiva e metodologia de estimativas de custos, Brasil

\begin{tabular}{|c|c|c|}
\hline $\begin{array}{l}\text { Razão de custo-efetividade incremental } \\
\text { (estimativas de custos para a tese)* }\end{array}$ & Sociedade & Sistema de Saúde \\
\hline \multicolumn{3}{|l|}{ Custos e desfechos não descontados } \\
\hline Custo incremental por caso evitado & $\mathrm{R} \$ 21$ & $\mathrm{R} \$ 43$ \\
\hline Custo incremental por morte evitado & $\mathrm{R} \$ 52.230$ & $\mathrm{R} \$ 107.221$ \\
\hline Custo incremental por AVS & $\mathrm{R} \$ 757$ & $\mathrm{R} \$ 1.554$ \\
\hline \multicolumn{3}{|l|}{ Custos e desfechos descontados (6\%) } \\
\hline Custo incremental por caso evitado & $\mathrm{R} \$ 30$ & $\mathrm{R} \$ 52$ \\
\hline Custo incremental por morte evitado & $\mathrm{R} \$ 72.947$ & $\mathrm{R} \$ 127.949$ \\
\hline Custo incremental por AVS & $\mathrm{R} \$ 1.057$ & $\mathrm{R} \$ 1.824$ \\
\hline \multicolumn{3}{|c|}{$\begin{array}{l}\text { * Inclusão de custos específicos do sistema de saúde suplementar (consulta, exames, hospitalização) e } \\
\text { inclusão de participação pública na dispensação de medicamentos. }\end{array}$} \\
\hline $\begin{array}{l}\text { Razão de custo-efetividade incremental } \\
\text { (estimativas de custos do estudo original) } * *\end{array}$ & Sociedade & Sistema de Saúde \\
\hline \multicolumn{3}{|l|}{ Custos e desfechos não descontados } \\
\hline Custo incremental por caso evitado & $\mathrm{R} \$ 29$ & $\mathrm{R} \$ 48$ \\
\hline Custo incremental por morte evitado & $\mathrm{R} \$ 70.955$ & $\mathrm{R} \$ 118.228$ \\
\hline Custo incremental por AVS & $\mathrm{R} \$ 1.028$ & $\mathrm{R} \$ 1.713$ \\
\hline \multicolumn{3}{|l|}{ Custos e desfechos descontados (6\%) } \\
\hline Custo incremental por caso evitado & $\mathrm{R} \$ 37$ & $\mathrm{R} \$ 57$ \\
\hline Custo incremental por morte evitado & $\mathrm{R} \$ 91.670$ & $\mathrm{R} \$ 138.947$ \\
\hline Custo incremental por AVS & $\mathrm{R} \$ 1.329$ & $\mathrm{R} \$ 2.014$ \\
\hline
\end{tabular}

** Soárez et al (2008)

AVS: Ano de vida salvo

Foi calculado o preço de nivelamento (breakeven), que é o preço da dose da vacina para o qual os custos com o programa de vacinação universal igualam os custos sem vacinação. Na perspectiva da sociedade, o preço de nivelamento da dose 
da vacina é de $\mathrm{R} \$ 12,26$ e na perspectiva do sistema de saúde $\mathrm{R} \$ 5,58$, redução de $70 \%$ nesta perspectiva em relação ao preço de compra da dose da vacina $(\mathrm{R} \$ 18,6)$.

\subsubsection{Análise de sensibilidade}

Os parâmetros variados um a um na análise de sensibilidade do estudo anterior de custo-efetividade de vacinação contra rotavírus (Soárez et al, 2008) foram incidência de diarréia, proporção de episódios de diarréia grave, moderada e leve, taxa de letalidade, cobertura vacinal, eficácia da vacina, custo da vacina, custo de hospitalização e taxa de desconto. A análise de sensibilidade univariada mostrou que os resultados do estudo de custo-efetividade de vacinação contra rotavírus foram mais sensíveis aos seguintes parâmetros: taxa de incidência de diarréia, proporção de episódios de diarréia grave, moderada e leve, cobertura vacinal e custo da vacina.

Para esta tese, as estimativas de custos de diarréia por rotavírus apresentadas têm seu impacto analisado na sensibilidade das razões de custo-efetividade incrementais. As análises de sensibilidade univariadas de todos os parâmetros de custos são feitas em relação às razões incrementais cujos custos e desfechos não foram descontados.

\subsubsection{Análise de sensibilidade para estimativas de custos e desconto}

Os seguintes itens de custos e desconto foram considerados na análise de sensibilidade univariada (Tabela 4): 
- Custo de consulta

Como o custo unitário de consulta identificado no SIA/DATASUS foi o de especialidade, com possível superestimação deste dado o financiamento do PAB para consultas gerais, variou-se o valor da consulta no público para baixo. Arbitrariamente, supôs-se que a consulta custasse $\mathrm{R} \$ 3,00$. Os custos dos casos ambulatoriais caem para $\mathrm{R} \$ 14,90$ e $\mathrm{R} \$ 53,01$ e os dos casos hospitalares para $\mathrm{R} \$$ 435,17 e R\$ 475,25, nas perspectivas do sistema de saúde e sociedade. Como apresentado na Tabela 4, uma variação maior que $50 \%$ do custo de consulta no SUS, que responde por $73 \%$ das consultas (Anexo, Tabela iii), implica aumento da razão de custo-efetividade incremental proporcionalmente menor (entre 3\% e 7\%).

- Custos de medicamentos

Os custos de medicamentos foram recalculados a fim de se analisar o impacto da estimação dos custos de medicamentos fornecidos pelo sistema de saúde valorada por preços específicos praticados no SUS (Banco de Preços em Saúde do Ministério da Saúde). Assumiu-se redução dos custos de medicamentos de 50\%. O custo domiciliar cai para $\mathrm{R} \$ 10,10$ na perspectiva da sociedade, os custos dos casos ambulatoriais para $\mathrm{R} \$ 17,42$ e $\mathrm{R} \$ 53,17$ e os custos dos casos hospitalares para $\mathrm{R} \$ 428,42$ e $\mathrm{R} \$ 468,49$ nas perspectivas do sistema de saúde e sociedade, respectivamente.

Variação negativa de $50 \%$ dos custos de medicamentos resulta em variação positiva da razão de custo-efetividade incremental entre $2 \%$ e $14 \%$, proporcionalmente inferior. Com a redução dos custos dos medicamentos, menos custos são evitados e desta forma a razão de custo-efetividade incremental sobe 
quando se considera a participação pública no fornecimento e compra dos medicamentos.

- Custos de produtos

O consumo de produtos foi extrapolado para o país todo a partir de dois municípios do estado de São Paulo. Considerando que o PIB per capita de Rio Claro (R\$14.154) e Guarulhos (R\$15.068) estão acima do PIB per capita do Brasil (R\$10.692) em 2004, para a análise de sensibilidade considerou-se redução de 30\% dos custos de produtos, não por variação dos custos unitários em si, baseados em preços de mercado, mas por redução de demanda e, portanto, de uso de recursos. $\mathrm{Na}$ perspectiva da sociedade, os custos domiciliar, ambulatorial e hospitalar cairiam para $\mathrm{R} \$ 9,25, \mathrm{R} \$ 50,71$ e $\mathrm{R} \$ 474,08$, respectivamente. A redução de $30 \%$ dos custos com produtos aumenta em cerca de $19 \%$ a razão de custo-efetividade incremental na perspectiva da sociedade.

- Custo de hospitalização

Para a hospitalização por rotavírus assume-se que os valores do SIH e TUNEP adotados no caso base sejam os menores. Não há estudos comparando custos e remunerações de AIH para rotavírus especificamente. Partindo-se do pressuposto que haja uma subestimação deste item de custo, houve na análise de sensibilidade acréscimo de 50\% nos valores de internação. A maioria das internações são feitas no SUS (Anexo, Tabela iii) e a TUNEP, que foi adotada como referência para os custo de internação no sistema de saúde suplementar, parte também da tabela SIH, de modo que o acréscimo de 50\% foi aplicada a todas as hospitalizações. Os custos em 
tratamento hospitalar subiriam para $\mathrm{R} \$ 630,84$ e $\mathrm{R} \$ 670,91$ nas perspectivas do sistema de saúde e sociedade, respectivamente.

A Tabela 4 mostra que aumento de $50 \%$ do custo de hospitalização reduz as razões de custo-efetividade incremental entre $22 \%$ e $45 \%$.

- Custo da dose da vacina

Para a análise de sensibilidade para preço da dose da vacina, foram simuladas reduções de preço de $50 \%$ e $25 \%$. Redução de $50 \%$ do preço, para $\mathrm{R} \$ 9,3$, torna a intervenção econômica da perspectiva da sociedade, uma vez que este preço está abaixo do preço de nivelamento $(\mathrm{R} \$ 12,26)$. Para a perspectiva do sistema de saúde, houve variação proporcionalmente maior (72\%). Também para redução de $25 \%$ do preço (R $\$ 13,95)$, as variações da razão de custo-efetividade incremental foram proporcionalmente maiores.

- Custo de administração

Para a análise de sensibilidade, foram considerados 3 cenários para a variação do de custo de administração $(\mathrm{R} \$ 1,00, \mathrm{R} \$ 5,00$ e $\mathrm{R} \$ 10,00)$. O valor máximo de $\mathrm{R} \$ 10,00^{37}$ baseou-se em estudo para a vacinação de empregados no setor privado feita para o Brasil (Burckel et al, 1999). O custo de administração de $\mathrm{R} \$ 10,65$ estimado em 1997 seria cerca de R\$18,00 em 2004, se corrigido pelo IPCA/IBGE. Assume-se que o valor no sistema público é inferior ao custo estimado no cenário privado mencionado. O aumento do custo de administração de cerca de 4 vezes

\footnotetext{
${ }^{37} \mathrm{O}$ valor de $\mathrm{R} \$ 10,00$ está próximo ao valor máximo de $\mathrm{R} \$ 9,5$ por dose para transporte de vacina BCG (40mg liofilizada). Para caixa com 6 ampolas, o custo é composto pelo frete de $\mathrm{R} \$ 47,00$
} 
aumenta a razão de custo-efetividade incremental entre de 50 e 105\%, dependendo da perspectiva. As demais variações de custo de administração mostram que os resultados apresentam também variações comparativamente menores.

- Taxa de desperdício

A taxa de desperdício aplicado ao modelo de rotavírus $(10 \%)$ veio da literatura internacional (Podewils et al, 2005), dado não haver estimativa nacional. Para análise de sensibilidade do modelo ao parâmetro mencionado considerou-se variação entre $5 \%$ e $15 \%$. Variações da taxa de desperdício têm impacto proporcionalmente menor nos resultados (variação inicial do parâmetro de $+-50 \%$ e variação nos resultados entre +- 6 e 13\%).

\section{- Desconto}

A taxa de desconto foi variada para 5\% para custos e desfechos, conforme recomendação do Ministério da Saúde em suas diretrizes de avaliação econômica (Brasil, 2007). Foi também aplicada a taxa de desconto de $4,76 \%$ calculada para Brasil (Valentim et al, 2008) para período de cinco anos. Mantendo a recomendação máxima de desconto da OMS (2003) para custos (6\%), taxas de desconto menores para desfechos (0 e 3\%) foram simuladas.

Conforme se pode observar todo desconto aplicado aumenta as razões de custo-efetividade incrementais. Como os descontos são aplicados apenas aos custos diretos e indiretos, dependendo da perspectiva, mas não aos custos do programa de 
vacinação $^{38}$, a análise de sensibilidade do parâmetro desconto para o modelo de árvore de decisão para rotavírus apresenta o comportamento das razões de custoefetividade incrementais para o caso de um único investimento inicial não descontado e custos diretos e indiretos futuros descontados. O desconto aplicado aos custos futuros diretos e indiretos implica que, no presente, aqueles são menores e o custo incremental maior, aumentando as razões de custo-efetividade incrementais. Taxas de desconto maiores diminuem o peso dos custos diretos e indiretos evitados no futuro, tornando a imunização menos custo-efetiva.

Reduções da taxa de desconto assim como taxas de desconto menores para desfechos do que custos diminuem o impacto de aumento das razões. As variações de todas as razões reportadas proporcionalmente superam as variações do parâmetro taxa de desconto.

${ }^{38}$ Vide item 4.1 .11 e nota 36. 
Tabela 4. Análise de sensibilidade univariada, estimativas de custos e desconto, rotavírus

\begin{tabular}{|c|c|c|}
\hline \multirow[t]{2}{*}{ Parâmetro variado } & \multicolumn{2}{|c|}{$\begin{array}{c}\text { Variação da Razão de Custo-Efetividade } \\
\text { Incremental }\end{array}$} \\
\hline & Sociedade & Sistema de Saúde \\
\hline \multicolumn{3}{|l|}{ Custo da consulta/SUS (-60\%) } \\
\hline Custo incremental por caso evitado & $\mathrm{R} \$ 23(6,97 \%)$ & $\mathrm{R} \$ 45(2,83 \%)$ \\
\hline Custo incremental por ano de vida salvo & $\mathrm{R} \$ 810(6,97 \%)$ & $\mathrm{R} \$ 1.598(2,83 \%)$ \\
\hline \multicolumn{3}{|l|}{ Custos de medicamentos/SUS (-50\%) } \\
\hline Custo incremental por caso evitado & $\mathrm{R} \$ 24(14,12 \%)$ & $\mathrm{R} \$ 44(2,07 \%)$ \\
\hline Custo incremental por ano de vida salvo & $\mathrm{R} \$ 864(14,12 \%)$ & $\mathrm{R} \$ 1.586(2,07 \%)$ \\
\hline \multicolumn{3}{|l|}{ Custos de produtos (-30\%) } \\
\hline Custo incremental por caso evitado & $\mathrm{R} \$ 25(19,38 \%)$ & $\mathrm{R} \$ 43$ \\
\hline Custo incremental por ano de vida salvo & $\mathrm{R} \$ 903(19,38 \%)$ & $\mathrm{R} \$ 1.554$ \\
\hline \multicolumn{3}{|l|}{ Custo de Hospitalização (+50\%) } \\
\hline Custo incremental por caso evitado & $\mathrm{R} \$ 12(-44,83 \%)$ & $\mathrm{R} \$ 34(-21,84 \%)$ \\
\hline Custo incremental por ano de vida salvo & $\mathrm{R} \$ 418(-44,83 \%)$ & $\mathrm{R} \$ 1.215(-21,84 \%)$ \\
\hline \multicolumn{3}{|l|}{ Preço da Vacina $=R \$ 9,30(-50 \%)$} \\
\hline Custo incremental por caso evitado & Econômica & $\mathrm{R} \$ 12(-71,44 \%)$ \\
\hline Custo incremental por ano de vida salvo & Econômica & $\mathrm{R} \$ 444(-71,44 \%)$ \\
\hline \multicolumn{3}{|l|}{ Preço da Vacina $=R \$ 13,95(-25 \%)$} \\
\hline Custo incremental por caso evitado & $\mathrm{R} \$ 6(-73,34 \%)$ & $\mathrm{R} \$ 28(-35,72 \%)$ \\
\hline Custo incremental por ano de vida salvo & $\mathrm{R} \$ 202(-73,34 \%)$ & $\mathrm{R} \$ 999(-35,72 \%)$ \\
\hline \multicolumn{3}{|l|}{ Custo de administração $=R \$ 1,00,(-62 \%)$} \\
\hline Custo incremental por caso evitado & $\mathrm{R} \$ 16(-23,66 \%)$ & $\mathrm{R} \$ 38(-11,52 \%)$ \\
\hline Custo incremental por ano de vida salvo & $\mathrm{R} \$ 578(-23,66 \%)$ & $\mathrm{R} \$ 1.375(-11,52 \%)$ \\
\hline \multicolumn{3}{|l|}{ Custo de administração $=R \$ 5,00(+89 \%)$} \\
\hline Custo incremental por caso evitado & $\mathrm{R} \$ 28(33,69 \%)$ & $\mathrm{R} \$ 51(16,41 \%)$ \\
\hline Custo incremental por ano de vida salvo & $\mathrm{R} \$ 1.012(33,69 \%)$ & $\mathrm{R} \$ 1.809(16,41 \%)$ \\
\hline \multicolumn{3}{|l|}{ Custo de administração $=R \$ 10,00(+277 \%)$} \\
\hline Custo incremental por caso evitado & $\mathrm{R} \$ 43(105,38 \%)$ & $\mathrm{R} \$ 66(51,32 \%)$ \\
\hline Custo incremental por ano de vida salvo & $\mathrm{R} \$ 1.554(105,38 \%)$ & $\mathrm{R} \$ 2.351(51,32 \%)$ \\
\hline \multicolumn{3}{|l|}{ Taxa de desperdício $=5 \%(-50 \%)$} \\
\hline Custo incremental por caso evitado & $\mathrm{R} \$ 18(-13,33 \%)$ & $\mathrm{R} \$ 41(-6,49 \%)$ \\
\hline Custo incremental por ano de vida salvo & $\mathrm{R} \$ 656(-13,33 \%)$ & $\mathrm{R} \$ 1.453(-6,49 \%)$ \\
\hline Taxa de desperdicio $=15 \%(+50 \%)$ & & \\
\hline Custo incremental por caso evitado & $\mathrm{R} \$ 24(13,33 \%)$ & $\mathrm{R} \$ 46(6,49 \%)$ \\
\hline Custo incremental por ano de vida salvo & $\mathrm{R} \$ 858(13,33 \%)$ & $\mathrm{R} \$ 1.655(6,49 \%)$ \\
\hline
\end{tabular}




\section{Taxa de desconto $=5 \%$}

Custo incremental por caso evitado

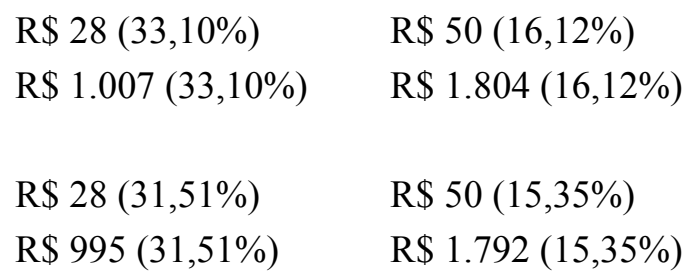

$\mathrm{R} \$ 28(31,51 \%)$

$\mathrm{R} \$ 50(15,35 \%)$ $\mathrm{R} \$ 995(31,51 \%)$

$\mathrm{R} \$ 1.792(15,35 \%)$

Custo incremental por ano de vida salvo

Taxa de desconto $=4,76 \%$

Custo incremental por caso evitado

Custo incremental por ano de vida salvo

Taxa de desconto $=6 \%$ (custos) e 3\% (desfechos)

Custo incremental por caso evitado

Custo incremental por ano de vida salvo

Taxa de desconto $=6 \%$ (custos) e $0 \%$ (desfechos)

Custo incremental por caso evitado

$\mathrm{R} \$ 26(24,75 \%)$

$\mathrm{R} \$ 46(6,57 \%)$

Custo incremental por ano de vida salvo
$\mathrm{R} \$ 49(12,96 \%)$

$\mathrm{R} \$ 1.755(12,96 \%)$

\subsubsection{Análise de impacto orçamentário}

A análise de impacto no orçamento foi feita para as perspectivas do PNI e Ministério da Saúde (Trueman et al, 2001). Foi calculado o custo incremental em cada perspectiva e a proporção deste custo em relação ao respectivo orçamento, para o ano de 2004. O orçamento do Ministério da Saúde para saúde em 2004 foi de $\mathrm{R} \$ 32.364 .874 .621$ (Brasil, 2004) e o orçamento do PNI para o mesmo ano aproximadamente R\$520 milhões (CGPNI/DEVEP/SVS/MS).

A vacinação universal contra rotavírus representa $23,4 \%$ do orçamento do PNI em 2004 (Tabela 5). Na perspectiva do Ministério da Saúde devem ser considerados também os custos diretos no cuidado da doença a serem evitados com a intervenção. Para tal, calculou-se a participação do SUS nos custos mencionados com base em estudo de custo-efetividade de vacinação contra rotavírus com 
estimativas de custos apenas do sistema público (Soárez et al, 2008), e correções para participação também apenas pública em uso de recursos. O SUS responde por aproximadamente $60 \%$ dos custos diretos no cuidado da doença evitados no caso de rotavírus. A vacinação universal contra rotavírus representa $0,36 \%$ do orçamento do MS em 2004. Foram simulados os impactos no orçamento correspondentes às análises de sensibilidade para as estimativas de custos diretos no cuidado da doença com maiores incertezas (custo de consulta e custo de hospitalização). Somente o custo de hospitalização resultou em mudança percentual do custo incremental em relação ao orçamento do MS (Tabela 6).

Após a introdução da vacinação universal contra rotavírus no calendário do PNI em 2006, seu orçamento passou para R\$750 milhões (moeda corrente) (CGPNI/DEVEP/SVS/MS). Em reais de $2004^{39}$, o orçamento de 2006 foi de R\$666 milhões, cerca de $\mathrm{R} \$ 146$ milhões a mais que o orçamento de 2004, tendo sido a vacinação contra rotavírus o fator principal de aumento do orçamento.

Tabela 5. Análise de impacto no orçamento, vacinação universal contra rotavírus, perspectiva do PNI, 2004

\begin{tabular}{lr}
\hline \multicolumn{1}{c}{ Perspectiva do PNI } & reais de 2004 \\
\hline & Caso base \\
Custo anual da vacinação contra rotavírus & 121.673 .966 \\
Custo incremental & 121.673 .966 \\
Orçamento do PNI (2004) & 520.000 .000 \\
Impacto da intervenção no orçamento (\%) & $23,40 \%$ \\
\hline
\end{tabular}

${ }^{39}$ Deflator IPCA/Saúde, IBGE 
Tabela 6. Análise de impacto no orçamento, vacinação universal contra rotavírus, perspectiva do Ministério da Saúde, 2004

\begin{tabular}{|c|c|c|c|}
\hline Perspectiva do MS & & reais de 2004 & \\
\hline & Caso base & $\begin{array}{l}\text { AS custo da } \\
\text { consulta }\end{array}$ & $\begin{array}{c}\text { AS custo da } \\
\text { hospitalização }\end{array}$ \\
\hline $\begin{array}{l}\text { Custo anual da vacinação } \\
\text { contra rotavírus }\end{array}$ & 121.673 .966 & 121.673 .966 & 121.673 .966 \\
\hline $\begin{array}{l}\text { Custos diretos no cuidado da } \\
\text { doença evitados }\end{array}$ & 5.553 .176 & 5.296 .831 & 7.528 .787 \\
\hline Custo incremental & 116.120 .790 & 116.377 .135 & 114.145 .179 \\
\hline Orçamento do MS (2004) & 32.364 .874 .621 & 32.364 .874 .621 & 32.364 .874 .621 \\
\hline $\begin{array}{l}\text { Impacto da intervenção no } \\
\text { orçamento }(\%)\end{array}$ & $0,36 \%$ & $0,36 \%$ & $0,35 \%$ \\
\hline
\end{tabular}




\subsection{Análise de custo-efetividade do programa de vacinação universal de crianças contra varicela}

\subsubsection{Introdução}

A infecção pelo vírus varicela-zoster (VVZ) se manifesta por meio de dois quadros clínicos distintos: a infecção primária se manifesta como varicela, após a qual o vírus estabelece latência (Hambleton et al, 2005). Muitos anos após a infecção primária pode ocorrer reativação do VVZ, que se manifesta como herpes-zoster (Heininger et al, 2006). Aproximadamente $15 \%$ da população apresenta reativação do VVZ durante a vida (Hambleton et al, 2005).

A varicela é doença comum da infância e tem distribuição universal. A grande maioria dos casos ocorre em menores de 10 anos de idade (Hambleton et al, 2005) e praticamente todos os adultos já foram infectados pelo VVZ. Embora considerada doença benigna, complicações como infecções bacterianas secundárias, pneumonia, meningite e encefalite podem ocorrer, com hospitalizações e mortes (Heininger et al, 2006). Devido à sua elevada contagiosidade, a varicela está associada a absenteísmo escolar da criança doente, o que implica freqüentemente na perda de dias de trabalho e de produtividade dos pais e/ou cuidadores.

A vacina contra a varicela, constituída de vírus vivo atenuado, está disponível desde a década de 70 . A vacina tem alta eficácia $(85 \%$ na prevenção contra a varicela e 95\% na prevenção contra doença grave), e é bastante segura e bem tolerada por crianças saudáveis (Hambleton et al, 2005; Seward et al, 2008). Eventos adversos sérios são raros e ocorrem na maioria dos casos em imunodeprimidos (Hambleton et al, 2005; Galea et al, 2008). 
Nos EUA, a introdução da vacina na rotina de imunização das crianças foi seguida de redução significativa da incidência de varicela, tendo sido observada diminuição do número de casos da doença tanto em vacinados como em nãovacinados (proteção de rebanho) (Hambleton et al, 2005a). Houve, também, redução na freqüência de hospitalização e de consultas ambulatoriais por varicela em todas as faixas etárias e redução dos óbitos por varicela como causa básica (Hambleton et al, 2005a; Nguyen, 2005; Zhou et al, 2005; Guris et al, 2008). A redução dos custos médicos diretos associados à assistência médica à varicela foi estimada em $74 \%$ (Zhou et al, 2005).

No Brasil, a vacina contra varicela está disponível desde 2000, e o Programa Nacional de Imunizações (PNI) adota a vacinação seletiva para indivíduos susceptíveis com maior risco de desenvolver doença grave e/ou complicações associadas à varicela (Brasil, 2008). Com essa estratégia de vacinação, menos de 1\% das crianças brasileiras de 1 a 4 anos foram vacinadas contra varicela no ano de 2004. A vacina está também disponível na rede privada. O programa prevê também o uso de imunoglobulina anti-varicela-zoster (VZIg) para profilaxia pós-exposição de indivíduos susceptíveis de alto risco de doença grave (Brasil, 2008).

As principais razões para a vacina contra varicela ainda não ter sido incluída no calendário de vacinação de rotina das crianças são seu alto custo e a percepção de que a varicela é doença benigna e inevitável em crianças saudáveis e, portanto, com menor prioridade do ponto de vista da saúde pública. Aparecem como fatores limitantes adicionais, o risco de mudança do perfil epidemiológico da varicela, com aumento do número de casos em adolescentes e adultos, população que apresenta maior risco de doença grave e complicações, e a preocupação quanto à possibilidade 
de aumento da incidência de herpes-zoster após a implementação da vacinação universal contra varicela, baseada em estudos que sugerem que, em indivíduos com infecção latente pelo VVZ, a re-exposição à varicela resulta em reforço da imunidade anti-VVZ e diminuição do risco de zoster (Wagenpfeil et al, 2004).

A avaliação econômica de vacinação infantil contra varicela conduzida majoritariamente em países desenvolvidos mostrou-se custo-efetiva ou não dependendo da perspectiva, do modelo adotado e dos parâmetros usados (Thiry et al, 2003).

Para o Brasil, foi realizada análise de custo-efetividade (ACE) da vacinação contra varicela na infância, vacina candidata para a introdução no calendário do PNI (Valentim et al, 2008a), a fim de se analisar a custo-efetividade da vacina no país e estimar preços da vacina que atenderiam aos padrões internacionais de custoefetividade.

A ACE a ser apresentada nesta tese utiliza o mesmo modelo e premissas da análise realizada anteriormente ${ }^{40}$ (Valentim et al, 2008a) com outra metodologia para estimativas de custos. As estimativas próprias de custos do sistema de saúde suplementar foram incluídas, sendo que no trabalho anterior a participação privada nos serviços de saúde foi valorada com base nos custos praticados no sistema público, provavelmente subestimados. Foram incluídos também custos de medicamentos no sistema público de saúde.

A tese se diferencia por avaliar separadamente na análise de sensibilidade os itens de custos que apresentam os maiores desafios metodológicos para estimação. A análise de sensibilidade específica para as estimativas de custos aumentam o

\footnotetext{
${ }^{40}$ Parâmetros usados na análise de custo-efetividade da vacinação contra varicela são apresentados no anexo, Tabela vi.
} 
detalhamento do estudo e permite a identificação dos itens de custos com maior influência nos resultados. A seguir são apresentadas as etapas metodológicas da ACE e finalmente discutidas as estimativas de custos.

\subsubsection{População alvo para intervenção}

A população alvo para a vacinação contra varicela é a de crianças aos 12 meses de idade. Dados demográficos vieram da PNAD 2003, sendo que para o estudo de custo-efetividade da vacinação contra varicela toda a população foi considerada no modelo, que incluiu proteção de rebanho. Nova coorte de crianças de 12 meses é vacinada a cada ano, dentro do horizonte temporal definido.

\subsubsection{Descrição das estratégias comparadas}

Duas estratégias foram comparadas, sendo que a estratégia de não vacinar incluiu a vacinação atual de grupos de risco, vacinação esta que não afeta o perfil epidemiológico da doença.

\section{Estratégia 1.}

"Não Vacinar" (manutenção do programa atual de vacinação de indivíduos com maior risco de doença grave e complicações)

\section{Estratégia 2.}

"Vacinar" (vacinação universal na infância - aos 12 meses)

\subsubsection{Horizonte temporal}

O horizonte temporal adotado foi o de 30 anos, período suficiente para se atingir estabilização epidemiológica de doença. 


\subsubsection{Descrição do modelo utilizado}

O modelo de varicela difere do modelo de rotavírus por incorporar proteção de rebanho, proteção indireta conseqüente da chance de contato com infectados ser menor (redução da probabilidade de infecção por suscetíveis). A inclusão da proteção de rebanho é feita através da simulação com modelos dinâmicos.

Toda a população foi analisada, dividida em sete faixas etárias $(<1$ ano, 1-4 anos, 5-9 anos, 10-14 anos, 15-44 anos, 45-64 anos e $>65$ anos).

O modelo dinâmico foi desenvolvido no compilador Microsoft Visual C++ (Microsoft), em sistema operante DOS, para os ajustes na solução da função de soroprevalência e na realização das simulações dos modelos matemáticos.

A modelagem matemática foi baseada em estudo de soroprevalência da infecção pelo VVZ conduzido em Caieiras, São Paulo (Yu et al 2000; 2001). Com base na proporção de soropositivos para cada faixa etária foi proposta uma função de soroprevalência. A partir dos dados sorológicos foi estimada a força de infecção idade e tempo-dependente. Para descrever a dinâmica de transmissão da varicela nesta população foi desenvolvido inicialmente um modelo que representasse a situação atual sem vacinação. Neste modelo adotado assumiu-se que a população total era dividida em três compartimentos: suscetíveis (S), infectados (I) e recuperados (R). Em seguida, para representar a situação após a implementação do programa de vacinação universal, foi adicionado ao modelo o compartimento dos vacinados (V). A passagem dos indivíduos de um compartimento para outro é determinada pelas taxas de transição, sendo escritas por equações diferenciais. 
Os efeitos de proteção de rebanho da vacinação universal contra varicela no modelo respondem à força de infecção variável. Este modelo forneceu para cada ano de análise a força de infecção nas duas estratégias analisadas: sem vacinação e após implementação do programa de vacinação universal, e a partir daí, o número de infectados de cada faixa etária para cada ano do horizonte temporal da análise (30 anos) (Figura 5, Tabela 7).

Para o caso base, considerou-se eficácia de $85 \%$ da vacina e cobertura vacinal de $80 \%$, com mínimo e máximo de $75 \%$ e $85 \%$ para análise de sensibilidade.

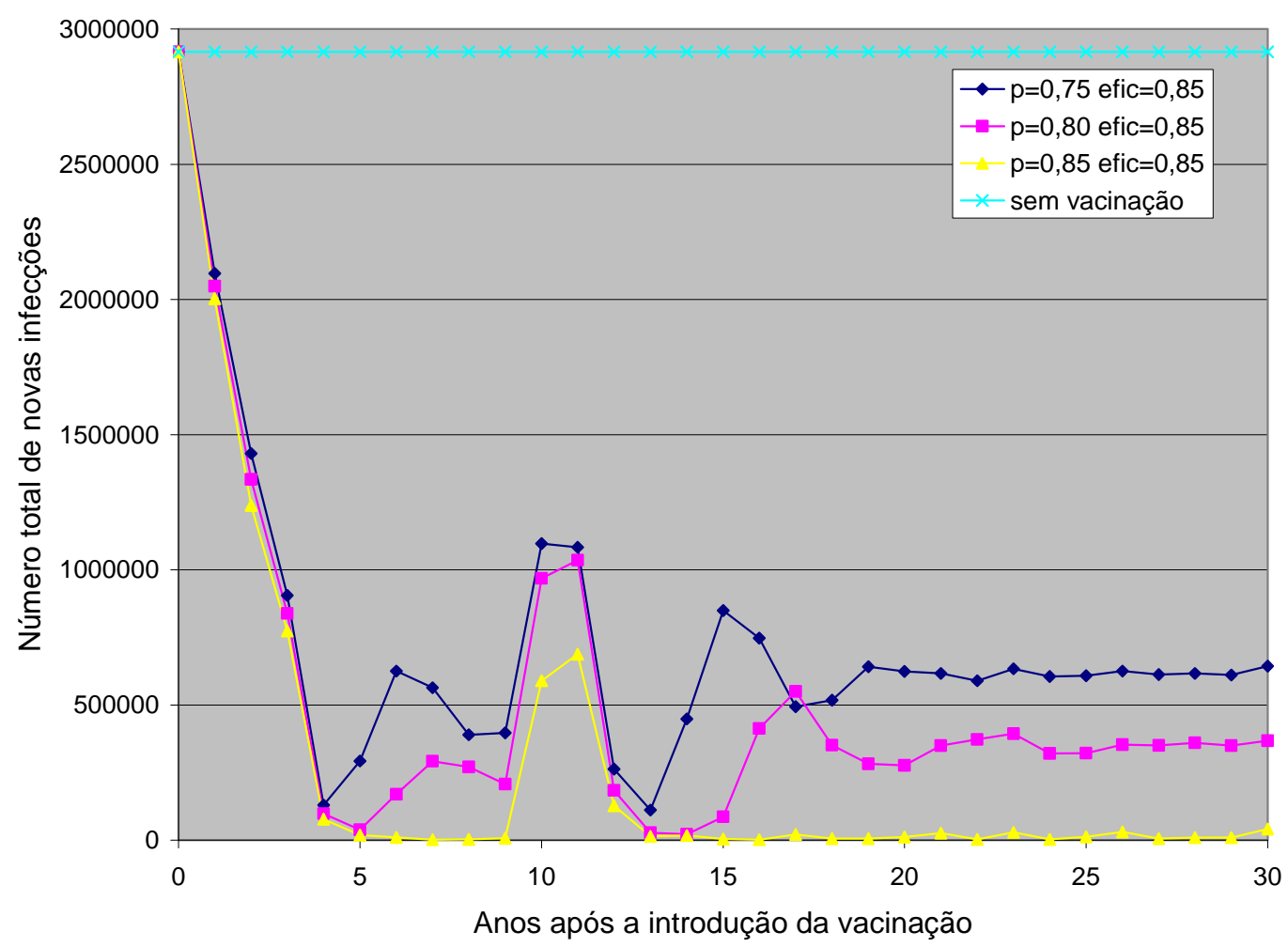

Figura 5. Número total de infectados nas duas estratégias analisadas, varicela, Brasil 
Tabela 7. Número de casos de varicela estimado pelo modelo dinâmico em 30 anos por cenário, Brasil

\begin{tabular}{lc}
\hline \multicolumn{1}{c}{ Cenários } & $\begin{array}{c}\text { Número de casos de varicela } \\
\text { em 30 anos }\end{array}$ \\
\hline Sem Vacinação & 87.458 .806 \\
Vacinação - 75\% de cobertura vacinal & 19.874 .063 \\
Vacinação - 80\% de cobertura vacinal & 13.036 .762 \\
Vacinação - 85\% de cobertura vacinal & 5.795 .109 \\
\hline
\end{tabular}

Foi assumido que a atual estratégia brasileira de vacinação contra varicela não tem impacto na epidemiologia da doença, dada a baixa cobertura vacinal alcançada. O modelo matemático desenvolvido não separou os casos de varicela em vacinados (geralmente mais leves) dos casos de varicela em não vacinados e considerou a efetividade da vacina constante ao longo do tempo. A utilização dos serviços de saúde e os custos decorrentes de possíveis efeitos adversos após a vacinação não foram considerados na análise. Não foi considerado no modelo o possível efeito da vacinação universal sobre a incidência de herpes-zoster.

O número de casos de varicela estimados pelo modelo dinâmico foi tabulado em Excel (Microsoft), onde demais dados epidemiológicos e econômicos foram integrados.

\subsubsection{Perspectivas}

1. Sociedade - na qual todos os custos diretos e indiretos foram valorados;

2. Sistema de saúde - na qual somente os custos diretos médicos foram valorados, incluindo sistemas público e de saúde suplementar. 


\subsubsection{Identificação dos desfechos na análise}

Assim como no estudo de rotavírus, foram calculadas três medidas sínteses: (1) custo incremental por caso evitado, (2) custo incremental por morte evitada e (3) custo incremental por ano de vida salvo. O modelo estimou o número de casos e mortes que ocorreriam nos 30 anos em cada uma das estratégias. Essas medidas de desfecho intermediárias foram convertidas em três medidas de desfecho finais: casos evitados, mortes evitadas e anos de vida ganhos.

Todos os casos estimados pelo modelo matemático, independente do tipo de tratamento, foram considerados para a medida síntese custo incremental por caso evitado. No entanto, para estimativas de custos no caso base, somente os custos ambulatoriais e hospitalares foram considerados, uma vez que não foi possível a avaliação dos casos domiciliares. Assume-se a não procura por serviços de saúde nos casos domiciliares, mais leves. Dada a alta contagiosidade da doença, possível impacto de custos indiretos incorridos em casos domiciliares é analisado na análise de sensibilidade.

\subsubsection{Estimativas de morbidade e mortalidade}

Dados da literatura, dos sistemas de informações do DATASUS e coleta primária de dados foram usados para estimar consultas, hospitalizações, taxas de letalidade e freqüência de seqüela após encefalite por varicela.

Taxas de hospitalização por faixa etária e permanência média foram estimadas com base no número de hospitalizações devido à varicela no SUS (SIH). O valor médio de três anos consecutivos (dois anos não epidêmicos, 2001 e 2002, e um epidêmico, 2003) foi usado. O número de hospitalizações foi ajustado para incluir as hospitalizações no sistema de saúde suplementar (23\%) (PNAD, 2003) (Valentim et 
al, 2008a). A taxa de hospitalização calculada, em relação ao número de casos, foi de $0,15 \%$.

Taxas de letalidade por faixa etária foram estimadas com base no número de mortes cuja causa primária registrada no SIM/DATASUS foi varicela. O número médio de mortes em três anos (2001-2003) foi dividido pelo número estimado de casos de varicela. Anos de vida perdidos foram calculados assumindo expectativa de vida de 69 anos (Censo 2000 IBGE), assim como inicialmente feito em rotavírus.

O número de casos de sequela por encefalite ao ano foi estimado com base no número médio de hospitalizações por encefalite por varicela (SIH/DATASUS) nos três anos (2001-2003), multiplicados pela freqüência esperada de seqüela neurológica permanente em pacientes com encefalite que sobreviveram (15\%) (Whitley, 2005). O número de casos de sequela ao ano foi então dividido pelo número estimado de todos os casos de varicela. A taxa de seqüela foi mantida para ambas as estratégias definidas.

A proporção de casos de varicela que receberam atendimento em serviços de saúde baseou-se na literatura internacional (Brisson et al 2002, 2003), dado não existir estimativa nacional. Assumiu-se que esta proporção seria no máximo igual à de países desenvolvidos. Para Canadá a média para todas as idades foi de $38 \%$ (Brisson et al, 2002). Para o Brasil, cenário hipotético considerou que 30\% dos casos de varicela seriam atendidos em serviços de saúde.

O número médio de consultas e a proporção de pacientes que precisaram de investigação complementar (laboratorial, radiográfica e encaminhamento para especialistas) e tratamento (antiviral, antibióticos etc) basearam-se em coleta primária de dados nos prontuários de três serviços de saúde de São Paulo: um serviço 
de atenção primária (Centro de Saúde Escola Prof. Samuel B. Pessoa, da Faculdade de Medicina da Universidade de São Paulo), um hospital secundário (Hospital Universitário/HU da USP) e um hospital terciário (Instituto da Criança do Hospital das Clínicas/ICr da FMUSP). As instituições acima foram escolhidas por serem representativas dos três níveis de atenção à saúde. Por serem serviços vinculados à instituição de ensino não podem ser consideradas como representativas em uma perspectiva nacional quanto ao volume e tipo de demanda, porém considerou-se que as condutas adotadas nos casos de varicela e zoster atendidos representam o tratamento adotado pelos profissionais no país.

\subsubsection{Estimativas de eficácia e cobertura vacinal}

Considerou-se que a vacinação contra varicela seria feita com dose única com cobertura de $80 \%$ da população a ser vacinada. A incorporação de uma segunda dose da vacina (Marin et al, 2007) no programa de vacinação universal é avaliada na análise de sensibilidade. Assumiu-se que a estratégia atual de vacinação de grupos de risco permaneceria por cinco anos após a implantação do programa de vacinação universal. A eficácia da vacina (85\%) foi mantida constante ao longo dos 30 anos. Eventos adversos da vacina não foram considerados na análise.

No Brazil, imunoglobulina (VZIg - Varicella-Zoster Immunoglobulin) está disponível no SUS para profilaxia pós-exposição de indivíduos suscetíveis com alto risco de desenvolver doença grave (Brasil, 2008). Após a introdução de vacinação universal, a recomendação de uso de VZIg para indivíduos susceptíveis expostos a um caso de varicela continua a mesma, tendo sido assumido que a proporção do 
número de frascos de VZIg / número de casos de varicela permanece igual ao do período pré-vacinação (Brisson et al, 2003).

Parâmetros epidemiológicos, de atendimento em serviços de saúde e referentes à vacina são apresentados no anexo (Tabela vi).

\subsubsection{Estimativas de custos}

As estimativas de custos a seguir baseiam-se no estudo de custo-efetividade de vacinação na infância contra varicela para o Brasil (Valentim et al, 2008a). Neste, a participação do sistema de saúde suplementar foi incluída, tendo sido seus custos valorados com base no sistema público de saúde. Como descrito no item 4.2.1, para esta tese foram incluídas as estimativas de custos específicas do sistema de saúde suplementar e custos de medicamentos no sistema público de saúde.

Todos os custos estão em reais de 2004. Valores coletados em outros anos que não 2004 foram corrigidos por deflatores (IPCA/Saúde, IGP-GI e INPC), de acordo com a variável tratada.

As estimativas de custos para varicela apresentam incerteza maior que as estimativas de custos para rotavírus. Ao contrário de rotavírus, para o qual houve estudo prospectivo de incidência da diarréia por rotavírus, no período de um ano, para se estimar os custos diretos e indiretos das diarréias em geral e por rotavírus em serviços de saúde de dois municípios do estado de São Paulo, a coleta de dados para uso de recursos para o tratamento de varicela ocorreu em apenas três instituições do município de São Paulo, em período curto, utilizando-se a metodologia de rapid assessment. Neste caso, as estimativas de custos de doença, paralelas à avaliação econômica de vacinação contra varicela, ficaram limitadas pela viabilidade de 
elaboração das estimativas de custos dentro do prazo que atendesse à necessidade do Ministério da Saúde, obedecendo a etapas obrigatórias, como a aprovação do projeto por comitês de ética, acesso a sistemas e prontuários, coleta e processamento dos dados.

\section{$\underline{\text { a. Custos diretos }}$}

a.1. Custos diretos no cuidado da doença

Os dados referentes a consultas, encaminhamentos, medicamentos e exames complementares resultam do levantamento primário dos três serviços de saúde de São Paulo citados. Os custos unitários do sistema de saúde suplementar foram pesquisados na ANS, CBHPM e TUNEP e incorporados para esta tese.

\section{a.1.1. Consultas médicas}

Os custos unitários das consultas ${ }^{41}$ foram pesquisados no SIA/DATASUS e na ANS para o ano de 2004. Como discutido em "Material e Métodos", o item consultas apresentou uma dificuldade de levantamento de dado em função da forma de financiamento no sistema público. Em decorrência do $\mathrm{PAB}$, não há valores de consultas a partir de 2000 no SIA/DATASUS. Como não existem ainda estudos para estimar o valor de uma consulta a partir desta forma de financiamento, adotou-se o valor de consulta de especialidade existente no sistema. $\mathrm{O}$ valor de $\mathrm{R} \$ 7,5$ está, desta forma, possivelmente superestimado. Para o sistema de saúde suplementar, foi

\footnotetext{
${ }^{41}$ Os custos unitários de consultas por varicela por faixa etária são apresentados no anexo, Tabela viii
} 
adotado o valor de consulta geral de R $\$ 26,14$ (Sistema de Informações de ProdutosSIP/ANS).

A partir da média de consultas por paciente (ICr e HU), calculou-se o custo com consultas por caso de varicela somente no SUS e no SUS e sistema de saúde suplementar. Para o cálculo conjunto considerou-se a participação dos sistemas público e privado (Anexo, Tabela vii). Foram adicionados os encaminhamentos para especialistas. $^{42}$

\section{a.1.2. Medicamentos}

Para as estimativas de custos de medicamentos, foram trabalhados dois grupos, crianças e adultos, sendo o corte feito aos 10 anos de idade. Para as crianças, as doses dos medicamentos foram calculadas para peso médio de 15 a $20 \mathrm{~kg}$. Foi utilizada a técnica de micro-costing.

Os custos dos medicamentos, com base nos preços ao consumidor da ABCFarma de junho de 2004 com 18\% de ICMS e Banco de Preços em Saúde do Ministério da Saúde, foram estimados a partir de princípios ativos e dosagens recomendadas para crianças e adultos. Houve uma reclassificação por classe terapêutica. Para cada princípio ativo, foi utilizado o menor preço vigente. Para as classes terapêuticas, foi utilizada a média quando mais de um princípio ativo. $\mathrm{O}$ Banco de Preços em Saúde/MS não disponibiliza séries históricas. Foram consideradas as modalidades de compra de pregão e concorrência pública nacional das secretarias estudais de saúde ou consórcio de municípios.

\footnotetext{
42 A média de consultas e encaminhamentos por faixa etária foi de 1,29 ( $<1$ ano), 1,18 (1-4 anos), 1,07 (5-9 anos), 1,16 (10-14 anos), 1,24 (15-44 anos), 1,21 (45-64 anos) e 1,25 ( $>65$ anos).
} 
Os medicamentos aciclovir, amoxicilina, maleato de dexclorfeniramina, paracetamol, prednisona, neomicina mais bacitramina, bromidrato de fenoterol, diclofenaco, permanganato de potássio e o produto talco mentolado foram os considerados para o levantamento de preços para varicela. Foram utilizadas as proporções de prescrição por classe terapêutica observada no ICr e HU. No caso de adultos com varicela, a proporção de uso de antiviral (aciclovir) observada no HU (10\%) foi considerada muito alta, em comparação com a literatura internacional (Banz et al, 2004), tendo sido adotado o valor referido de $2 \%$.

A partir do levantamento de prescrições da coleta primária por classe terapêutica, aplicou-se a freqüência relativa das mesmas aos custos unitários. A estimativa de custo com medicamentos levou em consideração o grupo de idade e o pagador. Nos casos de tratamento ambulatorial, as famílias arcam com os custos de medicamentos prescritos para casa, com exceção dos medicamentos distribuídos pelos serviços de saúde. O custo proporcional de medicamentos prescritos para casa e retirados em unidades públicas de saúde foi adicionado ao custo com medicamentos pagos pelo sistema de saúde. Houve um ajuste pela proporção de dispensação gratuita de medicamentos. Mesmo havendo diferenças entre os diversos medicamentos nas proporções de distribuição dos mesmos pelos serviços públicos, foram adotadas as médias levantadas na PNAD como válida para todos os itens (Anexo, Tabela iv).

Os custos dos medicamentos por caso de varicela foram estimados para quatro cenários diferentes (Tabela 8), variando a valoração dos custos (ABCFarma 
ou Banco de Preço em Saúde/MS ${ }^{43}$ ) e a dispensação pública de medicamentos ou não.

Tabela 8. Custos de medicamentos por caso de varicela em tratamento ambulatorial, de acordo com o pagador e cenário de estimativa de custo, reais de 2004

$\begin{array}{ccc}\text { Custos de medicamentos } & \text { Custos de } & \text { Custos de } \\ \text { para o sistema de saúde } & \begin{array}{c}\text { medicamentos para } \\ \text { a família }\end{array} & \text { medicamentos } \\ & & \end{array}$

Cenário 1: Custos valorados pela ABCFarma

\begin{tabular}{lccc} 
Varicela & & & \\
Crianças & 0,96 & 4,04 & 5,00 \\
Adultos & 1,06 & 10,39 & 11,45 \\
\hline
\end{tabular}

Cenário 2: Custos valorados pela $\mathrm{ABCFarma} \mathrm{com} \mathrm{ajuste} \mathrm{de} \mathrm{medicamentos} \mathrm{prescritos}$ para casa retirados no serviço público de saúde

\begin{tabular}{llcc} 
Varicela & & & \\
Crianças & 2,45 & 2,55 & 5,00 \\
Adultos & 4,76 & 6,69 & 11,45 \\
\hline
\end{tabular}

Cenário 3: Custos valorados pelo Banco de Preços em Saúde/MS e ABCFarma

\begin{tabular}{lccc}
\hline Varicela & & & \\
Crianças & 0,09 & 4,04 & 4,13 \\
Adultos & 0,08 & 10,39 & 10,47 \\
\hline
\end{tabular}

Cenário 4: Custos valorados pelo Banco de Preços em Saúde/MS e ABCFarma com ajuste de medicamentos prescritos para casa retirados no serviço público de saúde
Varicela
Crianças
0,18
2,55
2,73
Adultos
0,26
6,69
6,95

O cenário 4 é o adotado para o caso base da avaliação econômica de vacinação contra varicela, por ser o mais próximo do real. No caso de varicela, assumiu-se que as classes terapêuticas indicadas são contempladas pelo Programa de Assistência Farmacêutica Básica, com preços de compra diferenciados para o sistema público (Banco de Preços em Saúde/MS).

\footnotetext{
${ }^{43}$ Como explicado no item de custos de medicamentos em rotavírus, para esta doença não foi possível reestimar aqueles custos com base nos valores praticados no SUS porque não havia abertura de dados
} 
Como os dados primários para uso de recursos foram colhidos somente no setor público, devemos explicitar que para os custos ambulatoriais as estimativas de prescrição de medicamentos representam valores baixos. Deve-se considerar também que em muitos casos o medicamento não será prescrito, se ele não estiver disponível para distribuição. Outros pressupostos foram o de adesão total ao tratamento medicamentoso, e compra de todos os medicamentos prescritos. Esses pressupostos tendem a superestimar os valores calculados.

\section{a.1.3. Exames complementares}

Os custos unitários dos exames foram pesquisados no SIA/DATASUS e tabela CBHPM. Com bases nas proporções dos exames mencionados levantados no ICr e $\mathrm{HU}^{44}$ e participação do sistema de saúde suplementar em exames (Anexo, Tabela vii), o custo médio de exames para crianças e adultos foi de $\mathrm{R} \$ 1,24$ e $\mathrm{R} \$ 1,64$, respectivamente.

\section{a.1.4. Hospitalizações}

Para os custos hospitalares foram utilizados os CDs de AIH de 2001, 2002 e 2003 do DATASUS, com busca pelas CIDs de varicela. Os custos foram abertos de acordo com as faixas etárias estabelecidas para o modelo. Os valores médios de AIH vieram de 2003, ano mais recente do período selecionado para dados epidemiológicos (inclusão de ano epidêmico) e inflacionados para 2004 pelo IPCA/Saúde. Para a inclusão de custo do sistema de saúde suplementar, assim como

\footnotetext{
para tal.

${ }^{44} \mathrm{O}$ percentual dos casos de varicela nos quais foi solicitado exame foi de $8 \%$ para radiografia de tórax em crianças e $10 \%$ em adultos e $2 \%$ para hemogramas em crianças e $4 \%$ em adultos.
} 
feito para rotavírus, foi utilizada a $\mathrm{TUNEP}^{45}$. Foram aplicadas as freqüências de hospitalizações do SIH/DATASUS ${ }^{46}$ aos valores médios da TUNEP para se obter o valor médio ponderado para varicela no sistema de saúde suplementar. O valor médio estimado de internação por varicela pela TUNEP para todas as idades foi de $\mathrm{R} \$ 561,79$. Comparativamente, o valor médio de AIH de varicela para todas as idades foi de $\mathrm{R} \$ 356,73$. O valor de internação por varicela é aproximadamente $60 \%$ maior no sistema de saúde suplementar. O valor médio da hospitalização por varicela, por faixa etária $^{47}$, no SUS e sistema de saúde sumplementar, variou entre R\$391,84 e R\$571,15 no Brasil em 2004.

\section{a.1.5. Custos do tratamento de seqüela}

Incluiu-se no cálculo dos custos diretos os custos decorrentes do tratamento das seqüelas neurológicas por encefalite. Para o custo de tratamento de seqüelas, foi considerado cálculo da AACD para o custo do tratamento da criança com encefalopatia $^{48}$ (CID G80.0 - Paralisia Cerebral). O custo anual foi de R\$ 8.052,96, em 2006. Esse valor foi deflacionado para 2004, pelo IPCA-Saúde, resultando em

\footnotetext{
${ }^{45}$ A "Compatibilidade Procedimento SIH x CID 10" (SAS/MS) utilizada para varicela foi a seguinte: procedimentos 74300296 (Meningoencefalite a vírus, pediatria) e procedimento 74500287 (Meningoencefalite viral, clinica médica) referentes à CID B01.0 (Meningite por varicela), no valor de $\mathrm{R} \$ 921,9$; procedimento 74300296 (Meningoencefalite a vírus, pediatria) e procedimento 74500287 (Meningoencefalite viral, clinica médica) referentes à CID B01.1 (Encefalite por varicela) no valor de R \$921,9; procedimento 76300072 (Pneumonia em criança) referente à CID B01.2 (Pneumopatia varicelosa) no valor de $\mathrm{R} \$ 610,42$; procedimentos 47810017 (Intercorrência pós- transplante), 91300100 e 91500125 (Lesões superficiais infectadas) e procedimentos 91800013, 91801010, 91802016 (Hospital/dia: intercorrência após transplante de medula óssea) referentes à CID B01.8 (Varicela c/outra complicão) nos valores de $\mathrm{R} \$ 175,5, \mathrm{R} \$ 439,6, \mathrm{R} \$ 614,8$ e $\mathrm{R} \$ 236,25$ para os últimos três. Não há informação para a CID B01.9 (Varicela sem complicação). Não há, também, abertura de faixa etária na TUNEP. Desta forma a inclusão do custo do sistema de saúde suplementar em hospitalizações foi a mesma para todas as idades. Foi usada a participação do sistema de saúde suplementar nas hospitalizações (anexo) para sua inclusão no cenário base.

${ }^{46}$ As freqüências de hospitalização (SIH) por CID são: 0,09\% (B01.0); 0,5\% (B01.1); 84,93\% (B01.2); 13,34\% (B01.8) e 1,14\% (B01.9).

${ }^{47}$ Os custos unitários de hospitalização por varicela por faixa etária são apresentados no anexo, Tabela viii.
} 
custo anual de $\mathrm{R} \$ 7.127,78$. O cálculo do custo total de tratamento de seqüela (multiplicação do custo anual pelo número de casos de seqüelas ao ano) está superestimado uma vez que os pacientes apresentam seqüelas com diferentes níveis de comprometimento e nem todos necessitam de todos os tratamentos. Além disso, o acesso ao tratamento não é estendido a todos, sendo o custo total real inferior.

\section{a.2. Custos diretos não-médicos}

\section{a.2.1. Transporte}

Neste item estão incluídos os custos com transporte até local de atendimento. Os custos com transporte foram incluídos nos tratamentos ambulatorial e hospitalar quando a análise foi feita na perspectiva da sociedade.

Os custos com transporte foram estimados com base no valor da tarifa média de transporte público para capitais brasileiras (Associação Nacional das Empresas de Transportes Urbanos - NTU). O custo com transporte no tratamento ambulatorial levou em consideração o número médio de consultas por faixa etária e encaminhamentos. No tratamento hospitalar de pacientes até 14 anos de idade, além do transporte do próprio paciente, foi adicionado o transporte de cuidadores, calculado pelo número de dias de internação (2 viagens/ dia). Acima da referida idade, foram assumidas 4 viagens, incluindo o cuidador na internação e na alta da mesma acompanhando o paciente.

O deflacionamento dos valores em reais de 2006 foi feito pelo IGP-DI da FGV (deflator adotado pela NTU) para o ano de 2004, resultando em uma tarifa

\footnotetext{
${ }^{48}$ O tratamento para a CID G80.0 na AACD é composto por goteira, consulta, fisioterapia, terapia ocupacional, fonoaudiologia e psicologia.
} 
média de $\mathrm{R} \$ 1,60$. O custo de transporte por varicela variou entre $\mathrm{R} \$ 4,13$ e $\mathrm{R} \$ 15,49^{49}$.

\section{b. Custos indiretos ou de produtividade}

Os custos indiretos nesta análise referem-se ao tempo de trabalho perdido conseqüente de casos de varicela com total recuperação e também para a perda de produtividade do próprio paciente conseqüente de seqüela neurológica. Os custos indiretos foram incluídos nos tratamentos ambulatorial e hospitalar quando a análise foi feita da perspectiva da sociedade.

Para o cálculo dos custos indiretos foi adotado o Método de Capital Humano. Os dados usados para o Brasil foram extraídos dos microdados da PNAD 2003. Considerou-se para renda média a variável "renda mensal de todos os trabalhos" (V4719) ponderada pela proporção de economicamente ativos (PEA) (V4713), ambas as variáveis abertas por gênero e idade. A renda média da PEA foi convertida em renda diária, dividindo-se a renda média por 22 (dias úteis) e trabalhando-se com o total por faixa etária para idade acima de 15 anos. Para idade inferior a 15 anos, a renda usada foi a das mães, no caso a renda das mulheres entre 15 e 44 anos e sua respectiva participação no mercado de trabalho. Indivíduos acima de 65 anos foram tidos como aposentados e fora do mercado de trabalho ${ }^{50}$. O deflacionamento da renda foi feito pelo INPC do IBGE. A renda diária média estimada foi de $\mathrm{R} \$ 15,65$ para idade inferior a 15 anos, $\mathrm{R} \$ 22,01$ para idade entre $15 \mathrm{e}$ 44 anos e R $\$ 27,48$ para idade entre 45 e 64 anos.

\footnotetext{
${ }^{49}$ Os custos unitários de transporte por varicela por faixa etária e tipo de tratamento são apresentados no anexo, Tabela viii.
} 
Os custos indiretos foram calculados separadamente para cada tipo de tratamento. Os dias de ausência do trabalho foram estimados a partir do período de duração característicos da doença, levantamento de bases de dados (SIH/DATASUS), coleta primária e comparação com a literatura nacional (Marcitelli et al, 2006) e internacional (Thiry et al, 2003; Brisson et al, 2003). Os dias de absenteísmo foram também abertos por idade. Como exposto a seguir, o cálculo de custos indiretos foi simplificado ao retratar hipóteses que não apreendem a complexidade de relações existentes entre os doentes e o mercado de trabalho. Representam um modelo reduzido, mas com respaldo na realidade.

Para casos de varicela em tratamento ambulatorial, os cálculos de custos indiretos foram divididos em três etapas. Para crianças menores de 5 anos, dados da literatura para creches em Taubaté foram aplicados para o Brasil (Marcitelli et al, 2006). No estudo mencionado, $53,1 \%$ das mães que trabalham se ausentaram por causa de varicela do filho (a). No estado de São Paulo, é estimado que $10 \%$ das crianças $<5$ anos freqüentam creches oficiais (Comunicação pessoal, Helena Sato). Assumiu-se que nos 90\% restantes que não estão em creches as mães das crianças não se afastam do trabalho quando o filho adoece por ter algum esquema alternativo (parentes que tomam conta etc) ${ }^{51}$. Estabeleceu-se 5 dias de afastamento, considerando o ciclo de 7 dias da varicela e o número de dias úteis na semana. A renda diária foi multiplicada pelo número de dias (5), ponderado pela ausência das mães $(53,1 \%)$ e representação do grupo na população (10\%). Para idades entre 5 e 15 anos, assumiu-se afastamento de meio período (0,5 dia) (para acompanhamento em

\footnotetext{
${ }^{50}$ Esta foi uma suposição simplificadora dado que parte importante dos indivíduos acima de 65 anos são aposentados que trabalham e cuja renda pode ser importante para a sobrevivência de sua família (Lebrão ML, Duarte YAO. Pesquisa SABE, Saúde, Bem-Estar e Envelhecimento, OPAS, 2003).
} 
uma consulta médica) (Thiry et al, 2003), com a renda diária respectiva. Acima de 15 anos, retomou-se a ausência de 5 dias. O custo de produtividade por caso de varicela em tratamento ambulatorial variou entre $\mathrm{R} \$ 4,15$ e $\mathrm{R} \$ 137,41^{52}$.

Para o tratamento hospitalar, os dias de afastamento foram obtidos das médias de permanência de AIH de 2001, 2002 e 2003 para os CIDs de varicela. Para idade economicamente ativa (15 a 64 anos) os dias de internação foram multiplicados por dois, considerando-se o período de busca de tratamento anterior e intervalo de retorno ao trabalho, com base no que já foi feito na literatura (Brisson et al, 2003). Para idade inferior a 15 anos, utilizou-se apenas o período de internação, correspondendo ao afastamento da mãe do trabalho. Os respectivos dias de absenteísmo para varicela para cada faixa etária foram multiplicados pelas rendas diárias. O custo de produtividade por caso de varicela em tratamento hospitalar variou entre $\mathrm{R} \$ 71,98$ e $\mathrm{R} \$ 405,10^{53}$.

Para os casos de seqüelas permanentes, o custo indireto estimado por caso considerou os anos potenciais de trabalho perdidos pelo pacientes com seqüelas, no horizonte temporal de 30 anos. Assumiu-se início do período produtivo aos 18 anos, terminando ao se completar 65 anos. Trabalhou-se com as faixas etárias do modelo, de forma que para as quatro primeiras a idade inicial é 18 anos, enquanto para as duas faixas seguintes o cálculo foi feito com base na idade média do grupo. A renda adotada foi obtida na PNAD (2004), sendo o valor mensal de R\$ 474 multiplicado por 12 para se chegar à renda anual de $\mathrm{R} \$ 5.688$ e trabalhou-se com a expectativa

\footnotetext{
${ }^{51}$ Não foi considerado para o caso base preço sombra de mães fora do mercado de trabalho e preço sombra de cuidadores quando do não absenteísmo quando a mãe trabalha.

52 Os custos de produtividade por varicela por faixa etária em tratamento ambulatorial são apresentados no anexo, Tabela viii.

${ }^{53}$ Os custos de produtividade por varicela por faixa etária em tratamento hospitalar são apresentados no anexo, Tabela viii.
} 
média de vida da população brasileira. Desta forma, alguns casos podem exceder o horizonte temporal de 30 anos do modelo (Comunicação pessoal Mark Sculpher, Universidade de York). Para o cálculo de custo de produtividade de seqüela permanente não foi considerada a perda de produtividade do cuidador, dada a indisponibilidade de dados.

\section{c. Custos por tipo de tratamento e perspectiva}

A composição e divisão dos custos por tipo de tratamento definido foram:

- Ambulatorial: composto por consultas, medicamentos e exames complementares;

- Hospitalar: composto por consultas, medicamentos, produtos, exames complementares e internações.

A Tabela $9^{54}$ resume os custos por caso de varicela para as faixas etárias definidas para o modelo da doença, abertos para os tratamentos ambulatorial e hospitalar nas perspectivas do sistema de saúde e sociedade, comparando as estimativas de custos do estudo de custo-efetividade original (Valentim et al, 2008) e as estimativas de custos para esta tese, com a inclusão de custos específicos do sistema de saúde suplementar e de custos de medicamentos no sistema público de saúde. Considerando a perspectiva da sociedade, houve aumento das estimativas de custos entre $2 \%$ e $23 \%$ em tratamento ambulatorial e entre $1 \%$ e $14 \%$ em tratamento hospitalar.

\footnotetext{
${ }^{54}$ Custos unitários são apresentados no anexo, Tabela viii.
} 
Tabela 9. Custos por caso de varicela, de acordo com faixa etária, tipo de tratamento, perspectiva e metodologia de estimativas de custos, Brasil, reais de 2004

\begin{tabular}{|c|c|c|c|c|c|c|c|}
\hline \multirow[t]{3}{*}{ Faixa Etária } & \multirow[t]{3}{*}{ Tratamento } & \multicolumn{6}{|c|}{ Perspectivas } \\
\hline & & \multicolumn{3}{|c|}{ Sociedade } & \multicolumn{3}{|c|}{ Sistema de Saúde } \\
\hline & & (a) & (b) & $(\Delta)$ & (a) & (b) & $(\Delta)$ \\
\hline \multirow[t]{2}{*}{$<1 \mathrm{a}$} & Ambulatorial & 23,34 & 28,25 & $21 \%$ & 12,51 & 17,42 & $39 \%$ \\
\hline & Hospitalar & 454,52 & 510,19 & $12 \%$ & 353,59 & 409,3 & $16 \%$ \\
\hline \multirow[t]{2}{*}{$1-4 a$} & Ambulatorial & 22,14 & 26,48 & $20 \%$ & 11,67 & 16,01 & $37 \%$ \\
\hline & Hospitalar & 472,00 & 523,07 & $11 \%$ & 370,30 & 421,4 & $14 \%$ \\
\hline \multirow[t]{2}{*}{$5-9 a$} & Ambulatorial & 21,04 & 25,85 & $23 \%$ & 10,91 & 15,72 & $44 \%$ \\
\hline & Hospitalar & 473,18 & 536,65 & $13 \%$ & 371,82 & 435,3 & $17 \%$ \\
\hline \multirow[t]{2}{*}{$10-14 \mathrm{a}$} & Ambulatorial & 28,37 & 31,45 & $11 \%$ & 13,83 & 16,91 & $22 \%$ \\
\hline & Hospitalar & 455,23 & 520,95 & $14 \%$ & 362,31 & 428 & $18 \%$ \\
\hline \multirow[t]{2}{*}{$15-44 a$} & Ambulatorial & 135,34 & 139,11 & $3 \%$ & 14,65 & 18,42 & $26 \%$ \\
\hline & Hospitalar & 735,08 & 807,5 & $10 \%$ & 344,36 & 416,8 & $21 \%$ \\
\hline \multirow[t]{2}{*}{$45-64 a$} & Ambulatorial & 162,39 & 165,97 & $2 \%$ & 14,43 & 18 & $25 \%$ \\
\hline & Hospitalar & 990,82 & $1.035,14$ & $4 \%$ & 431,36 & 475,7 & $10 \%$ \\
\hline \multirow[t]{2}{*}{$+65 \mathrm{a}$} & Ambulatorial & 25,42 & 29,26 & $15 \%$ & 14,73 & 18,57 & $26 \%$ \\
\hline & Hospitalar & 602,97 & 606,81 & $1 \%$ & 585,88 & 589,7 & $1 \%$ \\
\hline
\end{tabular}

(a) Valentim et al (2008a); (b) Estimativas de custos recalculadas para esta tese, com a inclusão de custos específicos do sistema de saúde suplementar e de custos de medicamentos no sistema público de saúde.

Seguindo a lógica de tratamento progressivo descrito anteriormente, os custos de tratamento agregam os níveis anteriores. Separando os custos por perspectiva, a perspectiva da sociedade excede a do sistema de saúde ao incluir os custos de transporte, os custos de medicamentos desembolsados pelas famílias e os custos de produtividade.

d. Custos do programa nacional de imunização contra varicela (vacina e VZIG)

Os custos do programa de vacinação foram calculados a partir dos preços dos imunobiológicos praticados no sistema público, no Brasil. Assume-se que a vacinação é totalmente feita nos serviços públicos de saúde. 
O preço da dose de vacina de varicela fornecido pelo PNI foi R\$ 43,19 (Coordenação de Imunobiológicos/CGPNI). Assumiu-se uma taxa de desperdício de 10\% e um custo de administração de R \$2,65 (US\$1) (Podewils et al, 2005). O custo total da vacina de varicela foi então de $\mathrm{R} \$ 50,16$. Como apresentado no item de população alvo, a coorte de crianças vacinada a cada ano é a de crianças de 12 meses de idade (2.619.813, PNAD 2003).

O número de frascos de VZIg foi baseado na média para os anos de 2001 a 2003 (7.617), a um preço de R \$325,75 (Coordenação de Imunobiológicos / CGPNI). Nos 5 primeiros anos de vacinação, assumiu-se a continuidade da estratégia atual (98.181 doses ao ano). No período de 2001 a 2003, 50\% das doses de vacina foram administradas para crianças de 1 a 4 anos, portanto o número de doses utilizadas para a vacinação de grupos especiais deve diminuir a cada ano após a implantação da vacinação universal. Entretanto, uma vez que a taxa de decréscimo ano a ano não pôde ser estimada, a redução do número de doses não foi incorporada ao modelo no caso base, apenas na análise de sensibilidade.

\subsubsection{Desconto}

Os custos decorrentes da doença, os custos do programa de vacinação e os desfechos foram trazidos a valor presente a uma taxa de desconto anual de $6 \%$ (OMS, 2003). Como no modelo de varicela a cada ano nova coorte de crianças são vacinadas, ao contrário do modelo de rotavírus, os custos de vacinação foram descontados.

Para análise de sensibilidade, taxa de desconto de 5\% sugerida pelo MS (Brasil, 2007) e média da taxa de desconto social calculada para Brasil para 30 anos 
(horizonte temporal do modelo de varicela) de 4,82\% foram consideradas (Valentim et al, 2008), assim como taxas de desconto menores para desfechos (0 e 3\%).

\subsubsection{Custo-efetividade da vacinação contra varicela}

A Tabela 10 apresenta os resultados de desfechos e de custos do programa de vacinação universal contra varicela comparado à estratégia atual (vacinação de grupos de risco) em ambas as perspectivas nos 30 anos do programa. A partir das premissas do caso base (esquema vacinal com 1 dose, eficácia da vacina de $85 \%$ e cobertura de $80 \%$ ), o programa de vacinação universal preveniria 74.422 .058 casos, 112.292 hospitalizações e 2.905 mortes por varicela.

O programa de vacinação resultaria em custos adicionais aos serviços de saúde. Apesar das economias de custo total (direto e indireto) de R \$ 765.509.482 (R\$ 25.516.983 ao ano) na perspectiva da sociedade e de $\mathrm{R} \$ 471.035 .376(\mathrm{R} \$ 15.701 .179$ aa) na perspectiva do sistema de saúde, os custos de vacinação adicionais seriam de $\mathrm{R} \$ 3.030 .656 .287(\mathrm{R} \$ 101.021 .876 \mathrm{aa})$.

A inclusão de custos específicos do sistema de saúde suplementar e de custos de medicamentos no sistema público de saúde aumentou o custo total da doença na perspectiva da sociedade em aproximadamente $11 \%$, e $27 \%$ na perspectiva do sistema de saúde, assim como produziu maiores economias (acréscimo aproximado de $16 \%$ na perspectiva da sociedade e $29 \%$ na perspectiva do sistema de saúde) com a introdução da vacinação universal contra varicela (Tabela 10). 
Tabela 10. Estimativas de custos e impacto da doença associados à varicela, segundo perspectiva da análise e estratégia de vacinação, assumindo eficácia da vacina de $85 \%$ e cobertura vacinal de $80 \%$ (cenário-base), acumulados para horizonte temporal de 30 anos

\begin{tabular}{|c|c|c|c|c|}
\hline \multirow[b]{2}{*}{ Variável } & \multicolumn{2}{|r|}{ Sociedade } & \multicolumn{2}{|r|}{ Sistema de Saúde } \\
\hline & Estratégia atual & $\overline{\text { Estratégia de vacinação universal }}$ & Estratégia atual & Estratégia de vacinação universal \\
\hline \multicolumn{5}{|l|}{ Custo $^{a}$} \\
\hline Custo total da doença ${ }^{b, c}$ & 944.949.381 & 179.439.899 & 555.958 .980 & 84.923 .603 \\
\hline Custo total evitado & & 765.509 .482 & & 471.035.376 \\
\hline Mudança nos custos da doença & & $-81 \%$ & & $-85 \%$ \\
\hline Custo total da doença ${ }^{\mathbf{b}, \mathbf{d}}$ & 821.368 .711 & 161.292 .301 & 423.378 .310 & 66.776 .005 \\
\hline Custo total evitado & & 660.076 .410 & & 365.602 .305 \\
\hline Mudança nos custos da doença & & $-80 \%$ & & $-85 \%$ \\
\hline \multicolumn{5}{|l|}{ Custo da intervenção ${ }^{\mathrm{e}}$} \\
\hline A R\$ 43,19/dose & 147.739 .823 & 3.178.396.110 & 147.739 .823 & 3.178.396.110 \\
\hline Custo adicional de vacinação & & 3.030 .656 .287 & & 3.030 .656 .287 \\
\hline \multicolumn{5}{|l|}{ Impacto da doença } \\
\hline $\mathrm{N}^{\circ}$ total de casos & 87.458 .820 & 13.036 .762 & 87.458 .820 & 13.036 .762 \\
\hline $\mathrm{N}^{\mathrm{o}}$ de casos evitados & & 74.422 .058 & & 74.422 .058 \\
\hline Mudança no número de casos & & $-85 \%$ & & $-85 \%$ \\
\hline $\mathrm{N}^{\mathrm{o}}$ total de casos nos serviços de saúde & 26.372 .837 & 3.933 .931 & 26.372 .837 & 3.933 .931 \\
\hline $\mathrm{N}^{\mathrm{o}}$ de casos evitados nos serviços de saúde & & 22.438 .906 & & 22.438 .906 \\
\hline Mudança no número de casos nos serviços & & $-85 \%$ & & $-85 \%$ \\
\hline $\mathrm{N}^{\mathrm{o}}$ total de mortes & 3.580 & 675 & 3.580 & 675 \\
\hline $\mathrm{N}^{\mathrm{o}}$ de mortes evitadas & & 2.905 & & 2.905 \\
\hline Mudança no número de mortes & & $-81 \%$ & & $-81 \%$ \\
\hline $\mathrm{N}^{\circ}$ total de anos de vida perdidos & 194.828 & 34.105 & 194.828 & 34.105 \\
\hline $\mathrm{N}^{\mathrm{o}}$ de anos de vida ganhos & & 160.723 & & 160.723 \\
\hline Mudança no número de anos de vida perdidos & & $-83 \%$ & & $-83 \%$ \\
\hline $\mathrm{N}^{\mathrm{o}}$ total de hospitalizações & 135.195 & 22.903 & 135.195 & 22.903 \\
\hline $\mathrm{N}^{\mathrm{o}}$ de hospitalizações evitadas & & 112.292 & & 112.292 \\
\hline Mudança no número de hospitalizações & & $-83 \%$ & & $-83 \%$ \\
\hline
\end{tabular}


Para calcular a razão de custo-efetividade incremental, definida pela divisão do custo pela efetividade incremental, foi utilizada a fórmula:

Razão de Custo-Efetividade $=$ Custo com Estratégia atual - Custo com Estratégia de Incremental Vacinação Universal

Desfecho da Estratégia atual - Desfecho da Estratégia de Vacinação Universal

As razões de custo-efetividade incremental são apresentadas na Tabela 11. Como discutido na apresentação de resultados de rotavírus, não existe limiar nacional de custo-efetividade. A OMS sugere limiar baseado no PIB (WHOCHOICE). Caso uma intervenção tenha razão de custo-efetividade incremental menor que 1 x PIB per capita é considerada muito custo-efetiva. No intervalo entre 1 x PIB per capita e 3 x PIB per capita é custo-efetiva e acima de 3 x PIB per capita não mais custo-efetiva. A OMS usa DALYs como desfecho da razão incremental neste critério de limiar de custo-efetividade.

No caso de varicela, existe morbidade após o quadro agudo para os casos de seqüela. No entanto, não existem pesos dos DALYs específicos para varicela (OMS), e de modo geral as avaliações econômicas de vacinação contra varicela não consideraram medidas de desfecho combinadas de morbidade e mortalidade QALY ou DALY (Huse et al 1994; Lieu et al 1994; Beutels et al 1996; Coudeville et al. 1999; Scuffham et al 1999; Díez Domingo et al 1999; Scuffham et al 2000; Brisson et al 2002; Getsios et al 2002; Bans et al 2003; Hanslik et al 2003; Hsu et al 2003; Coudeville et al 2004; Thiry et al 2004; Ginsberg et al 2004; Pena-Rey et al 2004; Goldman et al 2005; Coudeville et al 2005; Lenne et al 2006) havendo cálculo 
específico de QALY apenas para Reino Unido (Brisson et al, 2003), portanto questionável para generalização. Apesar das limitações, anos de vida salvos continuam a medida de desfecho.

Considerando o PIB per capita do Brasil de R\$ 10.692 (IBGE) em 2004, o programa de vacinação universal contra varicela é custo-efetivo em ambas as perspectivas da sociedade e do sistema de saúde. Ao contrário de rotavírus, a vacinação contra varicela é apenas custo-efetiva, mas não muito custo-efetiva.

A inclusão das estimativas de custos do sistema de saúde suplementar e de custos de medicamentos no sistema público de saúde reduziu o custo incremental por ano de vida salvo em aproximadamente $4 \%$ nas duas perspectiva (sociedade e em sistema de saúde), com e sem desconto, em comparação com estudo com estimativas de custos baseados apenas no SUS (Valentim et al, 2008a).

A vacinação universal contra varicela ainda não faz parte do calendário do PNI. Os resultados do estudo de avaliação econômica apóiam a introdução da vacina por critérios técnicos de custo-efetividade caso o PNI adotasse o limiar de intervenção custo-efetiva, o que não aconteceria para um limiar de intervenção muito custo-efetiva. 
Tabela 11. Custo-efetividade da vacinação contra varicela por perspectiva e metodologia de estimativas de custos, Brasil

\begin{tabular}{|c|c|c|}
\hline $\begin{array}{l}\text { Razão de custo-efetividade incremental } \\
\text { (estimativas de custos para a tese)* }\end{array}$ & Sociedade & Sistema de Saúde \\
\hline \multicolumn{3}{|l|}{ Custos e desfechos não descontados } \\
\hline Custo incremental por caso evitado & $\mathrm{R} \$ 30$ & $\mathrm{R} \$ 34$ \\
\hline Custo incremental por morte evitado & $\mathrm{R} \$ 779.690$ & $\mathrm{R} \$ 881.052$ \\
\hline Custo incremental por AVS & $\mathrm{R} \$ 14.093$ & $\mathrm{R} \$ 15.926$ \\
\hline \multicolumn{3}{|l|}{ Custos e desfechos descontados (6\%) } \\
\hline Custo incremental por caso evitado & $\mathrm{R} \$ 16$ & $\mathrm{R} \$ 18$ \\
\hline Custo incremental por morte evitado & $\mathrm{R} \$ 808.923$ & $\mathrm{R} \$ 901.111$ \\
\hline Custo incremental por AVS & $\mathrm{R} \$ 14.834$ & $\mathrm{R} \$ 16.524$ \\
\hline \multicolumn{3}{|c|}{$\begin{array}{l}\text { * Inclusão de custos específicos do sistema de saúde suplementar (consulta, exames, hospitalização) e } \\
\text { inclusão de custos dos medicamentos no sistema público de saúde. }\end{array}$} \\
\hline $\begin{array}{l}\text { Razão de custo-efetividade incremental } \\
\text { (estimativas de custos do estudo original)** }\end{array}$ & Sociedade & Sistema de Saúde \\
\hline \multicolumn{3}{|l|}{ Custos e desfechos não descontados } \\
\hline Custo incremental por caso evitado & $\mathrm{R} \$ 32$ & $\mathrm{R} \$ 36$ \\
\hline Custo incremental por morte evitado & $\mathrm{R} \$ 815.982$ & $\mathrm{R} \$ 917.343$ \\
\hline Custo incremental por AVS & $\mathrm{R} \$ 14.749$ & $\mathrm{R} \$ 16.582$ \\
\hline \multicolumn{3}{|l|}{ Custos e desfechos descontados (6\%) } \\
\hline Custo incremental por caso evitado & $\mathrm{R} \$ 17$ & $\mathrm{R} \$ 19$ \\
\hline Custo incremental por morte evitado & $\mathrm{R} \$ 844.109$ & $\mathrm{R} \$ 936.297$ \\
\hline Custo incremental por AVS & $\mathrm{R} \$ 15.479$ & $\mathrm{R} \$ 17.170$ \\
\hline
\end{tabular}

** Valentim et al (2008a)

AVS: ano de vida salvo

Foi calculado o preço de nivelamento (breakeven), que é o preço da dose da vacina para o qual os custos com o programa de vacinação universal igualam os custos com a estratégia atual. Na perspectiva da sociedade, o preço de nivelamento da dose da vacina é de $R \$ 8,59$ e na perspectiva do sistema de saúde $R \$ 4,36$, redução 
de aproximadamente $90 \%$ nesta perspectiva em relação ao preço de compra da vacina $(\mathrm{R} \$ 43,19)$.

\subsubsection{Análise de sensibilidade}

Em análise de sensibilidade univariada (Valentim et al, 2008a) dos parâmetros do modelo como um todo, os seguintes foram variados: proporção dos casos de varicela atendidos em serviços de saúde, taxas de hospitalização, letalidade e sequelas; cobertura vacinal; número de doses do esquema vacinal; taxa de desperdício; número de doses anuais da vacina mantendo-se estratégia de vacinação dos grupos de risco; custos de tratamentos hospitalar e ambulatorial, preços da dose da vacina e custo de administração da vacina. A análise de sensibilidade mostrou que os resultados do estudo de custo-efetividade do programa são sensíveis ao preço da vacina e ao número de doses da vacina no esquema vacinal.

Para esta tese, as estimativas de custos de varicela apresentadas têm seu impacto analisado na sensibilidade das razões de custo-efetividade incrementais. As análises de sensibilidade univariadas são feitas em relação às razões incrementais cujos custos e desfechos não foram descontados.

Análise de sensibilidade univariada de limiar (threshold analysis) (Walker et al, 2001) foi conduzida com o propósito de encontrar o preço da vacina com esquemas de 1 e 2 doses que tornariam a intervenção muito custo-efetiva, de acordo com critério recomendado pela OMS. 


\subsubsection{Análise de sensibilidade para estimativas de custos e desconto}

Os seguintes itens de custos e desconto foram considerados na análise de sensibilidade univariada (Tabela 12):

- Custo de consulta

Como discutido na estimativa de custo de consulta, o valor de consulta de especialista do SUS está superestimado, considerando o financiamento per capita via PAB. Para análise de sensibilidade, variou-se o custo da consulta só no sistema público para menos da metade $(\mathrm{R} \$ 3,00)$. A variação de mais de $50 \%$ para baixo do valor da consulta no SUS resultou em aumento da razão de custo-efetividade incremental em menos de 4\%. Considerando que as consultas no SUS representam $73 \%$ do total de consultas, pode-se afirmar que os resultados são pouco sensíveis ao parâmetro custo de consulta.

- Custos de medicamentos

Conforme apresentado no item de estimativas de custos de medicamentos para varicela, quatro cenários foram considerados, com base na fonte de valoração (ABCFarma e Banco de Preços em Saúde/MS) e ajuste de medicamentos prescritos para casa retirados no serviço público de saúde.

Para a análise de sensibilidade são testados os cenários 1 (custos valorados pela ABCFarma), 2 (custos valorados pela ABCFarma com ajuste de medicamentos prescritos para casa retirados no serviço público de saúde) e 3 (custos valorados pelo Banco de Preços em Saúde/MS e ABCFarma). Nos cenário 1 e 2, como os custos 
valorados pela ABCFarma são mais altos, usar estas estimativas implica em reduções da razão de custo-efetividade incremental, uma vez que maiores custos serão evitados com a intervenção de vacinação universal contra varicela. No cenário 2 , como o sistema público arca com mais custos com medicamentos, a variação do resultado na perspectiva sistema de saúde aumenta. As variações são menores quando os custos são estimados pelo Banco de Preços em Saúde/MS (cenário 3), sendo este também incluído no caso base (cenário 4). De modo geral, as variações dos diferentes cenários para estimativa de custos de medicamentos não alteraram muito os resultados. Isto porque para varicela os custo com medicamentos não são tão altos (medicamentos mais caros apenas para casos com complicação). Para doenças com custos altos de medicamentos, as variações dos resultados serão maiores para diferentes formas de se estimar tais custos.

- Custo de hospitalização

Para a hospitalização para varicela assume-se que os valores do SIH/DATASUS e TUNEP adotados no caso base sejam os menores. Não há estudos comparando custos e remunerações de AIH para varicela especificamente. Partindose do pressuposto que haja uma subestimação deste item de custo, houve na análise de sensibilidade acréscimo de 50\% nos valores de internação. A maioria das internações são feitas no SUS (Anexo, Tabela vii) e a TUNEP, que foi adotada como referência para os custos de internação no sistema de saúde suplementar, parte também da tabela $\mathrm{SIH}$, de modo que o acréscimo de $50 \%$ foi aplicada a todas as hospitalizações. 
A Tabela 12 mostra que aumentos do custo de hospitalização reduzem as razões de custo-efetividade incremental. No entanto, os resultados são pouco sensíveis a variações deste parâmetro, dado que a taxa de hospitalização para varicela é baixa (cerca de $0,15 \%$ em relação ao número de casos).

- Custos de produtividade

As estimativas de custos de produtividade no caso base não consideraram os casos domiciliares. Para análise de sensibilidade, assume-se que para aqueles casos a perda de produtividade seja semelhante aos casos ambulatoriais, dada a contagiosidade da doença. A inclusão de perda de produtividade para casos domiciliares reduz a razão incremental de custo-efetividade em 12,33\% na perspectiva da sociedade. No entanto, a intervenção ainda continua acima do limiar de muito custo-efetiva.

Para os custos de produtividade por seqüela, não foi considerada no caso base aumento de produtividade ao longo da vida. Para a análise de sensibilidade, considerou-se aumento de produtividade do trabalho de $1 \%$ ao ano, com base em cálculo da produtividade do capital humano no Brasil entre $1950-2000$ de $0,7 \%{ }^{55}$ ao ano (Pessôa et al, 2003). O aumento de produtividade de $1 \%$ aa da renda perdida em decorrência de seqüela resultou em redução da razão de custo-efetividade incremental de $0,66 \%$, quase proporcional.

\footnotetext{
${ }^{55}$ Série interrompida de produtividade do IBGE entre 1991 e 1999 apresentou média anual de 2,43\% para a produtividade total do trabalho. Já o reajuste anual real de renda com base no salário mínimo entre 1945 e 2005 foi 2,35\% (IPEADATA, Acesso: 31 de janeiro de 2006).
} 
- Número de doses da vacina

Segunda dose da vacina, administrada em crianças entre 4 e 6 anos de idade, é recomendada na rotina de imunização dos EUA (Marin et al, 2007) após constatação de que após a implementação do programa de vacinação universal a maioria dos casos de varicela ocorria entre as pessoas vacinadas (Guris et al, 2008). Uma vez que o objetivo inicial do programa de vacinação universal contra varicela é reduzir as complicações decorrentes de doença grave, casos leves de varicela ocasionais em vacinados não significam falha do esquema de vacinação com dose única (Patrick, 2007). Outros países (Austrália, Canadá, Alemanha, Coreía do Sul e Uruguai) implementaram o programa de vacinação universal de uma dose (SadzotDelvaux et al, 2008; Macartney et al, 2008; Uruguai, 2008). Entretanto, países que considerem vacinação universal contra varicela devem analisar as vantagens e desvantagens dos esquemas vacinais com 1 e 2 doses.

Comparado com 1 dose, o esquema de vacinação com 2 doses é associado com eficácia maior e menor risco de varicela em vacinados (Kuter et al, 2004). Contudo, tem um grande impacto nos custos do programa de vacinação universal (Zhou et al, 2008).

Neste estudo de custo-efetividade de vacinação contra varicela, o esquema de vacinação universal com 2 doses, ao preço atual $(\mathrm{R} \$ 43,19)$, torna o programa não custo-efetivo. As variações das razões de custo-efetividade incrementais são proporcionalmente maiores em ambas as perspectivas, uma vez que a introdução de uma segunda dose implica em custos adicionais de administração e desperdício. A análise foi conservadora, uma vez que redução de morbidade e de utilização de 
recursos de saúde é esperada com aquele esquema (Kuter et al, 2004; Zhou et al, 2008).

- Custo da dose da vacina

O preço da vacina tem grande impacto no programa de vacinação contra varicela, como reportados em diversas avaliações econômicas (Lieu et al, 1994; Hsu et al, 2003; Banz et al, 2003; Ginsberg et al, 2004; Brisson et al, 2002)

Assume-se que o preço adotado para o caso base é o preço máximo a ser pago pelo Ministério da Saúde para a compra da vacina, via Fundo Rotatório/OPAS. Considerando que a vacinação universal contra varicela aumentaria o número de doses compradas de aproximadamente 100 mil para cerca de 2,8 milhões ao ano, é esperada redução do preço da vacina com a escala maior de compra (Comunicação Pessoal Gabriel Oselka, Reunião CTAI, Brasília, 2007).

Para a análise de sensibilidade para preço da dose da vacina, foram simuladas reduções de preço de $50 \%$ e $25 \%$. Redução de $50 \%$ do preço, para $\mathrm{R} \$ 21,60$, resulta em variação proporcionalmente maior, chegando a $63 \%$ na perspectiva da sociedade, assim como redução de $25 \%(\mathrm{R} \$ 32,40)$ implica redução da razão de custo-efetividade incremental de mais de 30\%, na mesma perspectiva. Com exceção da perspectiva do sistema de saúde com redução de $25 \%$ do preço da vacina, todas as demais tornam a intervenção muito custo-efetiva.

Análise de sensibilidade univariada de limiar (threshold analysis) indicou necessidade de redução do preço de vacina para tornar a intervenção muito custoefetiva. O preço da dose da vacina deve ser menor que $\mathrm{R} \$ 29,05$ e $\mathrm{R} \$ 33,28$ no esquema de vacinação com 1 dose e $\mathrm{R} \$ 13,32$ e R\$ 15,44 no esquema com 2 doses, 
sob as perspectivas do sistema de saúde e sociedade, respectivamente, de forma a tornar a vacinação universal contra varicela muito custo-efetiva. A redução de preço no esquema com 2 doses é maior que a metade do preço no esquema com 1 dose quando muito custo-efetivo em função do aumento conjunto de custo de administração e taxa de desperdício com a dose adicional.

- Custo de administração

Assim como para rotavírus, na análise de sensibilidade para o custo de administração foram considerados 3 cenários para a variação do custo de administração ( $\mathrm{R} \$ 1,00, \mathrm{R} \$ 5,00$ e $\mathrm{R} \$ 10,00)$. O valor máximo de $\mathrm{R} \$ 10,00^{56}$ baseou-se em estudo para a vacinação de empregados no setor privado feita para o Brasil (Burckel et al, 1999). O custo de administração de R\$10,65 estimado em 1997 seria cerca de $\mathrm{R} \$ 18,00$ em 2004, se corrigido pelo IPCA/IBGE. Assume-se que o valor no sistema público é inferior ao custo estimado no cenário privado mencionado.

Aumento do custo de administração de cerca de 4 vezes aumenta a razão de custo-efetividade incremental por volta de $20 \%$, proporcionalmente menor. O modelo de varicela é menos sensível a variações do custo de administração do que rotavírus, uma vez que para esta doença duas doses da vacina são requeridas, aumentando o peso do custo de administração. Variação do custo de administração para $\mathrm{R} \$ 1,00$ e $\mathrm{R} \$ 5,00$ tem comportamento semelhante à variação da taxa de desperdício para 5\% e 15\%, como mostrado a seguir.

\footnotetext{
${ }^{56}$ Vide nota 37.
} 
- Taxa de desperdício

A taxa de desperdício aplicado ao modelo de varicela (10\%) veio da literatura internacional (Podewils et al, 2005), dado não haver estimativa nacional. Para análise de sensibilidade do modelo ao parâmetro mencionado considerou-se variação entre $5 \%$ e $15 \%$. Variações da taxa de desperdício têm impacto proporcionalmente menor nos resultados.

\section{- Desconto}

A taxa de desconto foi variada para 5\% para custos e desfechos, conforme recomendação do Ministério da Saúde em suas diretrizes de avaliação econômica (Brasil, 2007). Foi também aplicada a taxa de desconto de $4,82 \%$ calculada para Brasil (Valentim et al, 2008a) para período de 30 anos. Mantendo a recomendação máxima de desconto da OMS (2003) para custos (6\%), taxas de desconto menores para desfechos, 0 e $3 \%$ foram simuladas.

Para taxas de desconto iguais para custos e desfechos, a razão de custoefetividade incremental aumenta conforme taxas maiores são aplicadas. Taxas de desconto maiores tornam a intervenção menos custo-efetiva. Para taxas de desconto menores para desfechos do que custos, o desconto tem comportamento diferente para varicela e rotavírus. Em varicela, a razão de custo-efetividade incremental do caso base sem desconto decresce quando uma taxa menor é aplicada para desfechos do que para custos. Para o modelo de varicela, nova coorte é vacinada a cada ano dentro do horizonte temporal, e os custos do programa de vacinação ocorrentes 
continuamente no futuro são também descontados. O desconto dos custos da intervenção no modelo dinâmico de múltiplas coortes para varicela faz com que a razão de custo-efetividade incremental seja mais sensível para variações do parâmetro desconto. 
Tabela 12. Análise de sensibilidade univariada, estimativas de custos e desconto, varicela

\begin{tabular}{|c|c|c|}
\hline \multirow[t]{2}{*}{ Parâmetro variado } & \multicolumn{2}{|c|}{$\begin{array}{l}\text { Variação da Razão de Custo-Efetividade } \\
\text { Incremental }\end{array}$} \\
\hline & Sociedade & Sistema de Saúde \\
\hline \multicolumn{3}{|l|}{ Custo da consulta/SUS (-60\%) } \\
\hline Custo incremental por caso evitado & $\mathrm{R} \$ 32(3,86 \%)$ & $\mathrm{R} \$ 36(3,41 \%)$ \\
\hline Custo incremental por ano de vida salvo & $\mathrm{R} \$ 14.637(3,86 \%)$ & $\mathrm{R} \$ 16.469(3,41 \%)$ \\
\hline \multicolumn{3}{|l|}{ Custo de Medicamentos $=$ Cenário 1} \\
\hline Custo incremental por caso evitado & $R \$ 30(-2,31 \%)$ & $\mathrm{R} \$ 34(-0,68 \%)$ \\
\hline Custo incremental por ano de vida salvo & $R \$ 13.768(-2,31 \%)$ & $\mathrm{R} \$ 15.817(-0,68 \%)$ \\
\hline \multicolumn{3}{|l|}{ Custo de Medicamentos $=$ Cenário 2} \\
\hline Custo incremental por caso evitado & $R \$ 30(-2,31 \%)$ & $\mathrm{R} \$ 34(-2,05 \%)$ \\
\hline Custo incremental por ano de vida salvo & $\mathrm{R} \$ 13.768(-2,31 \%)$ & $\mathrm{R} \$ 15.600(-2,05 \%)$ \\
\hline \multicolumn{3}{|l|}{ Custo de Medicamentos =Cenário 3} \\
\hline Custo incremental por caso evitado & $\mathrm{R} \$ 30(-1,45 \%)$ & $\mathrm{R} \$ 34(0,08 \%)$ \\
\hline Custo incremental por ano de vida salvo & $\mathrm{R} \$ 13.890(-1,45 \%)$ & $\mathrm{R} \$ 15.939(0,08 \%)$ \\
\hline \multicolumn{3}{|l|}{ Custo de Hospitalização (+50\%) } \\
\hline Custo incremental por caso evitado & $\mathrm{R} \$ 30(-1,01 \%)$ & $\mathrm{R} \$ 34(-0,89 \%)$ \\
\hline Custo incremental por ano de vida salvo & $\mathrm{R} \$ 13.951(-1,01 \%)$ & $\mathrm{R} \$ 15.783(-0,89 \%)$ \\
\hline \multicolumn{3}{|l|}{$\begin{array}{c}\text { Custos de produtividade: Inclusão de } \\
\text { casos domiciliares }\end{array}$} \\
\hline Custo incremental por caso evitado & $\mathrm{R} \$ 27(-12,33 \%)$ & $\mathrm{R} \$ 34$ \\
\hline Custo incremental por ano de vida salvo & $\mathrm{R} \$ 12.356(-12,33 \%)$ & $\mathrm{R} \$ 15.926$ \\
\hline Aumento de Produtividade (Seqüela) & & \\
\hline Custo incremental por caso evitado & $\mathrm{R} \$ 30(-0,66 \%)$ & $\mathrm{R} \$ 34$ \\
\hline Custo incremental por ano de vida salvo & $\mathrm{R} \$ 14.001(-0,66 \%)$ & $\mathrm{R} \$ 15.926$ \\
\hline \multicolumn{3}{|l|}{ Número de doses da vacina $=2$} \\
\hline Custo incremental por caso evitado & $\mathrm{R} \$ 73(140,32 \%)$ & $\mathrm{R} \$ 77(124,17 \%)$ \\
\hline Custo incremental por ano de vida salvo & $\mathrm{R} \$ 33.869(140,32 \%)$ & $\mathrm{R} \$ 35.701(124,17 \%)$ \\
\hline \multicolumn{3}{|l|}{ Preço da Vacina $=R \$ 21,60$ (-50\%) } \\
\hline Custo incremental por caso evitado & $R \$ 11(-63,36 \%)$ & $\mathrm{R} \$ 15(-56,07 \%)$ \\
\hline Custo incremental por ano de vida salvo & $R \$ 5.163(-63,36 \%)$ & $\mathrm{R} \$ 6.996(-56,07 \%)$ \\
\hline Preço da Vacina $=R \$ 32,40(-25 \%)$ & & \\
\hline Custo incremental por caso evitado & $\mathrm{R} \$ 21(-31,68 \%)$ & $\mathrm{R} \$ 25(-28,04 \%)$ \\
\hline Custo incremental por ano de vida salvo & $R \$ 9.628(-31,68 \%)$ & $\mathrm{R} \$ 11.461(-28,04 \%)$ \\
\hline
\end{tabular}


...continuação

Parâmetro variado

Variação da Razão de Custo-Efetividade Incremental

Sociedade

Sistema de Saúde

Custo de administração $=R \$ 1,00$ (-62\%)

Custo incremental por caso evitado

$\mathrm{R} \$ 29(-4,40 \%)$

R\$ $33(-3,89 \%)$

Custo incremental por ano de vida salvo

R\$ $13.473(-4,40 \%)$

$\mathrm{R} \$ 15.305(-3,89 \%)$

Custo de administração $=R \$ 5,00(+89 \%)$

Custo incremental por caso evitado

$\mathrm{R} \$ 32(6,27 \%)$

$\mathrm{R} \$ 36(5,55 \%)$

Custo incremental por ano de vida salvo

R\$ $14.977(6,27 \%)$

$\mathrm{R} \$ 16.809(5,55 \%)$

Custo de administração $=R \$ 10,00(+277 \%)$

Custo incremental por caso evitado

$\mathrm{R} \$ 36(19,61 \%)$

$\mathrm{R} \$ 40(17,35 \%)$

Custo incremental por ano de vida salvo

$\mathrm{R} \$ 16.856(19,61 \%) \quad \mathrm{R} \$ 18.689(17,35 \%)$

Taxa de desperdício $=5 \%(-50 \%)$

Custo incremental por caso evitado

$\mathrm{R} \$ 29(-5,76 \%)$

$\mathrm{R} \$ 33(-5,10 \%)$

Custo incremental por ano de vida salvo

$\mathrm{R} \$ 13.282(-5,76 \%)$

$\mathrm{R} \$ 15.114(-5,10 \%)$

Taxa de desperdicio $=15 \%(+50 \%)$

Custo incremental por caso evitado

$\mathrm{R} \$ 32(5,76 \%)$

$\mathrm{R} \$ 36(5,10 \%)$

Custo incremental por ano de vida salvo

$\mathrm{R} \$ 14.905(5,76 \%)$

$\mathrm{R} \$ 16.637(5,10 \%)$

Taxa de desconto $=5 \%$

Custo incremental por caso evitado

$\mathrm{R} \$ 18(-41,54 \%) \quad \mathrm{R} \$ 20(-42,32 \%)$

Custo incremental por ano de vida salvo

$\mathrm{R} \$ 14.712(4,39 \%)$

$\mathrm{R} \$ 16.403(3 \%)$

Taxa de desconto $=4,82 \%$

Custo incremental por caso evitado

$\mathrm{R} \$ 18(-40,59 \%) \quad \mathrm{R} \$ 20(-41,37 \%)$

Custo incremental por ano de vida salvo

$\mathrm{R} \$ 14.690(4,24 \%)$

$\mathrm{R} \$ 16.382(2,87 \%)$

Taxa de desconto $=6 \%$ (custos) e 3\% (desfechos)

Custo incremental por caso evitado

$\mathrm{R} \$ 16(-48,20 \%)$

$\mathrm{R} \$ 18(-48,93 \%)$

Custo incremental por ano de vida salvo

$\mathrm{R} \$ 10.582(-24,92 \%)$

R\$ $11.788(-25,98 \%)$

Taxa de desconto $=6 \%$ (custos) e $0 \%$ (desfechos)

Custo incremental por caso evitado

$\mathrm{R} \$ 15(-49,94 \%)$

$\mathrm{R} \$ 17(-50,65 \%)$

Custo incremental por ano de vida salvo

R\$ $7.056(-49,94 \%)$

$\mathrm{R} \$ 7.860(-50,65 \%)$

\subsubsection{Análise de impacto orçamentário}

A análise de impacto no orçamento foi feita para as perspectivas do PNI e Ministério da Saúde (Trueman et al, 2001). Foi calculado o custo incremental em cada perspectiva e a proporção deste custo em relação ao respectivo orçamento, para 
o ano de 2004. O orçamento do Ministério da Saúde para saúde em 2004 foi de $\mathrm{R} \$ 32.364 .874 .621$ (Brasil, 2004) e o orçamento do PNI para o mesmo ano aproximadamente R\$520 milhões (CGPNI/DEVEP/SVS/MS).

A vacinação universal contra varicela representaria quase $20 \%$ do orçamento do PNI em 2004 (Tabela 13). Na perspectiva do Ministério da Saúde devem ser considerados também os custos diretos no cuidado da doença a serem evitados com a intervenção. Para tal, calculou-se a participação do SUS nos custos mencionados com base em estudo de custo-efetividade de vacinação contra varicela com estimativas de custos apenas do sistema público (Valentim et al, 2008a), e correções para participação também apenas pública em uso de recursos. O SUS responde por aproximadamente $60 \%$ dos custos diretos no cuidado da doença evitados no caso de varicela. A vacinação universal contra varicela representaria $0,28 \%$ do orçamento do MS. Foram simulados os impactos no orçamento correspondentes às análises de sensibilidade para as estimativas de custos diretos no cuidado da doença com maiores incertezas (custo de consulta e custo de hospitalização). Somente o custo de consulta resultou em mudança percentual do custo incremental em relação ao orçamento do MS (Tabela 14). Como a taxa de hospitalização é baixa, as estimativas de custos para hospitalizações afetam pouco o custo incremental e seu impacto no orçamento. Foi também testado o preço da vacina no esquema de 1 dose que tornaria a intervenção muito custo-efetiva ( $\mathrm{R} \$ 29,05)$ na perspectiva do sistema de saúde. O impacto percentual no orçamento cairia para $13,4 \%$ e $0,19 \%$ nas perspectivas do PNI e MS. 
Tabela 13. Análise de impacto no orçamento, vacinação universal contra varicela, perspectiva do PNI, 2004

\begin{tabular}{lrr}
\hline \multicolumn{1}{c}{ Perspectiva do PNI } & \multicolumn{2}{c}{ reais de 2004 } \\
\hline & \multicolumn{1}{c}{ ASL muito } \\
Custo anual da vacinação contra varicela & $\begin{array}{c}\text { Caso base } \\
\text { custo-efetiva }\end{array}$ \\
Custo anual adicional da vacinação contra & 105.946 .537 & 73.093 .162 \\
varicela & 101.021 .876 & 69.695 .609 \\
Custo incremental & 101.021 .876 & 69.695 .609 \\
Orçamento do PNI (2004) & 520.000 .000 & 520.000 .000 \\
Impacto da intervenção no orçamento (\%) & $19,43 \%$ & $13,40 \%$ \\
\hline ASL: Análise de sensibilidade de limiar (threshold analysis) & &
\end{tabular}

Tabela 14. Análise de impacto no orçamento, vacinação universal contra varicela, perspectiva do Ministério da Saúde, 2004 reais de 2004

\begin{tabular}{|c|c|c|c|c|}
\hline & Caso base & $\begin{array}{l}\text { AS custo da } \\
\text { consulta }\end{array}$ & $\begin{array}{c}\text { AS custo da } \\
\text { hospitalização }\end{array}$ & $\begin{array}{l}\text { ASL muito } \\
\text { custo-efetiva }\end{array}$ \\
\hline $\begin{array}{l}\text { Custo anual da vacinação } \\
\text { contra varicela }\end{array}$ & 105.946 .537 & 105.946 .537 & 105.946 .537 & 73.093 .162 \\
\hline $\begin{array}{l}\text { Custo anual adicional da } \\
\text { vacinação contra varicela } \\
\text { Custos diretos no cuidado }\end{array}$ & 101.021 .876 & 101.021 .876 & 101.021 .876 & 69.695 .609 \\
\hline da doença evitados & 9.420 .707 & 7.672 .692 & 9.878 .626 & 9.420 .707 \\
\hline Custo incremental & 91.601 .169 & 93.349 .184 & 91.143 .250 & 60.274 .901 \\
\hline Orçamento do MS (2004) & 32.364 .874 .621 & 32.364 .874 .621 & 32.364 .874 .621 & 32.364 .874 .621 \\
\hline $\begin{array}{l}\text { Impacto da intervenção no } \\
\text { orçamento }(\%)\end{array}$ & $0,28 \%$ & $0,29 \%$ & $0,28 \%$ & $0,19 \%$ \\
\hline
\end{tabular}

AS: Análise de sensibilidade

ASL: Análise de sensibilidade de limiar (threshold analysis) 


\section{DISCUSSÃO}

As estimativas de custos estão condicionadas às características das doenças, como as agudas (auto-limitantes e de baixa comorbidade) e crônicas (alta comorbidade). O modelo para rotavírus foi exemplo de doença aguda que afeta apenas crianças, enquanto que o modelo de varicela foi exemplo de doença que afeta diferentes faixas etárias com sequela.

As estimativas de custos de doença para doenças agudas se referem aos custos do tratamento do caso delimitado temporalmente, que progredirá para total recuperação ou morte, e ou eventual seqüela, com maiores custos de perda de produtividade. Enquanto no estudo de custo-efetividade de vacinação contra rotavírus os custos diretos no cuidado da doença representaram $72 \%$ das economias de custos com a introdução da vacinação universal, no estudo de custo-efetividade de vacinação contra varicela os custos diretos no cuidado da doença representaram $62 \%$ das economias de custos com a introdução da vacinação universal. A introdução das estimativas de custos de produtividade por seqüelas em varicela contribui para a redução do peso dos custos diretos no cuidado desta doença. Em outros estudos de custo-efetividade de vacinação contra varicela, os custos indiretos tiveram peso ainda maior (Lieu et al, 1994; Banz et al, 2003; Ginsberg et al, 2004; Coudeville et al, 2005; Lenne et al, 2006). A não inclusão dos casos domiciliares no caso base do estudo de custo-efetividade de vacinação contra varicela e o redimento médio nacional baixo explicam o peso menor dos custos indiretos no estudo para o Brasil.

Especificamente sobre os custos de produtividade, a renda média adotada para o cálculo de perda de produtividade por seqüela afeta a razão de custo- 
efetividade incremental em sentido contrário. Quanto maior a renda, maiores os custos evitados com a intervenção e menor a razão. Isto tem uma implicação ética muito forte: se a doença/sequela incide sobre pessoas de grupos de renda mais alta, a intervenção caminha em direção ao limiar, favorecendo a introdução da intervenção. A diferença/desigualdade de renda se repete no modelo de custo-efetividade. Este é um dos limites dos estudos de custo-efetividade, que devem ter análises complementares quando se objetiva introduzir critérios de equidade.

No caso de varicela, as seqüelas tendem a ter distribuição homogênea entre os grupos de renda, pois são decorrentes da infecção viral em si, não se modificando muito pela ausência ou presença de tratamentos, mais paliativos.

A Tabelas 15 resume as alterações das estimativas de custos para a tese, com a inclusão de custos específicos do sistema de saúde suplementar, da participação pública na dispensação de medicamentos para rotavírus e de custos de medicamentos no sistema de saúde público para varicela. A Tabela 16 resume o impacto nos resultados das variações das estimativas de custos. $\mathrm{O}$ aumento de detalhamento das estimativas dos custos diretos no cuidado da doença, em comparação aos estudos originais (Sóarez et al, 2008; Valentim et al, 2008a), resultou em variações de custo por tipo de tratamento, custo total da doença, economia e razão de custo-efetividade incremental maiores em rotavírus do que varicela. O maior peso dos custos diretos no cuidado da doença para rotavírus ${ }^{57}$, assim como o fato de todos os casos receberem tratamento, enquanto para varicela

\footnotetext{
${ }^{57}$ A taxa de hospitalização por diarréia por rotavírus é superior à de varicela (3,2\% versus $\left.0,15 \%\right) \mathrm{e}$ para rotavírus houve inclusão das estimativas de custos de consumo de medicamentos e produtos em tratamento domiciliar. Os custos unitários de cuidado da doença, na perspectiva do sistema de saúde, são próximos em tratamento ambulatorial para as duas doenças ( $\mathrm{R} \$ 18,87$ em rotavírus e intervalo entre $\mathrm{R} \$ 15,72$ e $\mathrm{R} \$ 18,57$ em varicela) e maiores para internação por varicela ( $\mathrm{R} \$ 416,73$ versus
} 
foi assumido que $30 \%$ dos casos seriam atendidos em serviços de saúde, explicam as maiores variações em rotavírus. O maior detalhamento das estimativas de custos não alterou, no entanto, o nível de custo-efetividade de ambos os programas de vacinação. Considerando os limiares da OMS (2007), o programa de vacinação universal contra rotavírus já era muito custo-efetivo enquanto o programa de vacinação universal contra varicela, apesar da redução da razão de custo-efetividade incremental, continuou sendo apenas custo-efetivo.

O programa de vacinação universal contra varicela depende do impacto desconhecido da vacinação de rotina na epidemiologia do herpes zoster, não incluído no estudo de custo-efetividade apresentado. Uma vez que zoster é associado com maior morbidade, um aumento de sua incidência tende a tornar a intervenção menos custo-efetiva. (Brisson et al, 2002 e 2003; Goldman, 2005). O impacto da vacinação contra varicela no zoster é difícil de quantificar com base no conhecimento atual (Thiry et al, 2003). Caso o PNI assumisse o limiar de intervenção muito custoefetiva, o programa de vacinação universal contra varicela já não seria aceitável, independente da inclusão de zoster.

Apesar da participação privada em vacinação no país, assumiu-se que a vacinação, tanto contra rotavírus contra varicela, é toda feita no sistema público. À baixa participação anterior à vacinação universal soma-se a suposição de que com a introdução da vacina na rotina no setor público, a participação do setor privado na vacinação deve diminuir consideravelmente.

Os custos estimados para o tratamento de rotavírus e varicela buscaram se aproximar da assistência efetivamente prestada, não a que, do ponto de vista de

$\mathrm{R} \$ 383,83$ por rotavírus). O maior peso dos custos de cuidado da doença por rotavírus decorre de uso mais intensivo de recursos e não por custos unitários mais elevados. 
qualidade da assistência, seria a ideal. Um investimento no tratamento, com melhora da qualidade da assistência de saúde, geraria mais gastos e contribuiria para favorecer, no caso de varicela, a introdução da vacina, uma vez que mais custos de tratamento seriam evitados com a intervenção preventiva.

As estimativas de custos diferem não apenas em função das características das doenças, mas também pelas características da intervenção, se terapêuticas ou preventivas. Para vacinas há um alto investimento presente para benefícios futuros, sendo os resultados das análises de custo-efetividade (razão de custo-efetividade incremental) mais sensíveis às estimativas de custos da intervenção (preço da vacina). No caso do Brasil, para a estimativa do custo da vacinação, o preço a ser aplicado ao número de doses administradas (que depende do esquema vacinal, do tamanho da coorte e da cobertura vacinal) é determinado pela negociação via Fundo Rotatório da OPAS. Uma forma de tentar reduzir os preços das vacinas, contribuindo para sua introdução e sustentabilidade no Programa Nacional de Imunização, é fomentar sua produção nacional. A produção nacional não somente tem impactos microeconômicos, como redução de preços em mercado específico, redução esta que afeta sensivelmente resultados de estudos de custo-efetividade, induzindo intervenções a se tornarem custo-efetivas, como também impactos macroeconômicos, como geração de empregos, difusão de tecnologia e conhecimento e aumento da capacidade de exportação (Buss et al, 2005; Gadelha, 2008). O fomento à produção nacional na área da saúde ultrapassa a produção de vacinas e é parte da agenda de pesquisa em saúde aprovada pela $2^{\text {a }}$ Conferência Nacional de Ciência, Tecnologia e Inovação em Saúde de 2004, que tem o Complexo 
Econômico-Industrial da Saúde como um de seus itens (Guimarães et al, 2006). A Portaria $n^{\circ} 978$ de 2008 reitera a proposta de estímulo à produção nacional na área da saúde e “dispõe sobre a lista de produtos estratégicos, no âmbito do Sistema Único de Saúde, com a finalidade de colaborar com o desenvolvimento do Complexo Industrial da Saúde, instituindo a Comissão para Revisão e Atualização da referida lista" (Brasil, 2008). A Portaria $\mathrm{n}^{\circ} 978$ inclui vacinas como item estratégico. O Programa Nacional de Competitividade em Vacinas (Innovacina, Portaria $n^{0} 972$ de 04/05/2006), coordenado pelo Ministério da Saúde, contempla vacinas prioritárias para investimento em produção, desenvolvimento e inovação tecnológica. Para rotavírus, já incluída no calendário nacional, foi firmado acordo de transferência de tecnologia entre o fabricante e atual fornecedor, GlaxoSmithKline, e Biomanguinhos (Buss set al, 2005). O Instituto Butatan assinou acordo o NIH (National Institutes of Health) em 2005 para produzir vacina pentavalente de rotavírus. Estimam-se economias de divisas de ordem de US\$ 100 milhões com a introdução das vacinas contra rotavírus, influenza sazonal e surfactante pulmonar fabricados pelo Instituto Butatan (Raw et al, 2008). Para varicela, até 2010, em um cenário de existência de tecnologia, com projeto em fase inicial de desenvolvimento e com apoio financeiro incipiente, Biomanguinhos está construindo nova planta de vacinas virais, objetivando a produção da tríplice viral, onde também poderá ser produzido o componente varicela, com possível clonagem do vírus de varicela ou transferência tecnológica (Buss et al, 2005). Outra opção de vacina contra varicela é a combinação de vacina contra sarampo, caxumba, rubéola e varicela (MMRV), disponível em esquema de duas doses (Shinefield et al, 2008). MMRV substituiria MMR sem custos adicionais de administração, sendo o custo adicional a diferença com compras 
das duas vacinas. A redução do número de injeções contribui também para aumento da aceitação e cobertura da vacina.

Assim como para os estudos de custo-efetividade de vacinação contra rotavírus e varicela para o Brasil os resultados foram mais sensíveis às estimativas de custos do programa de vacinação, em especial o preço da vacina, na literatura o preço da vacina é confirmado como o determinante primário de custo-efetividade de programas de vacinação (Walker et al, 2005).

No entanto, apesar do preço da vacina ser o item de custo de maior peso, os custos de administração podem também ter um impacto importante, uma vez que a introdução de uma nova vacina a um programa de imunização pode causar custos adicionais decorrentes de expansão necessária de infra-estrutura. A introdução da vacina de rotavírus ao calendário nacional do PNI teve impactos não previstos sobre a infra-estrutura existente.

Uma das contribuições da tese foi discutir a viabilidade do uso dos dados secundários para estimar custos para avaliações econômicas para introdução de novas vacinas, enquanto instrumento de tomada de decisão. Apesar das limitações dos custos advindos de sistemas de informação (como foi o caso dos custos unitários de consulta e hospitalização), os resultados das análises de sensibilidade mostraram que as razões de custo-efetividade incrementais são pouco sensíveis aos custos mencionados, o que se repetiu na análise de impacto no orçamento. Não se deixa de considerar com isto os problemas dos valores disponíveis nos sistemas de informação oficiais. No caso das AIHs, a remuneração difere do custo em graus variados, dependendo do procedimento em questão. Além disto, o preenchimento de AIHs 
pode refletir uma lógica de pagamento de procedimentos de maior remuneração e não necessariamente a lógica de tratamento clínico.

Com exceção da análise de sensibilidade para custos de produtividade decorrente de seqüela de varicela, não foram incorporadas variações reais dos custos. No caso de rotavírus, o horizonte temporal de cinco anos permite admitir que os custos não variem muito desde o início de seguimento da coorte. Para varicela, o horizonte temporal de 30 anos já dificulta tal afirmação, sendo esta uma limitação do estudo de custo-efetividade apresentado. O preço da vacina pode variar nesse período, como com a proposta de produção nacional, assim como os demais itens considerados para estimativas de custos (consultas, medicamentos, exames, hospitalizações, transporte, rendimento etc) e práticas clínicas. Apesar dos estudos de custo-efetividade serem complexos, envolvendo perspectivas epidemiológicas, clínicas, econômicas e demográficas, são sempre abstrações e, portanto, reduções da realidade. Diante da incerteza e com objetivo de simplificação, para horizontes temporais longos, são mantidas fixas não apenas estimativas de custos, mas também parâmetros clínicos, epidemiológicos e demográficos. Também não foi incorporada inflação na projeção dos custos futuros, uma vez que se procurou trabalhar com os custos reais, opção metodológica predominante nos estudos de custo-efetividade.

A análise de impacto no orçamento para o ano de 2004 permitiu a comparação do impacto orçamentário das duas vacinas, rotavírus e varicela, anteriormente à decisão de incorporação da tecnologia (introdução da vacinação universal contra rotavírus). O impacto no orçamento do PNI da vacinação contra varicela foi inferior ao de rotavírus, tendo sido esta, no entanto, a escolhida. Ponderação deve ser feita em relação ao custo incremental para varicela. Apesar do 
custo de vacinação por criança ser maior para varicela $(\mathrm{R} \$ 50,16$ para esta e $\mathrm{R} \$ 46,22$ para rotavírus), a cobertura vacinal para o modelo de rotavírus foi maior (90\%) do que em varicela $(80 \%)$. A cobertura menor para varicela decorreu do modelo que considera população fechada, sem riscos maiores de contágio. Neste modelo fechado, a cobertura vacinal de $80 \%$ consegue controlar e estabilizar a doença por volta de 20 anos após a introdução da vacina. Os parâmetros demográficos e suas fontes também contribuíram para o maior custo anual de vacinação em rotavírus (coorte de nascidos vivos do Censo 2000 versus coorte de crianças com 1 ano de idade da PNAD 2003 em varicela). Para varicela, como já há custos com vacinação para grupos de risco desde 2000, o custo incremental é conseqüentemente menor do que para rotavírus, cuja vacinação era inexistente antes de sua introdução. No cenário pré-vacinação universal, os custos de diarréia por rotavírus referiam-se apenas ao orçamento do MS (custos de tratamento da doença), enquanto que para varicela seus respectivos custos recaem não apenas sobre o orçamento do MS mas também do PNI, responsável pela vacinção da estratégia atual de grupos de risco e pelo uso de imunoblobulina (VZIg).

Considerando o impacto orçamentário de mesma grandeza das duas vacinas (por volta de $20 \%$ ), a decisão de introdução da vacina contra rotavírus se justitifica pelo critério de custo-efetividade mais favorável àquela para o desfecho anos de vida salvos. Isto é conseqüência da maior taxa de letalidade em rotavírus $(0,03 \%)$ do que em varicela $(0,004 \%)$. Com uma taxa de letalidade 7,5 vezes maior, a introdução da vacinação universal contra rotavírus evita mais mortes e conseqüentemente mais anos de vida são salvos, também em função da coorte mais jovem (apenas crianças de 0-5 anos). Estas comparações permitem avaliar o quanto as estimativas de custos 
em avaliação econômicas estão condicionadas aos demais parâmetros epidemiológicos e clínicos: mesmo com custos adicionais semelhantes de introdução da intervenção/tecnologia, pelo critério de custo-efetividade, determinada intervenção se mostra mais prioritária pelas características da doença em questão.

Apesar da maior tradição das vacinas no campo das avaliações econômicas, o papel destas, assim como nas demais tecnologias de saúde, ainda não é decisivo, sendo discutido cada vez mais freqüentemente. Muitas vacinas possuem estudos de custo-efetividade sem, no entanto, terem sido incluídas em calendários de vacinação, como é o caso de varicela, que é uma vacina antiga, enquanto outras, com número menor de estudos, são incluídas rapidamente (Beutels et al, 2003). No caso do Brasil, a Avaliação de Tecnologia em Saúde (ATS) vem ganhando espaço, tendo sido item da sub-agenda de pesquisa em saúde aprovada pela $2^{\text {a }}$ Conferência Nacional de Ciência, Tecnologia e Inovação em Saúde de 2004, com 26 projetos de economia da saúde e avaliação de custos aprovados em 2005 (Guimarães et al, 2006). Não há ainda no país análise do papel das avaliações econômicas nos processos de incorporação de tecnologias em saúde.

Outro ponto a salientar é que as avaliações econômicas, quando existentes, são utilizadas apenas antes da intervenção ou tecnologia a ser incorporada. Após a introdução, são raríssimos os estudos de verificação e validação dos resultados dos estudos pré-introdução (Davis, 2005; Zhou et al, 2005).

Os estudos de custo-efetividade apresentados procuraram mostrar os desafios, os limites e as possibilidades das estimativas de custos para os estudos, assim como a condução de tais estimativas podem influenciar a tomada de decisão de incorporação de tecnologia. Reconhece-se a necessidade de mais estudos de custos 
em saúde no país, paralelamente a uma maior estruturação dos sistemas oficiais de dados de custos disponíveis, a fim de contribuírem para a padronização e acurácia das estimativas de custos a serem utilizadas não apenas em estudos de avaliação econômica. São reconhecidos também os limites das avaliações econômicas enquanto instrumento de tomada de decisão, que é ferramenta auxiliar importante enquanto sistematização de informações e disseminação das mesmas, tornando o processo de tomada de decisão mais técnico e transparente. 
Tabela 15. Alterações das estimativas de custos para a tese, por doença

\begin{tabular}{|c|c|c|c|c|}
\hline Doençalltens de custo* & $\begin{array}{l}\text { Estimativas de custos iniciais"\# } \\
\text { (relatórios para Ministério da Saúde e artigos publicados) }\end{array}$ & $\begin{array}{c}\text { Fontes } \\
\text { (custos unitários) }\end{array}$ & Alteraçổes das estimativas de custos para a tese & $\begin{array}{l}\text { Fontes para alteraçổes } \\
\text { (custos unitários) }\end{array}$ \\
\hline \multicolumn{2}{|l|}{ CUSTOS DIRETOS } & & & \\
\hline \multicolumn{5}{|c|}{ Custos diretos no cuidado da doença } \\
\hline Consultas & Média de consultas e encaminhamentos multiplicada por respectivo valor & SIADATASUS & Inclusẫo de custo de consulta do sistema de saúde suplementar & SIPIANS \\
\hline Medicamentos e produtos & Micro-costing (medicamentos classificados por classe terapêutica) & ABCPharma & Inclusẫo da participaçẫo pública na dispensaçẫo de medicamentos & PNAD \\
\hline Exames complementares & Frequência de exames multiplicada por respectivos valores & SIADATASUS & Inclusăo de custos de exames do sistema de saúde suplementar & CBHPM \\
\hline Hospitalizaçổes & AllHs Diarréia/Rotavírus & SHIDATASUS & Inclusẫo de custo de hospitalizaçẫo do sistema de saúde suplementar & TUNEP \\
\hline \multicolumn{5}{|l|}{ Custos diretos näo-médicos } \\
\hline \multicolumn{5}{|l|}{ CUSTOS INDIRETOS } \\
\hline \multicolumn{5}{|l|}{ Varicela } \\
\hline \multicolumn{5}{|l|}{ CUSTOS DIRETOS } \\
\hline \multicolumn{5}{|c|}{ Custos diretos no cuidado da doença } \\
\hline Consultas & Média de consultas e encaminhamentos multiplicada por respectivo valor & SIADATASUS & Inclusẵo de custo de consulta do sistema de saúde suplementar & SIPIANS \\
\hline Medicamentos & Micro-costing (medicamentos classificados por classe terapêutica) & ABCPharma & Inclusẫo de custos de medicamentos no sistema de saúde público & Banco de Preços/MS \\
\hline Exames complementares & Frequência de exames multiplicada por respectivos valores & SIADATASUS & Inclusẫo de custos de exames do sistema de saúde suplementar & CBHPM \\
\hline Hospitalizaçổes & AlHs Varicela & SHIDATASUS & Inclusăo de custo de hospitalizaçăo do sistema de saúde suplementar & TUNEP \\
\hline Tratamento de sequela & Pacote de tratamento AACD & AACD & - & - \\
\hline \multicolumn{5}{|l|}{ Custos diretos näo-médicos } \\
\hline \multicolumn{5}{|l|}{ CUSTOS INDIRETOS } \\
\hline Perda de produtividade (varicela) & Dias de absenteísmo multiplicados por salário diário & PNAD & - & $\cdot$ \\
\hline Perda de produtividade (sequela) & Anos de vidas improdutivos multiplicados por salário anual & PNAD & - & - \\
\hline
\end{tabular}


Tabela 16. Variações de custos, economia e razão de custo-efetividade incremental para a tese em comparação com estudos originais ${ }^{1,2}$, perspectiva da sociedade, por doença

\begin{tabular}{lcc}
\hline \multicolumn{1}{c}{ Itens de Resultado } & $\begin{array}{c}\text { Rotavírus } \\
(\Delta)\end{array}$ & $\begin{array}{c}\text { Varicela }^{2} \\
(\Delta)\end{array}$ \\
\hline Custo por tipo de tratamento & & \\
Ambulatorial & $+26 \%$ & $+2-23 \% *$ \\
Hospitalar & $+23 \%$ & $+1-14 \% *$ \\
\hline Custo total da doença & $+16 \%$ & $+11 \%$ \\
\hline Economia (custo total da doençaevitado) & $+18 \%$ & $+16 \%$ \\
\hline Razão de Custo-Efetividade Incremental ** & $-20 \%$ & $-4 \%$ \\
\hline Fontes: ${ }^{1}$ Sóarez et al $(2008) ;{ }^{2}$ Valentim et al $(2008$ a). & \\
* Mínimo e máximo das variações para todas as faixas etárias $^{*}$ & \\
** Desfecho ano de vida salvo, cenário base com desconto &
\end{tabular}




\section{CONCLUSÃO}

As estimativas de custos para avaliações econômicas, assim como para demais finalidades na economia da saúde, apresentam dificuldades pela não padronização de conceitos de custos e metodologias de custeio. Apesar do custo de oportunidade ser o recomendado, sua aplicação na prática apresenta dificuldades. Quanto aos métodos, tanto para custos diretos quanto indiretos não há consenso, estando os métodos condicionados pela disponibilidade de dados e escolhas teóricoconceituais ou mesmo práticas do pesquisador.

No Brasil ainda são escassos estudos de custos de doença. A tese apresentou dois casos distintos: estudo primário e prévio de custos para rotavírus, e estimativas com dados secundários e paralelas à avaliação econômica de vacinação universal para varicela. A tese analisou o impacto de maior detalhamento de estimativas de custos diretos no cuidado da doença nos custos por tipo de tratamento, custo total da doença, economia e razão de custo-efetividade incremental.

O maior detalhamento das estimativas de custos diretos no cuidado da doença para as avaliações econômicas dos programas de vacinação contra rotavírus e varicela não alterou o nível de custo-efetividade de ambos os programas. Os resultados de análise de sensibilidade apontam os custos do programa de vacinação, em especial o preço da vacina, como determinantes primários de custo-efetividade. 


\section{ANEXOS}

Tabela i. Taxa de Desconto Social (TDS), Brasil, 2005-2050

\begin{tabular}{|c|c|}
\hline Ano & TDS \\
\hline 2005 & $3,58 \%$ \\
\hline 2006 & $4,62 \%$ \\
\hline 2007 & $5,53 \%$ \\
\hline 2008 & $5,05 \%$ \\
\hline 2009 & $5,03 \%$ \\
\hline 2010 & $5,01 \%$ \\
\hline 2011 & $4,99 \%$ \\
\hline 2012 & $4,97 \%$ \\
\hline 2013 & $4,95 \%$ \\
\hline 2014 & $4,94 \%$ \\
\hline 2015 & $4,92 \%$ \\
\hline 2016 & $4,90 \%$ \\
\hline 2017 & $4,89 \%$ \\
\hline 2018 & $4,87 \%$ \\
\hline 2019 & $4,86 \%$ \\
\hline 2020 & $4,85 \%$ \\
\hline 2021 & $4,83 \%$ \\
\hline 2022 & $4,82 \%$ \\
\hline 2023 & $4,81 \%$ \\
\hline 2024 & $4,80 \%$ \\
\hline 2025 & $4,79 \%$ \\
\hline 2026 & $4,78 \%$ \\
\hline 2027 & $4,76 \%$ \\
\hline 2028 & $4,75 \%$ \\
\hline 2029 & $4,74 \%$ \\
\hline 2030 & $4,73 \%$ \\
\hline 2031 & $4,71 \%$ \\
\hline 2032 & $4,70 \%$ \\
\hline 2033 & $4,68 \%$ \\
\hline 2034 & $4,67 \%$ \\
\hline 2035 & $4,65 \%$ \\
\hline 2036 & $4,64 \%$ \\
\hline 2037 & $4,62 \%$ \\
\hline 2038 & $4,61 \%$ \\
\hline 2039 & $4,60 \%$ \\
\hline 2040 & $4,59 \%$ \\
\hline 2041 & $4,57 \%$ \\
\hline 2042 & $4,56 \%$ \\
\hline 2043 & $4,55 \%$ \\
\hline 2044 & $4,54 \%$ \\
\hline 2045 & $4,53 \%$ \\
\hline 2046 & $4,52 \%$ \\
\hline 2047 & $4,51 \%$ \\
\hline 2048 & $4,50 \%$ \\
\hline 2049 & $4,49 \%$ \\
\hline 2050 & $4,48 \%$ \\
\hline
\end{tabular}

Fonte: Valentim et al, 2008. 
Quadro i. Diretrizes de avaliação econômica

\begin{tabular}{|c|c|c|c|c|c|c|c|c|}
\hline & Alemanha & Austrália & Áustria & $\begin{array}{l}\text { Bálticos (Latvia, } \\
\text { Lituânia, Estônia) }\end{array}$ & Bélgica & Canadá & China & Escócia \\
\hline $\begin{array}{c}\text { Título e } \\
\text { ano do } \\
\text { Documento }\end{array}$ & $\begin{array}{c}\text { "German } \\
\text { Recommendations on } \\
\text { health economic } \\
\text { evaluation studies. } \\
\text { Revised version of the } \\
\text { Hannover Consensus", } \\
1995\end{array}$ & $\begin{array}{l}\text { "Guidelines for the } \\
\text { pharmaceutical } \\
\text { industry on } \\
\text { preparation of } \\
\text { submissions to the } \\
\text { Pharmaceutical } \\
\text { Benefits Advisory } \\
\text { Committee", 2002 } \\
\end{array}$ & $\begin{array}{l}\text { "Guidelines on } \\
\text { Health Economic } \\
\text { Evaluations", } 2006\end{array}$ & $\begin{array}{l}\text { "Guideline for } \\
\text { economic evaluation of } \\
\text { pharmaceuticals", } 2002\end{array}$ & $\begin{array}{c}\text { "A proposal for } \\
\text { methodological } \\
\text { guidelines for economic } \\
\quad \text { evaluation of } \\
\text { pharmaceuticals", } 1995\end{array}$ & $\begin{array}{l}\text { "Guidelines for } \\
\text { economic evaluation of } \\
\text { pharmaceuticals", } 1997\end{array}$ & $\begin{array}{c}\text { "Chinese } \\
\text { Pharmacoeconomic } \\
\text { Evaluation Guideline", } \\
2006\end{array}$ & $\begin{array}{l}\text { "Scottish Medicines } \\
\text { Consortium" }\end{array}$ \\
\hline Perspectiva & Sociedade & $\begin{array}{l}\text { Sociedade e Sistema } \\
\text { de Saúde }\end{array}$ & $\begin{array}{c}\text { Além da Sociedade, } \\
\text { Sistema de Saúde e } \\
\text { outras }\end{array}$ & $\begin{array}{l}\text { Sistema de Saúde. Se } \\
\text { relevante, sociedade }\end{array}$ & $\begin{array}{l}\text { Sociedade, Instituto } \\
\text { Nacional de Saúde e } \\
\text { Seguro de Invalidez }\end{array}$ & $\begin{array}{c}\text { Sociedade, } \\
\text { transparentemente } \\
\text { aberta em perspectivas } \\
\text { relevantes }\end{array}$ & $\begin{array}{l}\text { Sociedade e Sistema de } \\
\text { saúde }\end{array}$ & $\begin{array}{l}\text { Sistema de Saúde, } \\
\text { Pacientes e } \\
\text { Famílias }\end{array}$ \\
\hline $\begin{array}{l}\text { Custos a } \\
\text { serem } \\
\text { incluídos }\end{array}$ & $\begin{array}{l}\text { Todos os custos diretos } \\
\text { e indiretos. Custos de } \\
\text { oportunidade, } \\
\text { administrativos e } \\
\text { marginais podem ser } \\
\text { usados. Metódo de } \\
\text { Fricção recomendado } \\
\text { para custos indiretos. }\end{array}$ & $\begin{array}{l}\text { Custos diretos } \\
\text { médicos, Serviços } \\
\text { Sociais, Custos } \\
\text { Indiretos. Mudanças } \\
\text { em capacidade } \\
\text { produtiva como } \\
\text { desfecho da terapia } \\
\text { não são encorajados. }\end{array}$ & $\begin{array}{c}\text { Custos relevantes } \\
\text { para a perspectiva } \\
\text { escolhida. Custos } \\
\text { indiretos reportados } \\
\text { separdamente. }\end{array}$ & $\begin{array}{l}\text { Somente custos diretos } \\
\text { de cuidado à saúde. Se } \\
\text { relevante, inclusão de } \\
\text { todos os custos fora do } \\
\text { sistema de saúde, } \\
\text { separadamente. }\end{array}$ & $\begin{array}{l}\text { Todos custos relevantes } \\
\text { devem ser reportados, e } \\
\text { custos indiretos } \\
\text { apresentados } \\
\text { separadamente. }\end{array}$ & $\begin{array}{l}\text { Todos os custos diretos } \\
\text { de cuidado à saúde, } \\
\text { custos de serviços } \\
\text { sociais, custos de } \\
\text { spillover em outros } \\
\text { setores, e custos para } \\
\text { paciente e família. }\end{array}$ & $\begin{array}{l}\text { Depende do objetivo do } \\
\text { estudo. Todos os custos } \\
\text { relevantes devem ser } \\
\text { apresentados } \\
\text { detalhadamente. Custos } \\
\text { indiretos devem ser } \\
\text { apresetados } \\
\text { separadamente. }\end{array}$ & $\begin{array}{l}\text { Recursos diretos do } \\
\text { cuidado à saúde. }\end{array}$ \\
\hline $\begin{array}{l}\text { Fontes dos } \\
\text { Custos }\end{array}$ & - & $\begin{array}{c}\text { Manual de Itens de } \\
\text { Recursos e Custos } \\
\text { Associados, listas de } \\
\text { DRGs. }\end{array}$ & $\begin{array}{l}\text { Preços unitários } \\
\text { recentes. }\end{array}$ & $\begin{array}{l}\text { Adaptar custos locais, } \\
\text { sendo específico. }\end{array}$ & $\begin{array}{l}\text { Custos padrões. } \\
\text { Especificar fontes. }\end{array}$ & $\begin{array}{l}\text { "CCOHTA Guidance } \\
\text { Document for the } \\
\text { Costing Process" }\end{array}$ & Preços unitários recentes. & $\begin{array}{l}\text { Refletir contexto } \\
\text { escocês ou do } \\
\text { Reino Unido }\end{array}$ \\
\hline $\begin{array}{l}\text { Desconto } \\
\text { de Custos }\end{array}$ & Base: $5 \%$, AS: $3 \%, 10 \%$ & $5 \%$ & $5 \%$; AS:(3\%-10\%) & $5 \%$ & Base: $5 \%$; AS: $0-5 \%$ & $\begin{array}{l}\text { Padrão: } 5 \% \text {; base } 3 \% \text {; } \\
\text { mínimo: } 0 \%\end{array}$ & Com e sem desconto & $\begin{array}{c}\text { Base: } 6 \% \text {; AS: } 0 \% \text {, } \\
\text { Taxa do Tesouro }\end{array}$ \\
\hline \begin{tabular}{|c|} 
Desconto \\
de \\
Desfechos
\end{tabular} & Base: $5 \%$, AS: $3 \%, 10 \%$ & $0 \%$ ou $5 \%$ & $5 \%$; AS:(3\%-10\%) & $5 \%$ & Base: $5 \%$; AS: $0-5 \%$ & $\begin{array}{l}\text { Padrão: } 5 \% \text {; base } 3 \% \text {; } \\
\text { mínimo: } 0 \%\end{array}$ & Com e sem desconto & $\begin{array}{l}\text { Base: } 1,5 \% \text {; } \\
\text { AS:0\%; Taxa do } \\
\text { Tesouro }\end{array}$ \\
\hline $\begin{array}{l}\text { Análise de } \\
\text { Impacto } \\
\text { Financeiro }\end{array}$ & - & $\begin{array}{l}\text { Obrigatório, para os } \\
\text { orçamentos do PBS } \\
\text { (Pharmaceutical } \\
\text { Benfits Scheme) e } \\
\text { governamental para } \\
\text { saúde, para } 2 \text { anos. }\end{array}$ & Possível & Não & - & $\begin{array}{l}\text { Exercício orçamentário } \\
\text { para organizações } \\
\text { afetadas, não parte da } \\
\text { avaliação econômica }\end{array}$ & Sim & Não \\
\hline
\end{tabular}




\begin{tabular}{|c|c|c|c|c|c|c|c|}
\hline & Espanha & Estados Unidos & Finlândia & França & Holanda & Hungria & $\begin{array}{c}\text { Inglaterra e País de } \\
\text { Gales }\end{array}$ \\
\hline $\begin{array}{l}\text { Título e ano } \\
\quad \text { do } \\
\text { Documento }\end{array}$ & $\begin{array}{l}\text { "Economic analysis of } \\
\text { health technologies and } \\
\text { programmes: A Spanish } \\
\text { proposal for } \\
\text { methodological } \\
\text { standardization", } 1995 \\
\end{array}$ & $\begin{array}{l}\text { Gold et al. Cost- } \\
\text { Effectiveness in Health } \\
\text { and Medicine. New } \\
\text { York: Oxford University } \\
\text { Press, } 1996 .\end{array}$ & $\begin{array}{l}\text { "Guidelines for } \\
\text { preparation of an account } \\
\text { of health-economic } \\
\text { aspects", } 1999\end{array}$ & $\begin{array}{l}\text { "Guideline and } \\
\text { recommendations for } \\
\text { French PE studies", } 2003\end{array}$ & $\begin{array}{l}\text { "Guidelines for } \\
\text { pharmacoeconomic } \\
\text { research", } 1999\end{array}$ & $\begin{array}{l}\text { "A Hungarian proposal } \\
\text { for methodology } \\
\text { standards", } 2002\end{array}$ & $\begin{array}{l}\text { "Guide to the Methods of } \\
\text { Technology Appraisals", } \\
2004\end{array}$ \\
\hline Perspectiva & $\begin{array}{l}\text { Dependente da questão } \\
\text { da avaliação }\end{array}$ & Sociedade & Sociedade & $\begin{array}{l}\text { Depende do objetivo do } \\
\text { estudo }\end{array}$ & Sociedade & $\begin{array}{c}\text { Para audiência que a } \\
\text { análise se refere.Se mais } \\
\text { de uma perspectiva, } \\
\text { devem ser reportadas } \\
\text { separadamente. }\end{array}$ & $\begin{array}{c}\text { Caso de referência: NHS } \\
\text { e PSS (personal social } \\
\text { services). Não referência: } \\
\text { sociedade sem custo de } \\
\text { produtividade }\end{array}$ \\
\hline $\begin{array}{l}\text { Custos a } \\
\text { serem } \\
\text { incluídos }\end{array}$ & $\begin{array}{l}\text { Depende da questão em } \\
\text { estudo. Custos diretos. } \\
\text { Custos indiretos podem } \\
\text { ou não ser incluídos. }\end{array}$ & $\begin{array}{l}\text { Todos os recursos usados } \\
\text { relevantes para a análise } \\
\text { e de magnitude } \\
\text { considerável para caso de } \\
\text { referência. }\end{array}$ & $\begin{array}{l}\text { Todos os custos diretos } \\
\text { de cuidado à saúde e } \\
\text { custos sociais } \\
\text { comparáveis. Custos } \\
\text { indiretos devem ser } \\
\text { apresentados } \\
\text { separadamente. }\end{array}$ & $\begin{array}{l}\text { Depende do objetivo do } \\
\text { estudo. Todos os custos } \\
\text { relevantes devem ser } \\
\text { aresentados detalhada e } \\
\text { separadamente, inclusive } \\
\text { custos indiretos. }\end{array}$ & $\begin{array}{l}\text { Custos diretos dentro e } \\
\text { fora do Sistema de } \\
\text { Saúde. Custos futuros de } \\
\text { cuidado à saúde para } \\
\text { doença não relacionada } \\
\text { em expectativa de vida } \\
\text { adicional deves ser } \\
\text { excluído. Perdas de } \\
\text { Produtividade pelo } \\
\text { Método de Fricção. } \\
\end{array}$ & $\begin{array}{l}\text { Depende da perspectiva } \\
\text { do estudo }\end{array}$ & $\begin{array}{c}\text { Custos de recursos } \\
\text { diretos e indiretos } \\
\text { potentiais para o NHS } \\
\text { (National Health Service) } \\
\text { e PSS (Personal Social } \\
\text { Service). }\end{array}$ \\
\hline $\begin{array}{l}\text { Fontes dos } \\
\text { Custos }\end{array}$ & $\begin{array}{l}\text { Custo de produção. Preço } \\
\text { de Mercado. }\end{array}$ & $\begin{array}{l}\text { Todos os custos devem } \\
\text { ser valoreados como } \\
\text { custos de oportunidade. }\end{array}$ & - & - & $\begin{array}{c}\text { Custos padrões } \\
\text { publicados planejados } \\
\text { para } 1999 .\end{array}$ & $\begin{array}{l}\text { Devem ser claramente } \\
\text { apresentados. Se da } \\
\text { perspectiva do Seguro } \\
\text { Nacional de Saúde, as } \\
\text { fontes devem ser as taxas } \\
\text { de financiamento } \\
\text { definidas nos contratos e } \\
\text { dados de custos do } \\
\text { Centro de Informação } \\
\text { para Saúde. }\end{array}$ & $\begin{array}{l}\text { Lista oficial atual } \\
\text { publicada pelo } \\
\text { Departmento de Saúde } \\
\text { e/ou Governdo de Gales } \\
\text { (Welsh Assembly } \\
\text { Government). }\end{array}$ \\
\hline $\begin{array}{l}\text { Desconto de } \\
\text { Custos }\end{array}$ & $6 \%$ & $\begin{array}{c}\text { Base: } 3 \% \text { e } 5 \% ; \\
\text { AS: } 0 \sim 7 \%\end{array}$ & $5 \%$ e $0 \%$ & $2.5 \sim 5 \%$ & Base: $4 \%$, e AS & Base: $5 \%$; AS: 3-6\% & Base: $3.5 \%$; AS: $0 \sim 6 \%$ \\
\hline $\begin{array}{c}\text { Desconto de } \\
\text { Desfechos }\end{array}$ & $6 \%$ & $\begin{array}{c}\text { Base: } 3 \% \text { e } 5 \% \\
\text { AS: } 0 \sim 7 \% \\
\end{array}$ & $5 \%$ e $0 \%$ & Com e sem desconto & Base: $4 \%$, e AS & Base: $5 \%$; AS: $0-6 \%$ & Base: $3.5 \%$; AS: $0 \sim 6 \%$ \\
\hline $\begin{array}{l}\text { Análise de } \\
\text { Impacto } \\
\text { Financeiro }\end{array}$ & Não & Não & Não & - & Não & $\begin{array}{l}\text { Impacto para período de } \\
\qquad 3-5 \text { anos }\end{array}$ & $\begin{array}{l}\text { Sim, custo deve ser } \\
\text { desagregado } \\
\text { organização (NHS, PSS, } \\
\text { hospital etc) e categorias } \\
\text { de orçamento }\end{array}$ \\
\hline
\end{tabular}




\begin{tabular}{|c|c|c|c|c|c|c|}
\hline & Irlanda & Israel & Itália & Noruega & Nova Zelândia & Polônia \\
\hline $\begin{array}{l}\text { Título e ano } \\
\text { do } \\
\text { Documento }\end{array}$ & $\begin{array}{c}\text { "Irish Healthcare } \\
\text { Technology Assessment } \\
\text { Guidelines/ } \\
\text { Pharmacoeconomic } \\
\text { guidelines", } 1999\end{array}$ & $\begin{array}{l}\text { "Guidelines for the } \\
\text { submission of a request to } \\
\text { include a pharmaceutical } \\
\text { product in the national list } \\
\text { of health services", } 2002\end{array}$ & $\begin{array}{l}\text { "Guidelines for economic } \\
\text { evaluation", } 2001\end{array}$ & $\begin{array}{l}\text { "Norwegian guidelines for } \\
\text { pharmacoeconomic } \\
\text { analysis in connection with } \\
\text { applications for } \\
\text { reimbursement", } 2000\end{array}$ & $\begin{array}{l}\text { "A prescription for } \\
\text { pharmacoeconomic } \\
\text { analysis", } 1999\end{array}$ & $\begin{array}{l}\text { "Guidelines for } \\
\text { conducting } \\
\text { pharmacoeconomic } \\
\text { evaluation" }\end{array}$ \\
\hline Perspectiva & $\begin{array}{l}\text { Sistema de saúde ou } \\
\text { Sociedade }\end{array}$ & $\begin{array}{c}\text { Seguros Médicos (Sick } \\
\text { Funds) do Seguro Nacional } \\
\text { de Saúde }\end{array}$ & $\begin{array}{l}\text { Sociedade, Serviço de } \\
\text { Saúde Nacional Italiano }\end{array}$ & Sociedade e pagador & $\begin{array}{l}\text { Autoridade de Financiamento } \\
\text { de Saúde / PHARMAC }\end{array}$ & $\begin{array}{l}\text { Sociedade, com e sem } \\
\text { custos indireto }\end{array}$ \\
\hline $\begin{array}{l}\text { Custos a } \\
\text { serem } \\
\text { incluídos }\end{array}$ & - & $\begin{array}{l}\text { Custos de tratamento, } \\
\text { recursos para terapia de } \\
\text { suporte e tratamento de } \\
\text { efeitos colaterais. }\end{array}$ & $\begin{array}{l}\text { Sociedade: custos diretos e } \\
\text { indiretos. Para custos } \\
\text { indiretos, Método do } \\
\text { Capital Humano. }\end{array}$ & $\begin{array}{c}\text { Todos os custos relevantes } \\
\text { para sociedade e Seguro } \\
\text { Nacional, apresentados } \\
\text { separadamente. }\end{array}$ & $\begin{array}{l}\text { Custos diretos da HFA } \\
\text { (Health Funding Authority) e } \\
\text { pacientes. Custos indiretos } \\
\text { reconhecidos dentro do } \\
\text { critério de decisão da } \\
\text { PHARMAC (Pharmaceutical } \\
\text { Management Agency of New } \\
\text { Zealand). }\end{array}$ & $\begin{array}{l}\text { Todos os custos diretos } \\
\text { (médicos + não- } \\
\text { médicos), custos } \\
\text { indiretos dentro do } \\
\text { Sistema de Saúde, se } \\
\text { relacionados. Perdas de } \\
\text { Produtividade } \\
\text { apresentadas } \\
\text { separadamente. } \\
\end{array}$ \\
\hline $\begin{array}{l}\text { Fontes dos } \\
\text { Custos }\end{array}$ & $\begin{array}{l}\text { Modelos de custos sem } \\
\text { consenso. }\end{array}$ & $\begin{array}{c}\text { Preços dos serviços } \\
\text { ambulatoriais do Ministério } \\
\text { da Saúde }\end{array}$ & $\begin{array}{l}\text { Usar microcustos a partir } \\
\text { de estudos feitos juntos as } \\
\text { estruturas de saúde. }\end{array}$ & $\begin{array}{l}\text { Refletir condições } \\
\text { norueguesas. }\end{array}$ & $\begin{array}{l}\text { Preços médios pagos pela } \\
\text { HFA, DRGs. }\end{array}$ & $\begin{array}{l}\text { Preços unitários mais } \\
\text { recentes. }\end{array}$ \\
\hline $\begin{array}{c}\text { Desconto de } \\
\text { Custos }\end{array}$ & - & - & Base:3\%; AS: $0 \% \sim 8 \%$ & $2.5 \sim 5 \%$. AS:0 8\% & Base: $10 \%$; AS: $0,5,15 \%$ & $0 \%, 5 \%$ \\
\hline $\begin{array}{c}\text { Desconto de } \\
\text { Desfechos }\end{array}$ & - & - & Base:3\%; AS: $0 \% \sim 8 \%$ & $2.5 \sim 5 \%$. AS:0 8\% & Base: $10 \%$; AS: $0,5,15 \%$ & $0 \%, 5 \%$ \\
\hline $\begin{array}{l}\text { Análise de } \\
\text { Impacto } \\
\text { Financeiro }\end{array}$ & Não & $\begin{array}{l}\text { Para primeiros três anoas } \\
\text { após inclusão }\end{array}$ & $\begin{array}{l}\text { Primeiro e segundo ano de } \\
\text { comercialização }\end{array}$ & Não & Não & Sim, separadamente \\
\hline
\end{tabular}




\begin{tabular}{|c|c|c|c|c|c|}
\hline & Portugal & Rússia (Federação) & Suécia & Suíça & Brasil \\
\hline $\begin{array}{l}\text { Título e ano } \\
\quad \text { do } \\
\text { Documento }\end{array}$ & $\begin{array}{c}\text { "Guidelines for economic } \\
\text { drug evaluation studies", } \\
1998\end{array}$ & $\begin{array}{l}\text { "The standardization } \\
\text { system in the Russian } \\
\text { federation health care } \\
\text { system. Clinico-economic } \\
\text { studies", } 2002\end{array}$ & $\begin{array}{l}\text { "General guidelines for } \\
\text { economic evaluation } \\
\text { from the } \\
\text { Pharmaceutical } \\
\text { Benefits Board", } 2003\end{array}$ & $\begin{array}{c}\text { "Manual for the } \\
\text { standardization of clinical } \\
\text { and economic evaluation } \\
\text { of medical technology", } \\
1998\end{array}$ & $\begin{array}{c}\text { "Diretrizes } \\
\text { metodológicas para } \\
\text { estudos de avaliação } \\
\text { econômica te } \\
\text { tecnologias para o } \\
\text { Ministério da Saúde", } \\
\text { versão preliminar, } \\
2008 \\
\end{array}$ \\
\hline Perspectiva & $\begin{array}{l}\text { Sociedade, aberta em } \\
\text { perspectivas relevantes }\end{array}$ & $\begin{array}{l}\text { Sociedade, Sistema de } \\
\text { Saúde Federal, } \\
\text { Institucional, Paciente e } \\
\text { Família, Seguradoras }\end{array}$ & Sociedade & $\begin{array}{l}\text { Sociedade, } \\
\text { Pagador/Agência de } \\
\text { reembolso, Provedor, } \\
\text { Paciente, Empregador }\end{array}$ & $\begin{array}{l}\text { Sistema de Saúde; } \\
\text { Sociedade, com } \\
\text { abertura }\end{array}$ \\
\hline $\begin{array}{l}\text { Custos a } \\
\text { serem } \\
\text { incluídos }\end{array}$ & $\begin{array}{l}\text { Custos diretos de cuidado } \\
\text { à saúde, custos dos } \\
\text { serviços sociais e outros } \\
\text { setores relacionados, } \\
\text { custos para os pacientes e } \\
\text { suas famílias. Inclusão de } \\
\text { perdas de produtividade, } \\
\text { mensuradas pelo Método } \\
\text { do Capital Humano, deve } \\
\text { ser justificada. } \\
\end{array}$ & $\begin{array}{l}\text { Inclusão mais completa } \\
\text { possível de custos (custos } \\
\text { diretos médicos e não } \\
\text { médicos, custos indiretos). }\end{array}$ & $\begin{array}{c}\text { Todos os custos } \\
\text { relevantes. Perda de } \\
\text { produtividade pelo } \\
\text { Método de Capi.tal } \\
\text { Humano }\end{array}$ & $\begin{array}{l}\text { Depende da perspectiva } \\
\text { do estudo. }\end{array}$ & $\begin{array}{c}\text { Depende da } \\
\text { perspectiva do estudo. }\end{array}$ \\
\hline $\begin{array}{l}\text { Fontes dos } \\
\text { Custos }\end{array}$ & $\begin{array}{l}\text { Custos padrões (preços de } \\
\text { tratamento). }\end{array}$ & $\begin{array}{l}\text { Tarifas de Serviços } \\
\text { Médicos no MMI, tarifas } \\
\text { de serviços comerciais } \\
\text { médicos, tarifas médias de } \\
\text { 3-5 instituições, cálculos } \\
\text { próprios. Estimativas de } \\
\text { preços médios de } \\
\text { medicamentos. }\end{array}$ & $\begin{array}{l}\text { Preços de venda } \\
\text { (Apoteket) para } \\
\text { medicamentos. }\end{array}$ & $\begin{array}{c}\text { Taxas de reembolso } \\
\text { estabelecidas pelos } \\
\text { seguros de saúde, tarifas e } \\
\text { outras taxas admiistrativas } \\
\text { fixas ao invés de preços de } \\
\text { mercado. }\end{array}$ & $\begin{array}{c}\text { Tabelas de } \\
\text { remuneração do SUS, } \\
\text { considerando a } \\
\text { perspectiva do sistema } \\
\text { de saúde.. }\end{array}$ \\
\hline $\begin{array}{c}\text { Desconto de } \\
\text { Custos }\end{array}$ & $5 \%$ & $5 \%$ & Base:3\%; AS:0 5\% & $2.5 \%, 5 \%, 10 \%$ & Base: $5 \%$, AS: $0,10 \%$ \\
\hline $\begin{array}{c}\text { Desconto de } \\
\text { Desfechos }\end{array}$ & $5 \%$ ou sem desconto & - & $\begin{array}{c}\text { Base:3\%; AS:0 5\%; } \\
0 \%\end{array}$ & $2.5 \%, 5 \%, 10 \%$ & $\begin{array}{c}\text { Base: } 5 \%, \text { AS: } 0, \\
10 \% \\
\end{array}$ \\
\hline $\begin{array}{l}\text { Análise de } \\
\text { Impacto } \\
\text { Financeiro }\end{array}$ & Não & Não & Não & $\begin{array}{c}\text { Não especificado, } \\
\text { mencionado estimação de } \\
\text { custo baseado em } \\
\text { prevalência }\end{array}$ & Incluir \\
\hline
\end{tabular}

Fonte: Pharmacoeconomic Guidelines Around The World (ISPOR. Disponível em: <http://www.ispor.org/peguidelines/index.asp>. Acesso: 20 de abril de 2008); Schulenburg e Hoffmann, 2000. 
Tabela ii. Probabilidades usadas na análise de custo-efetividade da vacinação contra rotavírus, Brasil

\begin{tabular}{|c|c|c|c|}
\hline Probabilidades & $\begin{array}{l}\text { Valor para o } \\
\text { caso base }\end{array}$ & $\begin{array}{l}\text { Intervalos - Análise } \\
\text { de sensibilidade }\end{array}$ & Fonte \\
\hline \multicolumn{4}{|l|}{ Impacto da doença } \\
\hline Incidência de diarréia & 1 & & Sartori et al (2008), Premissa \\
\hline Diarréia por rotavírus leve & 0,7437 & $(0,6392-0,8335)$ & Sastry et al (2005),Premissa \\
\hline $\begin{array}{l}\text { Diarréia por rotavírus } \\
\text { moderada }\end{array}$ & 0,2247 & $(0,1438-32,18)$ & Sartori et al (2008) \\
\hline Diarréia por rotavírus grave & 0,0316 & $(0,0227-0,039)$ & Sartori et al (2008) \\
\hline Hospitalização por rotavírus ${ }^{\text {a }}$ & 0,9908 & & Sartori et al (2008) \\
\hline Mortalidade por rotavírus $^{\text {a }}$ & 0,0092 & $\pm 25 \%$ do caso base & Sartori et al (2008) \\
\hline Cobertura vacinal (\%) & & \pm 10 do caso base & \\
\hline Não vacinados & 0,10 & & PNI, Premissa \\
\hline Vacinados & 0,90 & & PNI, Premissa \\
\hline 2 doses ${ }^{b}$ & 0,80 & & PNI, Premissa \\
\hline 1 dose $^{b}$ & 0,20 & & PNI, Premissa \\
\hline \multicolumn{4}{|l|}{ Eficácia da vacina } \\
\hline \multicolumn{4}{|l|}{2 doses } \\
\hline Contra diarréia leve & 0,63 & $(0,56-0,70)$ & Salinas et al (2005), Premissa \\
\hline Contra diarréia moderada & 0,63 & $(0,56-0,70)$ & Salinas et al (2005), Premissa \\
\hline Contra diarréia grave & 0,847 & $(0,717-0,924)$ & Ruiz-Palacios et al (2006) \\
\hline \multicolumn{4}{|l|}{1 dose } \\
\hline Contra diarréia leve & 0,50 & $(0,44-0,56)$ & Salinas et al (2005), Premissa \\
\hline Contra diarréia moderada & 0,50 & $(0,44-0,56)$ & Salinas et al (2005), Premissa \\
\hline Contra diarréia grave & 0,818 & $(0,684-0,924)$ & Ruiz-Palacios et al (2006) \\
\hline
\end{tabular}

${ }^{a}$ De todas as diarréias graves (3,16\% do total de diarréias) 99,08\% constituiriam casos hospitalares com recuperação e $0,92 \%$ evoluíram p/ morte.

${ }^{\mathrm{b}}$ Dos vacinados (90\% do total da população), $80 \%$ (72\% do total da população) receberam 2 doses e $20 \%$ (18\% do total da população) receberam 1 dose.

Fonte: Sóarez et al, 2008. 
Tabela iii. Participação pública e privada por tipo de atendimento recebido em serviços de saúde, crianças menores de 5 anos, Brasil, 2003

\begin{tabular}{|c|c|c|c|c|c|c|c|c|}
\hline & \multirow{3}{*}{ Atendimento recebido (V3360) } & \multicolumn{5}{|c|}{ Serviço era público ou privado? (V1361) } & \multicolumn{2}{|c|}{ Participação } \\
\hline & & & & Não & Não- & & & \\
\hline & & Público & Particular & sabe & aplicável & Total & Público & Particular \\
\hline 01 & Consulta médica & 1.097 .193 & 397.582 & 2.178 & & 1.496 .953 & $73 \%$ & $27 \%$ \\
\hline 02 & Consulta odontológica & 318 & 704 & & & 1.022 & $31 \%$ & $69 \%$ \\
\hline 03 & Consulta de agente comunitário ou de parteira & 499 & & & & 499 & $100 \%$ & $0 \%$ \\
\hline 04 & Consulta de outros profissionais de saúde (fonoaudiólogos, psicólogos, etc.) & 3.424 & 2.176 & & & 5.600 & $61 \%$ & $39 \%$ \\
\hline 05 & Consulta na farmácia & 543 & 21.598 & & & 22.141 & $2 \%$ & $98 \%$ \\
\hline 06 & Quimioterapia, radioterapia, hemodiálise, hemoterapia & 339 & 487 & & & 826 & $41 \%$ & $59 \%$ \\
\hline 07 & Vacinação, injeção, curativo, medição de pressão ou outro atendimento & 28.269 & 5.138 & & & 33.407 & $85 \%$ & $15 \%$ \\
\hline 08 & Cirurgia em ambulatório & 694 & 639 & & & 1.333 & $52 \%$ & $48 \%$ \\
\hline 09 & Gesso ou imobilização & 865 & & & & 865 & $100 \%$ & $0 \%$ \\
\hline 10 & Internação hospitalar & 31.400 & 9.413 & & & 40.813 & $77 \%$ & $23 \%$ \\
\hline 11 & Exames complementares & 15.825 & 8.918 & & & 24.743 & $64 \%$ & $36 \%$ \\
\hline 12 & Somente marcação de consulta & & & & 4.627 & 4.627 & $0 \%$ & $0 \%$ \\
\hline \multirow[t]{3}{*}{13} & Outro atendimento & 9.792 & 5.755 & & & 15.547 & $63 \%$ & $37 \%$ \\
\hline & Não-aplicável & & & & 26.983 & 26.983 & $0 \%$ & $0 \%$ \\
\hline & Total & 1.189 .161 & 452.410 & 2.178 & 31.610 & 1.675 .359 & $71 \%$ & $27 \%$ \\
\hline
\end{tabular}

Fonte: PNAD 2003, elaboração própria.

Amostra expandida para a população (ponderação V4729 - peso da pessoa). Seleção de dados: Crianças $<5$ anos $($ V8005<5) cujo motivo de atendimento foi Doença (V3351=9). 
Tabela iv. Proporção de medicamentos prescritos que são recebidos gratuitamente no SUS, Brasil, 2003.

\begin{tabular}{lc}
\hline Faixa etária & Medicamento receitado que é recebido gratuitamente* \\
\hline$<1 \mathrm{a}$ & $32,1 \%$ \\
$1-4 \mathrm{a}$ & $39,6 \%$ \\
$5-9 \mathrm{a}$ & $39,1 \%$ \\
$10-14 \mathrm{a}$ & $38,8 \%$ \\
$15-44 \mathrm{a}$ & $30,7 \%$ \\
$45-64 \mathrm{a}$ & $36,9 \%$ \\
$+65 \mathrm{a}$ & $35,9 \%$ \\
\hline Total & $34,7 \%$ \\
\hline
\end{tabular}

Fonte: PNAD 2003. Tabulação própria. *Exceto amostra grátis. Foi usada como proxy para a dispensação pública de medicamentos a variável V1363 dos microdados da PNAD, cuja pergunta foi "Recebeu algum medicamento gratuito (exceto amostra grátis)". 
Tabela v. Custos unitários médios por tipo de tratamento, Sistema Único de Saúde e Sistema de Saúde Suplementar, rotavírus, Brasil, reais de 2004

\begin{tabular}{lrrr}
\hline Itens de Custo & Domiciliar & Ambulatorial & Hospitalar \\
\hline Consultas & & 15,02 & 13,02 \\
Exames Complementares & & 0,96 & 21,06 \\
Medicamentos & 3,35 & 7,60 & 21,01 \\
Produtos & 8,43 & 20,87 & 16,41 \\
Internação & & & 383,83 \\
Transporte & & 6,23 & 13,08 \\
Custos de produtividade & & 6,30 & 10,58 \\
\hline
\end{tabular}


Tabela vi. Parâmetros utilizados no modelo de análise de custo-efetividade da introdução da vacinação universal contra varicela na infância, Brasil

\begin{tabular}{|c|c|c|c|}
\hline Parâmetro & $\begin{array}{l}\text { Valor para o caso } \\
\text { base }\end{array}$ & $\begin{array}{l}\text { Intervalo- Análise de } \\
\text { sensibilidade }\end{array}$ & Fonte \\
\hline \multicolumn{4}{|l|}{ Epidemiológicos } \\
\hline Taxa de letalidade & $0,004 \%$ & $(0,003 \% ;, 006 \%)$ & SIM \\
\hline Taxa de seqüela & $0,00015 \%$ & $(0,000075 \% ; 0,000225 \%)$ & SIH;Whitley (2005) \\
\hline \multicolumn{4}{|l|}{ Serviços de Saúde } \\
\hline Atendimento em Serviços de Saúde & $30 \%$ & $(20 \% ; 60 \%)$ & Premissa; Brisson et al $(2002,2003)$ \\
\hline Hospitalizações & $0,15 \%$ & $(0,15 \% ; 0,27 \%)$ & SIH, PNAD \\
\hline \multicolumn{4}{|l|}{ Vacinação } \\
\hline Eficácia da vacina & $85 \%$ & - & $\begin{array}{l}\text { Hambleton et al (2005); Seward et al } \\
(2008)\end{array}$ \\
\hline Cobertura vacinal & $80 \%$ & $(75 \% ; 85 \%)$ & Premissa \\
\hline Número de doses & 1 & $(1 ; 2)$ & Marin et al (2007) \\
\hline Taxa de desperdício & $10 \%$ & $(7,5 \% ; 12,5 \%)$ & Podewils et al(2005) \\
\hline
\end{tabular}

Fonte: Valentim et al, 2008a. 
Tabela vii. Participação pública e privada por tipo de atendimento recebido em serviços de saúde, população total, Brasil, 2003

\begin{tabular}{|c|c|c|c|c|c|c|c|c|}
\hline & \multirow{3}{*}{ Atendimento recebido (V3360) } & \multicolumn{5}{|c|}{ Serviço era público ou privado? (V1361) } & \multicolumn{2}{|c|}{ Participação } \\
\hline & & & & Não & Não- & & & \\
\hline & & Público & Particular & sabe & aplicável & Total & Público & Particular \\
\hline 01 & Consulta médica & 7.613 .298 & 3.541 .873 & 20.184 & 215 & 11.175 .570 & $68 \%$ & $32 \%$ \\
\hline 02 & Consulta odontológica & 12.072 & 12.005 & 0 & & 24.077 & $50 \%$ & $50 \%$ \\
\hline 03 & Consulta de agente comunitário ou de parteira & 10.560 & 209 & 0 & & 10.769 & $98 \%$ & $2 \%$ \\
\hline 04 & Consulta de outros profissionais de saúde (fonoaudiólogos, psicólogos, etc.) & 75.241 & 66.469 & 576 & & 142.286 & $53 \%$ & $47 \%$ \\
\hline 05 & Consulta na farmácia & 8.217 & 227.917 & 1.732 & & 237.866 & $3 \%$ & $96 \%$ \\
\hline 06 & Quimioterapia, radioterapia, hemodiálise, hemoterapia & 51.176 & 25.907 & 1.198 & & 78.281 & $65 \%$ & $33 \%$ \\
\hline 07 & Vacinação, injeção, curativo, medição de pressão ou outro atendimento & 211.470 & 64.623 & 1.769 & & 277.862 & $76 \%$ & $23 \%$ \\
\hline 08 & Cirurgia em ambulatório & 58.155 & 45.111 & 338 & & 103.604 & $56 \%$ & $44 \%$ \\
\hline 09 & Gesso ou imobilização & 9.299 & 6.430 & 0 & & 15.729 & $59 \%$ & $41 \%$ \\
\hline 10 & Internação hospitalar & 219.724 & 101.732 & 1.736 & 210 & 323.402 & $68 \%$ & $31 \%$ \\
\hline 11 & Exames complementares & 272.681 & 165.910 & 2.823 & & 441.414 & $62 \%$ & $38 \%$ \\
\hline 12 & Somente marcação de consulta & 0 & 0 & 0 & 81.177 & 81.177 & $0 \%$ & $0 \%$ \\
\hline \multirow[t]{3}{*}{13} & Outro atendimento & 83.219 & 74.066 & 1.347 & & 158.632 & $52 \%$ & $47 \%$ \\
\hline & Não-aplicável & & & & 269.966 & 269.966 & $0 \%$ & $0 \%$ \\
\hline & Total & 8.625 .112 & 4.332 .252 & 31.703 & 351.568 & 13.340 .635 & $65 \%$ & $32 \%$ \\
\hline
\end{tabular}

Fonte: PNAD 2003, elaboração própria.

Amostra expandida para a população (ponderação V4729 - peso da pessoa). Seleção de dados: População total cujo motivo de atendimento foi Doença (V3351=9). 
Tabela viii. Custos unitários médios por tipo de tratamento e faixa etária, Sistema Único de Saúde e Sistema de Saúde Suplementar, varicela, Brasil, reais de 2004

\begin{tabular}{|c|c|c|c|c|c|c|c|c|c|c|c|c|c|c|}
\hline \multirow[b]{2}{*}{ Itens de Custo por faixa etária } & \multicolumn{7}{|c|}{ Ambulatorial } & \multicolumn{7}{|c|}{ Hospitalar } \\
\hline & $<1$ & $1--4$ & $5--9$ & $10--14$ & $15-44$ & $45-64$ & $>65$ & $<1$ & $1--4$ & $5--9$ & $10--14$ & $15-44$ & $45-64$ & $>65$ \\
\hline Consultas & 16,00 & 14,59 & 14,30 & 15,41 & 16,52 & 16,10 & 16,67 & 16,00 & 14,59 & 14,30 & 15,41 & 16,52 & 16,10 & 16,67 \\
\hline Exames Complementares & 1,24 & 1,24 & 1,24 & 1,24 & 1,64 & 1,64 & 1,64 & 1,24 & 1,24 & 1,24 & 1,24 & 1,64 & 1,64 & 1,64 \\
\hline Medicamentos & 2,73 & 2,73 & 2,73 & 6,95 & 6,95 & 6,95 & 6,95 & 2,73 & 2,73 & 2,73 & 6,95 & 6,95 & 6,95 & 6,95 \\
\hline Internação & & & & & & & & 391,84 & 405,36 & 419,57 & 411,12 & 398,36 & 457,67 & 571,15 \\
\hline Transporte & 4,13 & 3,77 & 3,43 & 3,70 & 3,97 & 3,87 & 4,00 & 15,30 & 15,49 & 15,49 & 6,40 & 6,40 & 6,40 & 6,40 \\
\hline Custos de produtividade & 4,15 & 4,15 & 4,15 & 4,15 & 110,03 & 137,41 & 0,00 & 74,80 & 75,74 & 75,74 & 71,98 & 263,63 & 405,10 & 0,00 \\
\hline
\end{tabular}




\section{REFERÊNCIAS BIBLIOGRÁFICAS}

Adam T, Evans DB, Koopmanschap MA. Cost-effectiveness analysis: can we reduce variability in costing methods? International Journal of Technology Assessmente in Health Care, 19:2 (2003), 407-420.

Afonja AS. Rapid assessment methodologies: Application to health and nutrition programmes in Africa. In: Scrimshaw NS, Gleason GR, editors. Rapid assessment procedures - qualitative methodologies for planning and evaluation of health related programs. Boston, MA: International Nutrition Foundation for Developing Countries (INFDC), 1992.

Akobundu E, Ju J, Blatt L, Mullins CD. Cost-of-Illness Studies, Pharmacoeconomics, 2006; 24(9): 869-90.

Andrade MV, Maia AC, Noronha KVMS, Financiamento do Setor de Saúde Suplementar no Brasil: uma investigação empírica a partir dos dados da PNAD/98, Fórum de Saúde Suplementar, ANS.

Andrus JK, Fitzsimmons J, Carrasco P, di Fabio JL, Tambini G, Periago MR. Fundo Rotatório de Imunização da OPAS: sustentabilidade de programas de imunização na América Latina e Caribe, in Buss, PM, Temporão, JG, Carvalheiro, JR (org) Vacinas, Soros \& Imunizações no Brasil, Fiocruz, RJ, 2005.

Araújo DV, Tavares LR, Veríssimo R, Ferraz MB, Mesquita ET. Custo da Insuficiência Cardíaca no Sistema Único de Saúde, Arquivos Brasileiros de Cardiologi, vol. 84, $\mathrm{n}^{\mathrm{o}}$ 5, maio 2005.

Arrow K. Uncertainty and the welfare economics of medical care, The American Economic Review, vol. LIII, no 5, 1963.

Banz K, Wagenpfeil S, Neiss A, et al. The cost-effectiveness of routine childhood varicella vaccination in Germany. Vaccine, 2003; 21:1256-67.

Banz K, Wagenpfeil S, Neiss A, Hammerschmidt T, Wutzler P. The burden of varicella in Germany, Eur J Health Econom, 2004, 5: 46-53.

Beutels P, Clara R, Tormans G, Van Doorslaer E, Van Damme P. Costs and benefits of routine varicella vaccination in German children. J Infect Dis 1996; 174 (suppl 3): $335-341$.

Beutels P, Van Doorslaer E, Van Damme P, Hall J. Methodological issues and new developments in the economic evaluation of vaccines, Expert Review of Vaccines, 2003.

Beutels P, Van Damme P, Oosterhuis-Kafeja F. Effecten en kosten van de vaccinatie van Belgische kinderen met geconjugeerd pneumococcenvaccin. Health Technology 
Assessment (HTA). Brussel: Federaal Kenniscentrum voor de gezondheidszorg (KCE); 2006. KCE reports 33A (D/2006/10.273/21).

BCB (Banco Central do Brasil). Disponível em: http://www5.bcb.gov.br/pec/conversao/conversao.asp?id=txconversao $>$. Acesso: $15 / 01 / 2005$.

Bittencourt ONS. O Emprego do Método de Custeio Baseado em Atividades Activity-Based Costing (ABC) - como instrumento e apoio à decisão na área hospitalar. Dissertação de Mestrado apresentada à Escola de Administração da Universidade Federal Do Rio Grande Do Sul, Porto Alegre, 1999.

Bloom D; Canning D, Weston M. The Value of Vaccination. World Economics, vol.6, no.3, 2005.

Bos JM, Beutels P, Annemans L, Postma MJ. Valuing prevention through economic evaluation: some considerations regarding the choice of discount model for health effects with focus on infectious disease. Pharmacoeconomics 2004; 22: 1171-9.

Bos JM, Postma MJ, L, Annemans L. Discounting Health Effects in Pharmacoeconomic Evaluations Current Controversies. Pharmacoeconomics 2005; 23 (7): 639-649.

Brasil, Ministério da Saúde, Secretaria de Assistência à Saúde (SAS). Relatório de Compatibilidade Procedimento x CID, Brasília, Janeiro de 2003.

Brasil, Ministério da Saúde. Orçamento 2004. Disponível em: $<$ http://portal.saude.gov.br/portal/arquivos/pdf/LOA_2004.pdf $>$. Acesso: 20 de junho de 2008.

Brasil, Ministério da Saúde. Portaria no 972 de 03 de maio de 2006, Gabinete do Ministro, publicada em 04/05/2006. Disponível em: $<$ http://portal.saude.gov.br/saudelegis/>. Acesso: 21 de junho de 2008 .

Brasil, Ministério da Saúde, Secretaria de Ciência, Tecnologia e Insumos Estratégicos, Departamento de Ciência e Tecnologia. Diretrizes Metodológicas para Estudos de Avaliação Econômica de Tecnologias em Saúde para o Ministério da Saúde, Brasília, 2007 (versão preliminar).

Brasil, Ministério da Saúde. Programa Nacional de Imunizações (PNI). Imunobiológicos Especiais e suas Indicações. Disponível em: $<$ http://portal.saude.gov.br/portal_arquivos/pdf/cries_indicações_271106.pdf $>$. Acesso: 28 de Janeiro de 2008.

Brasil, Ministério da Saúde. Portaria no 978 de 16 de maio de 2008, Gabinete do Ministro, Diário Oficial da União, Brasília, publicada em 19/05/2008. 
Brisson M, Edmunds WT. The cost-effectiveness of varicella vaccination in Canada. Vaccine 2002; 20: 1113-25.

Brisson M, Edmunds W J. Varicella vaccination in England and Wales: cost-utility Analysis, Arch Dis Child 2003;88:862-869.

Brisson M, Edmunds WJ. Impact of Model, Methodological, and Parameter Uncertainty in the Economic Analysis of Vaccination Programs, Med Decis Making 2006; 26:434-446.

Brouwer WBF, Koopmanschap MA. On the economic foundations of CEA. Ladies and gentlemen, take your positions! Journal of Health Economics 19 (2000) 439459 .

Brouwer WBF, van Exel NJA, Koopmanschap MA, Rutten FFH. Productivity costs before and after absence from work: as important as common? Health Policy 61 (2002) 173-187.

Brouwer WBF, Culyer AJ, van Exel NJA, Rutten AAH. Welfarism vs. Extrawelfarism. Journal of Health Economics 27 (2008) 325-338.

Brue SL, História do Pensamento Econômico, SP: Thomson, 2005.

Buchanan JM. Essays on the political economy, Honolulu: University of Hawaii, 1989.

Burckel E, Ashraf T, Sousa Filho JPG, Forleo Neto E, Guarino H, Yauti C et al. Economical Impact of Pruividing Workplace Ingluenza Vaccination, Pharmacoecnomics 1999, 16(5): 563-76.

Buss PM, Temporão JG, Carvalheiro JR (org), Vacinas, Soros e Imunizações no Brasil, RJ: Editora Fiocruz, 2005.

Byford S, McDaid D, Sefton T, Because it's worth it. A practical guide to conducting economic evaluation in the social welfare field. Contemporary research issues. Joseph Rowntree Foundation, York, UK, 2003.

Caplin A, Leahy J.The Social Discount Rate," Journal of Political Economy, 2004, $112,1257-1268$.

Carlin JB, Jackson T, Lane L, Bishop RF, Barnes GL. Cost-effectiveness of rotavirus vaccination in Australia. Aust N Z J Public Health, 1999; 23(6):611-6.

Carvalho DMT, Financiamento da assistência médico-hospitalar no Brasil, Ciência\&Saúde Coletiva, 12 (4): 879-892, 2007. 
Constenla D, O'Ryan M, Navarrete MS, Antil L, Rheingans RD. Evaluación de costo-efectividad de la vacuna anti-rotavirus en Chile. Rev Méd Chile, 2006 Jun;134(6):679-88.

Coudeville L, Paree F, Lebrun T, Sailly JC. The value of varicella vaccination in healthy children: cost-benefit analysis of the situation in France. Vaccine. 1999; $17(2): 142-51$.

Coudeville L, Brunot A, Giaquinto C, Lucioni C, Dervaux B. Varicella vaccination in Italy: an economic model evaluation of different scenarios. Pharmacoeconomics 2004; 22(13):839-55.

Coudeville L, Brunot A, Szucs TD, Dervaux B. The economic value of childhood varricella vaccination in France and Germany. Value in Health 2005; 8(3):209-22.

Culyer A.J. The normative economics of health care finance and provision. In: McGuire A, Fenn P, Mayhew K (eds) Providing Health Care: The Economics of Alternative Systems of Finance and Delivery. Oxford Univ. Press, Oxford, 1991.

Curtis L, Netten A. Unit costs of health \& social care, PSSRU, University of Kent, 2006.

Cyrillo D, Aguirre B, Paulani L, Campino ACC, Oliveira RG, Paccez JD. Custos Diretos do Tratamento de AIDS no Brasil: Metodologias e Estimativas Preliminares, Relatório de Conteúdo Estimativa dos Custos dos Tratamentos da AIDS no Brasil 1996, Sub-projeto CA-96, FIPE, MS, PN DST/AIDS, SP: 1998.

DATASUS. Informações de Saúde. Disponível em: $<$ http://tabnet.datasus.gov.br/cgi/tabcgi.exe?pni/cnv/DPniuf.def $>$. Acesso: 9 de Janeiro de 2006.

DATASUS. Sistema de Informações Ambulatoriais (SIA). Disponível em: < http://w3.datasus.gov.br/datasus/datasus.php?area=359A1B375C2D0E0F359G902H 0I1Jd2L22M0N\&VInclude=../site/infsaude1.php $>$.

DATASUS. Sistema de Informações Hospitalares (SIH). Disponível em: < http://w3.datasus.gov.br/datasus/datasus.php?area=359A1B375C2D0E0F359G902H 0I1Jd2L22M0N\&VInclude=../site/infsaude1.php $>$.

DATASUS. Sistema de Informações de Mortalidade (SIM). Disponível em: $<$ http://w3.datasus.gov.br/datasus/datasus.php?area=359A1B378C5D0E0F359G22H 0I1Jd5L25M0N\&VInclude=../site/infsaude.php $>$.

Davis MM, Varicella Vaccine, Cost-effectiveness Analyses, and Vaccination Policy, $J A M A, 2005$, vol 294, no 7.

Díez Domingo J, Ridao M, Latour J, Ballester A, Morant A. A cost benefit analysis of routine varicella vaccination in Spain. Vaccine 1999; 17(11-12):1306-11. 
Dranove D. Measuring costs, in Sloan F (ed) Valuing health care. Costs, benefits and effectiveness of pharmaceuticals and other medical technologies, Cambridge University Press, p:61-75, 1996.

Drèze J, Stern N. Policy reform, shadow prices and market prices, Journal of Public Economics, 1990,42, 1-45.

Drummond MF, Schulpher M, Torrance JW, O'Brien BJ, Stoddart GL. Methods for the Economic Evaluation of Health Care Programmes, Oxford: Oxford University Press, 1997.

Drummond MF, Chevat C, Lothgren M, Do we fully understand the economic value of vaccines? Vaccine 25 (2007) 5945-57.

Fapesp, Pesquisa Fapesp, março 2007, no 133.

Feldstein MS.The derivation of social time preference rates, Kyklos 18, 277-87, 1965.

Finkler SA. The distinction between costs and charges, Annals of Internal Medicine, 102-109, 1982.

Fisher TK, Anh DD, Antil L, Cat ND, Kilgore PE, Thiem VD, et al. Health care costs of diarrheal disease and estimates of the cost-effectiveness of rotavirus vaccination in Vietnam, $J$ Infect Dis, 2005 Nov 15;192(10):1720-6.

Fiuza EPS, Lisboa MB. Bens Credenciais e Poder de Mercado: Um Estudo Econométrico da Indústria Farmacêutica Brasileira, Seminários EPGE, 2001.

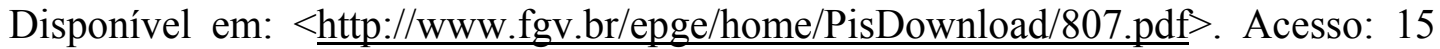
de janeiro de 2003.

Gadelha CAG. Complexo Econômico-Industrial da Saúde: uma visão geral. Seminário sobre o Complexo Econômico-Industrial da Saúde, BNDES/Ministério da Saúde, RJ, 19 a 21 de maio de 2008, Diapositivo.

Galea SA, Sweet A, Beninger P, Steinberg SP, LaRussa PS, Gershon AA, Sharrar RG. The safety profile of varicella vaccine: a 10-year review, J Infect Dis, 2008; 197 (Suppl 2): S165-9.

Galambos L. What are the prospects for a new golden era in vaccines? em Health system snapshots: perspectives from six countries, Eurohealth v.14 n.1, 2008.

Garber AM, Phelps CE. Economic foundations of cost-effectiveness analysis, Journal of Health Economics 16 (1997) 1-31.

Getsios D, Caro JJ, Caro $G$ et al. Instituting a routine varicella vaccination program in Canada: an economic evaluation, Pediatr Infect Dis J, 2002; 21:542-7. 
Ginsberg GM, Somekh E. Cost containment analysis of childhood vaccination against varicella in Israel, Journal of Infection, 2004; 48:119-33.

Glass RI, Bresee JS, Turcios R, Fischer TK, Parashar UD, Steele D. Rotavirus vaccines: targeting the developing world, Journal of Infectious Diseases, 2005; 192(suppl 1):S160-S166.

Gold M, Siegel JE, Russel LB, Weinstein MC. Cost-Effectivenness in Health and Medicine. Oxford: Oxford University Press, 1996.

Goldman GS. Cost-benefit analysis of universal varicella vaccination in the U.S. taking into account the closely related herpes-zoster epidemiology, Vaccine, 2005; 9;23(25):3349-55.

Gomes RM. Tabela de procedimentos, medicamentos e OPM do SUS. MS, SAS, DRAC e CGSI, 2007, Diapositivo.

Graeve D, Beutels P. Economic Aspects of Pneumococcal Pneumonia: A Review of the Literature, Pharmacoeconomics 2004; 22 (11): 719-740.

Guimarães R, Santos LMP, Angulo-Tueste A, Serruya SJ. Defining and implementing a National Policy dor Science and Technology and Innovation in Health: lessons from the Brazilian experience, Cad. Saúde Pública, RJ, 22(9): 17751794, 2006.

Guris D, Jumaan AO, Mascola L, Watson BM, Zhang JX, Chaves SS, et al. Changing varicella epidemiology in active surveillance-United States, 1995-2005, $J$ Infect Di,. 2008.

Gyldmark M, A review of cost studies of intensive care units: problems with the cost concept, Crit Care Med, 1995; 23 (5): 964-72.

Hambleton S, Gershon AA. Preventing Varicella-zoster disease, Clin Microbiol Reviews, 2005; 18 (1): 70-80.

Hambleton S, Phill D, Gershon AA. The impact of varicella vaccination in the United States. Semin Pediatr Infect Dis, 2005a; 16: 38-43.

Hammod J, Keeney R, Raiffa H. Smart choice. A practical guide to making better decisions. Harvard Business School Press. Boston, EUA, 1999.

Hanslik T, Boelle PY, Schwarzinger M, et al. Varicella in French adolescents and adults: individual risk assessment and cost-effectiveness of routine vaccination, Vaccine, 2003;21:3614-22.

Hauck K, Smith P, Goddard M.The economics of priority setting for health care: a literature review, HNP Discussion Paper 28878, 2004. 
Heininger U, Seward JF. Varicella. Lancet. 2006; 368: 1365-76.

Hepburn C. Discounting climate change damages: Working note for the Stern review, mimeo, 2006.

Hjelmgren J, Berggren F, Andersson F. Health Economic Guidelines - Similarities, Differences and Some Implications, Value in Health, vol.4, no3, 2001.

Homma A. Caminhos para o desenvolvimento da biotecnologia da produção pública de imunobiológicos no Brasil. Mesa: Estratégias dos Produtores Públicos em Biotecnologia: desafios para o desenvolvimento tecnológico. Seminário sobre o Complexo Econômico-Industrial da Saúde, BNDES/Ministério da Saúde, RJ, 19 a 21 de maio de 2008, Diapositivo.

Hsu HC, Lin RS, Tung TH, Chen THH. Cost-benefit analysis of routine childhood vaccination against chickenpox in Taiwan: decision from different perspectives, Vaccine, 2003; 21:3982-87.

Hurley J. Welfarism, extra-welfarism and evaluative economic analysis in the health care sector. In: Barer ML, Getzen TE, Stoddard GL (eds) Health, Health Care and Health Economics: Perspectives on Distribution. Wiley, Chichester, 1998.

Huse DM, Meissner HC, Lacey MJ, et al. Childhood vaccination against chickenpox: an analysis of benefits and costs, J Pediatr, 1994;124(6):869-874.

IBGE, Instituto Brasileiro de Geografia e Estatística. Censo Demográfico 2000. Disponível em: $<$ http://www.ibge.gov.br/home/estatistica/populacao/default_censo_2000.shtm>. Acesso: 30 de janeiro de 2006.

IBGE, Instituto Brasileiro de Geografia e Estatística. Pesquisa Nacional de Amostra de Domicílios (PNAD), Cd-Rom 2003.

IBGE, Instituto Brasileiro de Geografia e Estatística. Sistema de Contas Nacionais. Disponível em: $\quad<\mathrm{http} / /$ www.ibge.gov.br/home/estatistica/economia/contas nacionais/referencia2000/2005/default.shtm>. Acesso: 7 de novembro de 2007.

IBGE, Instituto Brasileiro de Geografia e Estatística. Produto Interno Bruto dos Municípios 2002-2005. Disponível em: $<$ http://www.ibge.gov.br/home/estatistica/economia/pibmunicipios/2005/tab01.pdf $>$. Acesso: 09 de junho de 2008.

Iglesias CP, Drummond MF, Rovira J. Health-care decision-making processes in Latin América: Problems and prospects for the use of economic evaluation. International Journal of Technology Assessmente in Health Care, 21:1 (2005), 1-14. 
ISPOR, International Society for Pharmacoeconomics and Outcomes Research. Conferência $2^{\circ}$ Capítulo Brasileiro. Disponível em: < http://www.ispor.org/local_chapters/Brazil/index.asp>. Acesso: 04/06/2008.

Jiang B, Gentsch JR, Glass RI. The role of serum antibodies in the protection against rotavirus disease: an overview, Clin Infec Dis, 2002; 34:1351-61.

Kane R, Johnson RL, Town RJ, Bulter M. Economic Incentives for Preventive Care. Evidence Report/Technology Assessment No. 101, AHRQ Publication no. 04-E0242. Rockville, MD. Agency for Healthcare Research and Quality, 2004.

Koopmanschap MA, Rutten FFH, van Ineveld BM, van Roijen L. The friction cost method for measuring indirect costs of disease, Journal of Health Economics 14 (1995) 171-189.

Kuter B, Matthews H, Shinefield H, Black S, Dennehy P, Watson B, et al. Ten years follow-up of healthy children who received one or two injections of varicella vaccine, Pediatr Infect Dis J, 2004; 23: 132-7.

Labelle R, Stoddart G, Rice T. A re-examination of the meaning and importance of supplier-induced demand. J Health Econ. 1994 Oct;13(3):369-72.

LeadDiscovery. The Therapeutic and Prophylactic Vaccine Market. Reino Unido, 2004. Disponível em:

$<$ http://www.leaddiscovery.co.uk/reports/The\%20Therapeutic\%20and\%20Prophylac tic\%20Vaccine\%20Market.html>. Acesso: 12 de outubro de 2006.

Lenne X, Diez Domingo J, Gil A, Ridao M, Lluch JA, Dervaux B. Economic evaluation of varicella vaccination in Spain - Results from a dynamic model, Vaccine, 2006; 24: 6980-9.

Lieu TA, Cochi SL, Black SB, Halloran ME, Shinefield HR, Holmes SJ et al. Costeffectiveness of a routine varicella vaccination program for US children, JAMA, 1994;2:271(5)375-381.

Liljas B. How to Calculate Indirect Costs in Economic Evaluations, Pharmacoeconomics 1998; 13 (1 Pt 1): 1-7.

Macartney KK, Burgess MA. Varicella vaccination in Austrália and New Zealand, $J$ Infect Dis, 2008; 197 (Suppl 2): S191-5.

Marcitelli R, Bricks LF, Varicella zoster in children atteding day care centers, Clinics 2006; 61(2):147-52.

Marin M, Güris D, Chaves SS, Schmid S, Seward JF. Prevention of Varicella. Recommendations of the Advisory Committee on Immunization Practices (ACIP). MMWR 2007; 56 (RR-4): 1-40. 
Meltzer D. Accounting for future costs in medical cost-effectiveness analysis, Journal of Health Economics 16 (1997) 33-64.

Milstien J, Candries B. Economics of vaccine development and implementation: changes over the past 20 years, Departamento de Vacinas e Biológicos, OMS.

Mogyorosy, Z, Smith P, The main methodological issues in costing health care services: a literature review, CHE Research Paper 7, The University of York, 2005

Mushkin, SJ. Toward a definition of health economics. Public Health Reports. Vol. 73, No.9 785-93, 1958.

Newhouse JP. Medical care costs: how much welfare loss? Journal of Economic Perspectives 1992, 6(3): 3-21.

Nguyen HQ, Jumaan AO, Seward JF. Decline in Mortality due to varicella after implementation of varicella vaccination in the United States, $N$ Engl J Med, 2005; 352: $450-8$.

Novaes HMD. Avaliação de programas, serviços e tecnologias em saúde. Rev. Saúde Pública, São Paulo, v. 34, n. 5, 2000.

NTU, Associação Nacional das Empresas de Transportes Urbanos. Políticas Tarifárias. $\quad$ Disponível

em: $<$ http://www.ntu.org.br/banco/tarifas/evoluc_tarifas.htm>. Acesso: 15 de setembro de 2006.

Okazaki R. Identificação de Ineficiências na Cadeia de Valor da Saúde a partir da Análise da Gestão de Compras de Quatro Hospitais Privados no Município de São Paulo, Mestrado em Administração de Empresas. Fundação Getúlio Vargas, SP, Brasil, 2006.

OMS, Organização Mundial da Saúde. WHO guide to cost-effectiveness analysis. What is generalized cost-effectiveness analysis. Edited by Tan-Torres Edejer,T.; Baltussen,R.; Adam,T.; Hutubessy,R.; Acharya,A.; Evans,D.B.; Murray,C.J.L., 2003.

OMS, Organização Mundial da Saúde. Vaccine Introduction Guidelines. Adding a vaccine to a national immunization programme: decision and implementation, 2005.

OMS, Organização Mundial da Saúde. CHOosing Interventions that are CostEffective (WHOCHOICE). Cost-effectiveness thresholds. Disponível em: $<$ http://www.who.int/choice/costs/CER_thresholds/en/index.html $>$. Acesso: 29 de Janeiro de 2007.

OMS, Organização Mundial da Saúde.WHO guide for standardization of economic evaluations of immunization programmes, 2008. 
OMS, Organização Mundial da Saúde. Disability weights. Resources for national burden of disease studies. Disponível em: $<$ http://www.who.int/healthinfo/bodreferencedisabilityweights.xls $>$. Acesso: 12 de junho de 2008.

Oostenbrink JB, Koopmanschap MA, Rutten FFH, Standardisation of Costs: The Dutch Manual for Costing in Economic Evaluations, Pharmacoeconomics 2002; 20 (7): 443-454.

Patrick D. Prevention Strategies: Experience of varicella vaccination Programmes. Herpes. 2007; 14 (Suppl2): 48A-51A.

Parashar UD, Hummelman EG, Bresee JS, Miller MA, Glass RI. Global illness and deaths caused by rotavirus disease in children. Emerg Infect Dis. 2003;9(5):565-72.

Pena-Rey I, Pérez-Farinós N, Cortés-García M, Amela-Heras C. Coste-efectividad de la vacunación contra la varicela en adolescents en Espana. Gac Sanit. 2004;18(4):287-94.

Pessôa SA, Gomes V, Veloso F. Evolução da Produtividade Total dos Fatores na Economia Brasileira: Uma Análise Comparativa. Pesquisa e Planejamento Econômico, Rio de Janeiro, v. 33, n. 3, p. 389-434, 2003.

Planisa. Planejamento e Organização de Instituições de Saúde. Apuração dos Custos de Procedimentos Hospitalares: Alta e Média Complexidade. [CD-ROM]. Projeto Reforsus; 2002.

Podewils LJ, Antil L, Hummelman E, Bresee J, Parashar UD, Rheingans R. Projected cost-effectiveness of rotavirus vaccination for children in Asia. $J$ Infect Dis. 2005;192(Suppl 1):S133-45.

Raftery J. Costing in economic evaluation, BMJ 2000; 320: 1597.

Rheingans RD, Constela D, Antil L, Innis BL, Breuer T. Potential cost-effectiveness of vaccination for rotavirus gastroenteritis in eight Latin American and Caribbean countries. Rev Panam Salud Publica. 2007;21(4): 205-16.

Ruiz-Palacios GM, Pérez-Schael I, Velázquez FR, Abate H, Breuer T, Clemens SC, et al. Safety and efficacy of an attenuated vaccine against severe rotavirus gastroenteritis. New Engl J Med. 2006;354(1): 11-22.

Sadzot-Delvaux C, Rentier B, Wutzler P, Asano Y, Suga S, Yoshikawa T, et al.Varicella vaccination in Japan, South Korea and Europe. J Infect Dis. 2008; 197 (Suppl 2): S185-90.

Salinas B, Schael IP, Linhares AC, Ruiz-Palacios GM, Guerrero ML, Yarzábal JP, et al. Evaluation of safety, immunogenicity and efficacy of an attenuated rotavirus 
vaccine, RIX4414: a randomized, placebo-controlled trial in Latin American infants. Pediatr Infect Dis J. 2005;24(9):807-16.

Sartori AM, Valentim J, de Soárez PC, Novaes HM. Rotavirus morbidity and mortality in children in Brazil. Rev Panam Salud Pública. Revista Panamericana de Salud Pública / Pan American Journal of Public Health, 23 (2): 92-100, 2008.

Sastry N, Burgard S. The prevalence of diarrheal disease among Brazilian children: trends and differentials from 1986 to 1996. Soc Sci Med. 2005;60(5):923-35.

Schulenburg, JMG, Hoffmann, C, Review of European guidelines for economic evaluation of medical technologies and pharmaceuticals, HEPAC, 2000 .1: 2-8.

Scuffham P, Devlin N, Eberhart-Phillips J, et al. The cost-effectiveness of introducing a varicella vaccine to the New Zealand immunization schedule. Soc Sci Med.1999;49(6):763-79.

Scuffham PA, Lowin AV, Burgess MA. The cost-effectiveness of varicella vaccine programs for Australia. Vaccine. 2000;18(5-6):407-15.

Sen AK. Isolation, Assurance and the Social Rate of Discount, Quarterly Journal of Economics, 1967 81, 112-124.

Sen AK. Approaches to the choice of discount rates for social benefit cost analysis". In: Robert C. Lind (Ed). Discounting for time and risk in energy policy. Baltimore: Johns Hopkins University Press, 325-350, 1982.

Seward JF, Marin M, Vázquez M. Varicella effectiveness in the US vaccination program: a review. J Infect Dis. 2008; 197 (Suppl 2): S82-9.

Shinefield HR, Black S, Kuter BJ. Varicella immunogenicity with 1- and 2-dose regimens of Measles-Mumps-Rubella-Varicella Vaccine. J Infect Dis. 2008; 197 (Suppl 2): S152-5.

Simonsen L, Viboud C, Elixhauser A, Taylor RJ, Kapikian AZ. More on RotaShield and intussusception: the role of age at the time of vaccination. J Infect Dis. 2005 Sep 1;192(Suppl 1):S36-43.

Smith JC, Haddix AC, Teutsch SM, Glass RI. Cost-effectiveness analysis of a rotavirus immunization program for the United States. Pediatrics. 1995; 96: 609-15.

Soárez PC; Valentim J; Sartori AMC; Novaes HMD. Cost-effectiveness analysis of universal childhoood vaccination program against rotavirus in Brazil. Revista Panamericana de Salud Pública / Pan American Journal of Public Health, 23 (4): 221-230, 2008.

Soárez PC, Ciconelli RM, Kowalski CC, Ferraz MB. Estudo prospectivo da diarréia para estimativa da incidência por rotavírus e do custo da gastroenterite por rotavírus em crianças menores de 5 anos. Relatório Técnico. Centro Paulista de Economia da 
Saúde (CPES)/Escola Paulista de Medicina/Universidade Federal de São Paulo e Secretaria de Estado da Saúde de São Paulo. São Paulo, 2005.

Solla JJSP, dos Reis AAC, Soter APM, de Palma JJL. Mudanças recentes no financiamento federal do Sistema Único de Saúde: atenção básica à saúde, Rev. Bras. Matern. Infant, Recife, 7 (4): 495-502, out/dez. 2007.

Spackman M. Time discounting and of the cost of capital in government, Fiscal Studies (2004) vol. 25, no. 4, 467-518.

Sugden R, Williams A. 1978. The Principles of Practical Cost-Benefit Analysis. Oxford: Oxford University Press, 1978.

Szucs T. Health economic research on vaccinations and immunisation preactices- an introductory primer, Vaccine 23 (2005) 2095-2103.

Thiry N, Beutels P, Van Damme P, Van Doorslaer E. Economic Evaluations of Varicella Vaccination Programmes: A Review of the Literature, Pharmacoeconomics 2003; 21 (1): 13-38.

Thiry N, Beutels P, Tancredi F, Romano L, Zanetti A, Bonanni P et al. An economic evaluation varicella vaccination in Italian adolescents. Vaccine. 2004;22:3546-62.

Tranmer J, Guerriere DN, Ungar WJ, Coyte PC.Valuing Patient and Caregiver Time: A Review of the Literature, Pharmacoeconomics 2005; 23 (5): 449-459.

Trueman P, Drummond M, Hutton J. Developing Guidance for Budget Impact Analysis, Pharmacoeconomics, vol.19, n 6, 2001, pp. 609-621.

Tucker AW, Haddix AC, Bresee JS, Holman RC, Parashar UD, Glass RI. Costeffectiveness analysis of a rotavirus immunization program for the United States. JAMA. 1998; 279(17):1371-6.

Uruguai, Ministério de Salud Publica, Republica Oriental del Uruguay. Certificado Esquema de Vacunacion Año 2008. Disponível em: http://www.msp.gub.uy/noticia_1710_1.html. Acesso: 29 de Março de 2008.

Valentim J, Prado Jr JM. Social Discount Rates, 2008. Disponível em: $<$ http://papers.ssrn.com/sol3/papers.cfm?abstract $\mathrm{id}=1113323>$. Acesso: 12 de maio de 2008. (Resumo publicado em Value in Health vol 11 (6), 2008)

Valentim J, Sartori AM, Soárez PC, Amaku M, Azevedo RS, Novaes HM. Costeffectiveness analysis of universal childhood vaccination program against varicella in Brazil, Vaccine 2008a, v.26: 6281-6291.

Velázquez FR, Matson DO, Calva JJ, Guerrero ML, Morrow AL, Carter-Campbell S, et al. Rotavirus infection in infants as protection against subsequent infections. New Engl J Med. 1996;335(14):1022-8. 
Vesikari T, Matson DO, Dennehy P, Van Damme P, Santosham M, Rodriguez Z, et al. Safety and efficacy of a pentavalent humanbovine (WC3) reassortant rotavirus vaccine. New Engl J Med. 2006;354(1):23-33.

Wagenpfeil S, Neiss A, Wutzler P. Effects of varicella vaccination on herpes zoster incidence. Clin Microbiol Infect. 2004; 10: 954-60.

Walker D, Fox-Rushby J. Allowing for uncertainty in economic evaluations: qualitative sensitivity analysis. Health Policy Plan 2001; 16(4):435-443.

Walker D, Rheingans R. Cost-effectiveness of rotavirus vaccines, Expert Rev. Pharmacoeconomics Outcomes Res. 5(5), 593-601 (2005).

Weinstein MC, Stason WB. Foundations of cost-effectiveness analysis for health and medical practices. New England Journal of Medicine 1977, 296, 716-721.

Weinstein MC, Manning Jr WJ. Theoretical issues in cost-effectiveness analysis, Journal of Health Economics 16 (1997) 121-128.

Whitley RJ. Varicella Zoster Virus. In: Mandell, Douglas and Bennett's Principles and Practice of Infectious Diseases. Organized by Mandell GL, Bennett JE and Dolin R. Edited by Elsevier Churchill Livingstone. 6th edition, 2005. Chapter 133: 1780-6.

Williams A. Cost-benefit analysis: applied welfare economics or general decision aid. In: Williams, A., Giardina, E._Eds.., Efficiency in the Public Sector. Edward Elgar, London, 1993.

Williams I, Bryan S. Understading the limited impact of economic evaluation in health care resource allocation: A conceptual framework. Health Policy 80 (2007) 135-143.

Yu ALF, Costa JM, Amaku M, Pannuti CS, Souza VA, Zanetta DM, et al. Three year seroepidemiological study of varicella-zoster virus in São Paulo, Brazil. Rev Inst Med Trop, S. Paulo. 2000; 42 (3): 125-8.

Yu ALF, Amaku M, Burattini MN, Massad E, Azevedo RS. Varicella transmission in two samples of children with different social behaviour in the State of São Paulo, Brazil. Epidemiol Infect. 2001; 127: 493-500.

Zhou F, Harpaz R, Jumaan AO, Winston CA, Shefer A. Impact of varicella vaccination on health care utilization. JAMA. 2005; 294 (7): 797-802.

Zhou F, Ortega-Sanchez, Guris D, Shefer A, Lieu T, Seward JF. An economic analysis of the universal varicella vaccination program in the United States. J Infect Dis. 2008; 197 (Suppl 2): S156-64. 